\title{
Radical Perfluoroalkylation of Arenes via Carbanion Intermediates
}

Lucas W. Hernandez, William P. Gallagher, Carlos A. Guerrero, Francisco Gonzalez-Bobes, John R. Coombs*

Chemical Process Development, Bristol-Myers Squibb, 1 Squibb Drive, New Brunswick, New Jersey 08903, United States

john.coombs@bms.com

\section{Supporting Information}

\section{Table of Contents}

1.1 Solvent Screen for the Perfluoroalkylation ..................................................... S2

1.2 Failed Substrates for the Perfluoroalkylation ..................................................... S2

2 NMR Spectra of New Compounds................................................................................... S3 


\subsection{Solvent Screen for the Perfluoroalkylation}

Table S1. Solvents screened for the perfluoroalkylation reaction.
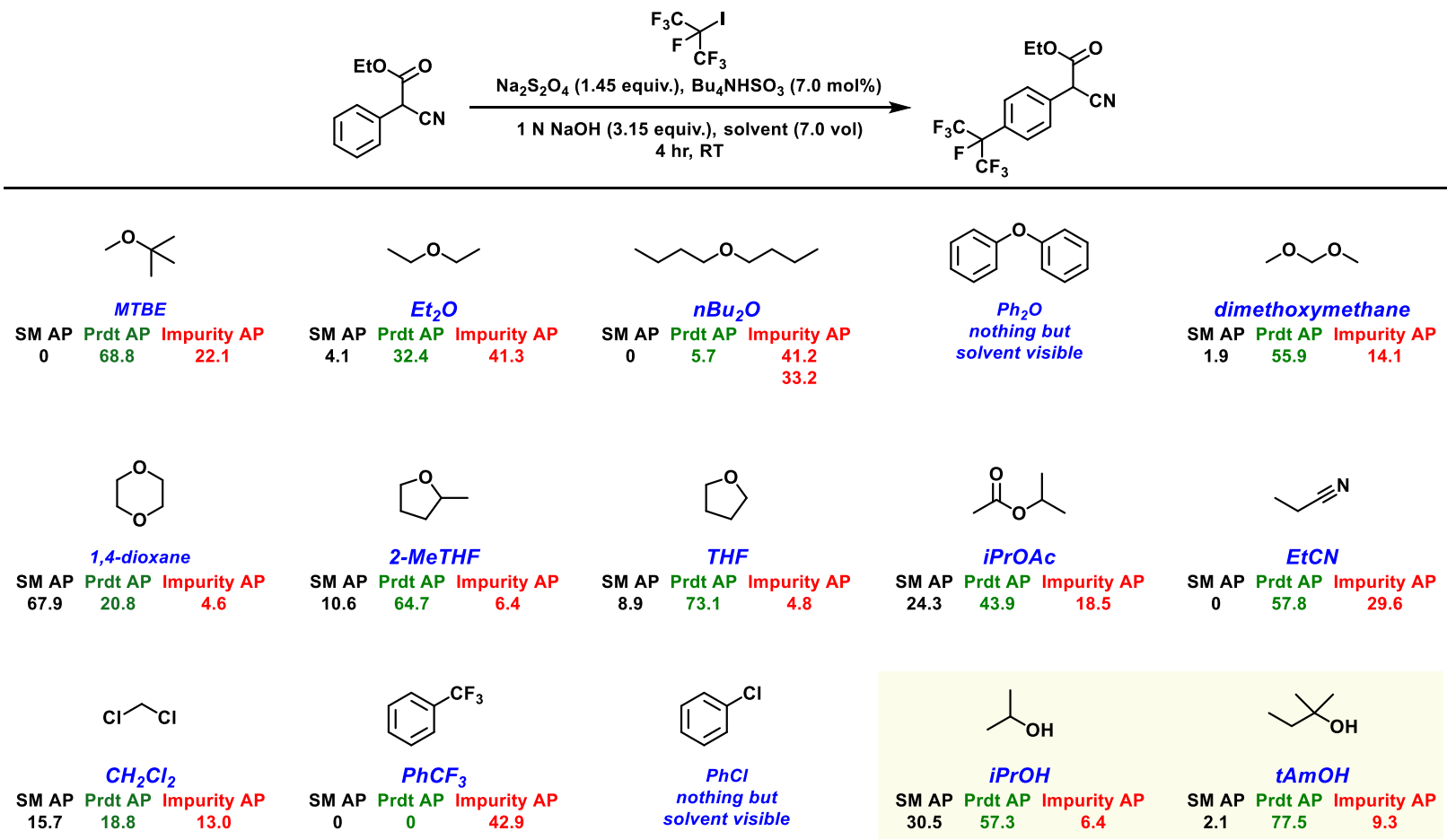

\subsection{Failed Substrates for the Perfluoroalkylation}

Table S2. Failed substrates for the perfluoroalkylation reaction.

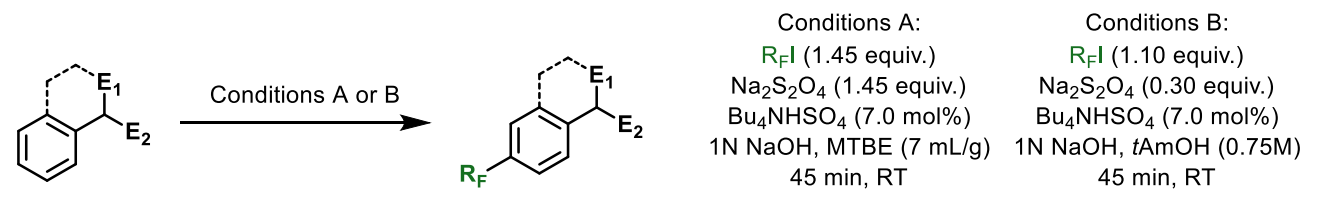

(1)<smiles></smiles><smiles>N#CC(c1ccccc1)c1cccnc1</smiles>

mixtures of
isomers

OEt<smiles>CCOC(=O)C(=O)C(C#N)c1ccccc1</smiles><smiles>N#CC(c1ccccc1)c1cccc2ncccc12</smiles>

mixtures of isomers isomers<smiles>N#CC(C(=O)C(F)(F)F)c1ccccc1</smiles><smiles>CC(NC1=C(S(=O)(=O)c2ccc(F)cc2)c2ccccc2CC1)c1ccccc1</smiles>

空 $=0$

aldehyde

${ }_{\mathrm{F}}^{\mathrm{F}} \mathrm{F}_{\mathrm{F}}^{\prime}$, 罗

Ritter's reagent<smiles>CS(=O)(=O)C(C(=O)c1ccccc1)c1ccccc1</smiles><smiles>O=C(c1ccccc1)C(c1ccccc1)S(=O)(=O)c1ccc(F)cc1</smiles><smiles>CCOC(=O)C(C)C(=O)C(C)c1ccccc1</smiles>

$$
{ }_{\mathrm{F}}^{\mathrm{F}_{15} \mathrm{C}_{7}} \chi_{\mathrm{F}}^{\mathrm{Br}}
$$<smiles>CCOC(=O)C(c1ccccc1)c1ccccc1</smiles>

saponification<smiles>O=C1c2ccccc2C(=O)C1c1ccccc1</smiles><smiles>CCC(=O)C(c1ccccc1)S(=O)(=O)c1ccc(C)cc1</smiles><smiles>O=[N+]([O-])[C-]C(c1ccccc1)c1ccccc1</smiles><smiles>N#CC(c1ccccc1)c1cc(Cl)cc(Cl)c1</smiles><smiles>N#CC(C(=O)Oc1ccccc1)c1cc(C(F)(F)F)cc(C(F)(F)F)c1</smiles><smiles>O=S(=O)(c1ccc(F)cc1)C1C(=NO)CCc2ccccc21</smiles> 


\section{NMR Spectra of New Compounds}



( ${ }^{1} \mathrm{H} \mathrm{NMR}, \mathrm{CDCl}_{3}, 500 \mathrm{MHz}$ )



p.
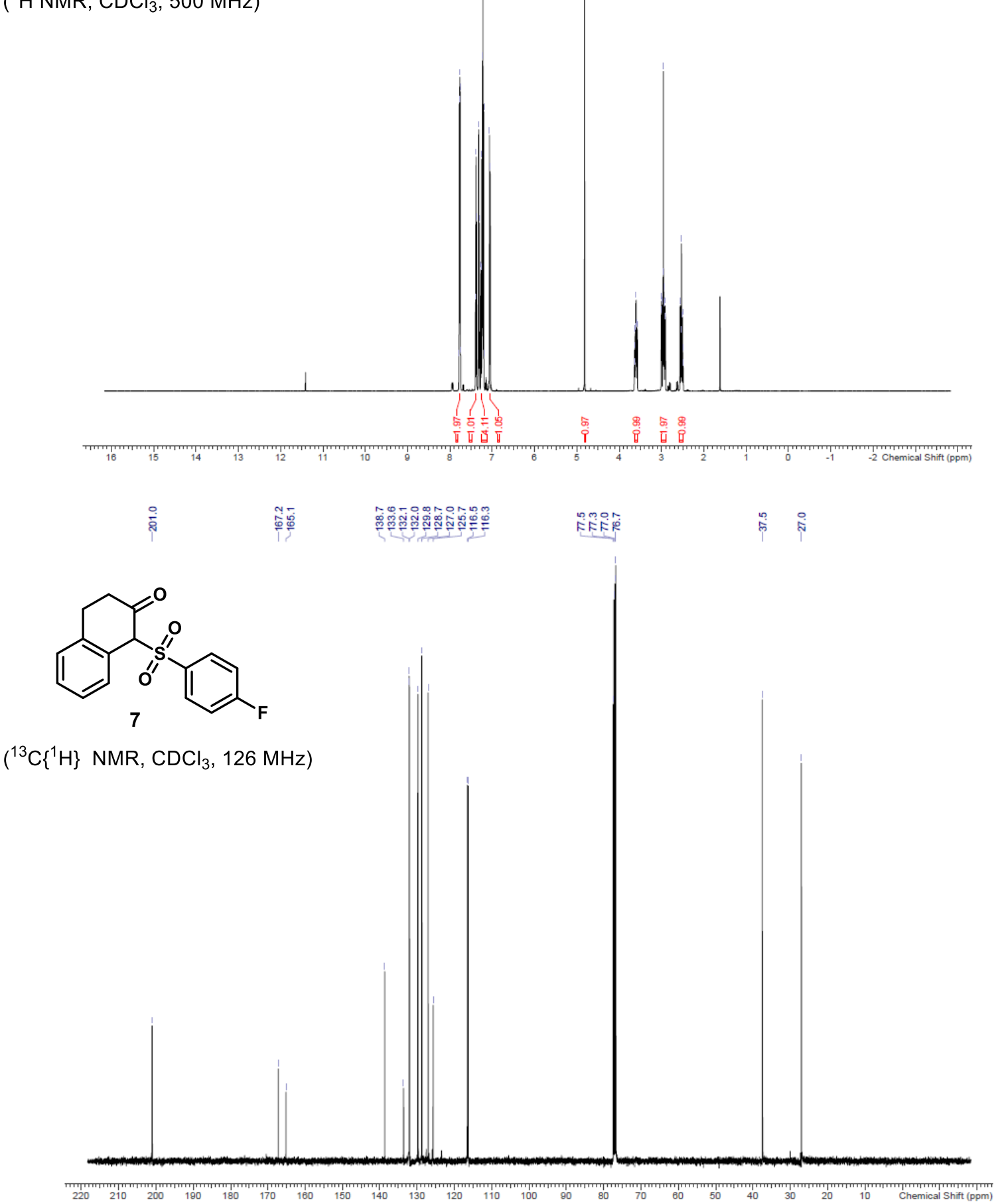


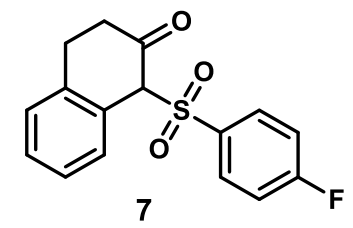

$\left({ }^{19} \mathrm{~F}\right.$ NMR, $\left.\mathrm{CDCl}_{3}, 376 \mathrm{MHz}\right)$

(
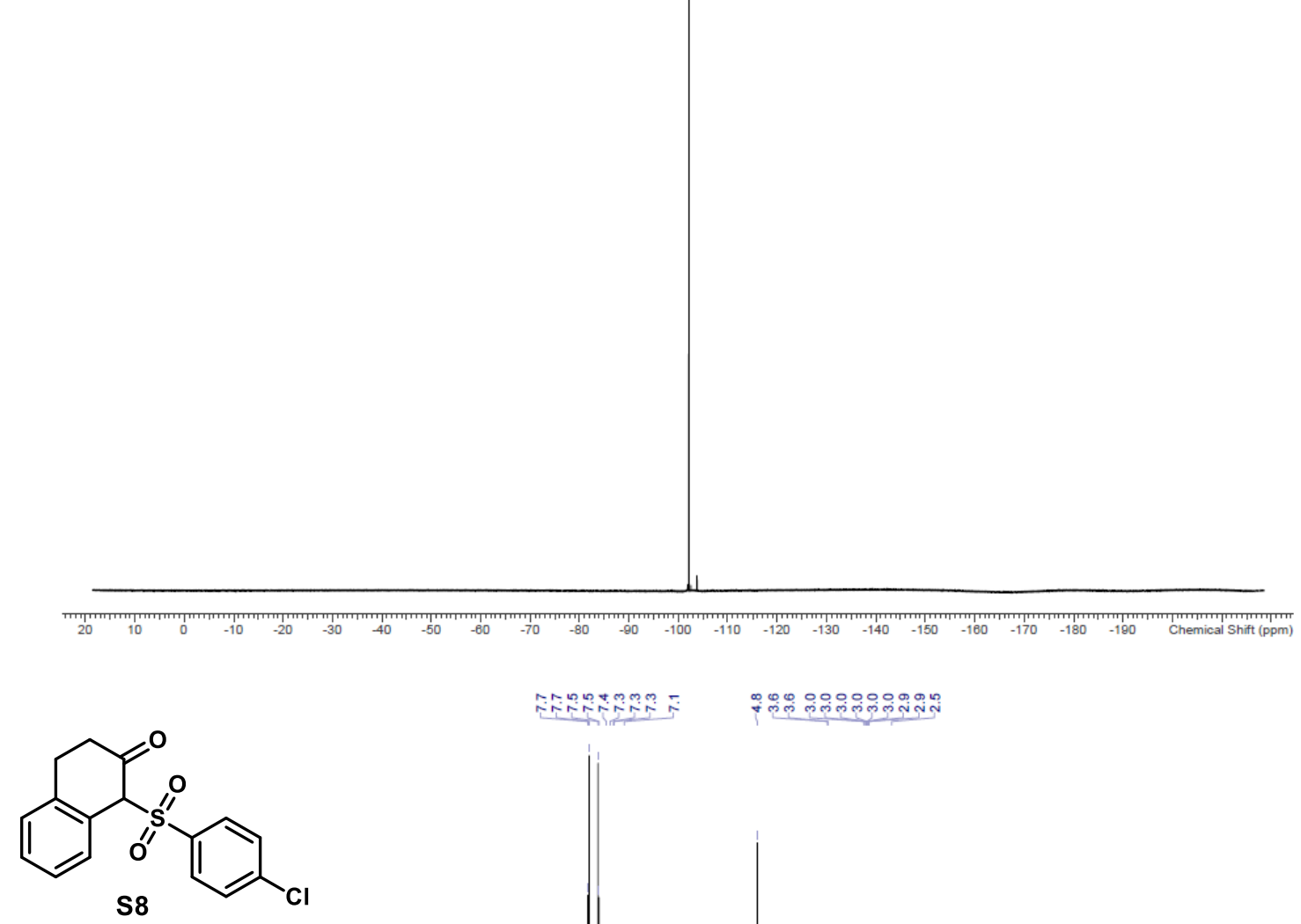

$\left({ }^{1} \mathrm{H} \mathrm{NMR}, \mathrm{CDCl}_{3}, 500 \mathrm{MHz}\right)$

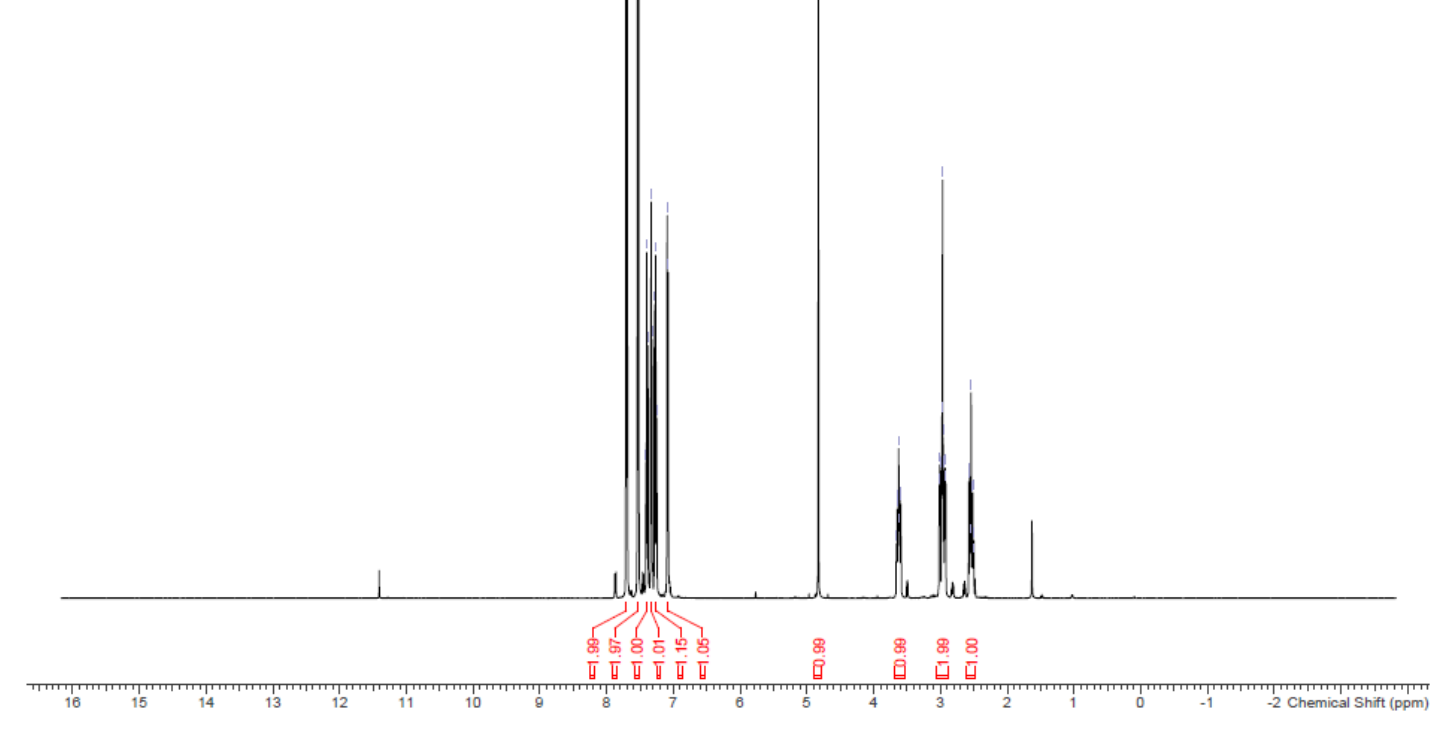




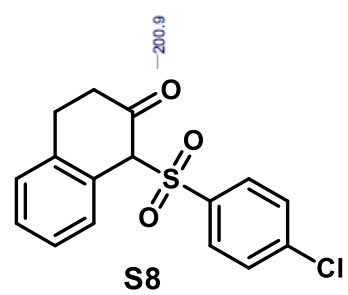

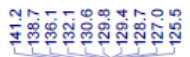

$\stackrel{\vec{F}}{*}$

$\stackrel{\text { i }}{\mathrm{i}}$

$\left({ }^{13} \mathrm{C}\left\{{ }^{1} \mathrm{H}\right\} \mathrm{NMR}, \mathrm{CDCl}_{3}, 126 \mathrm{MHz}\right)$

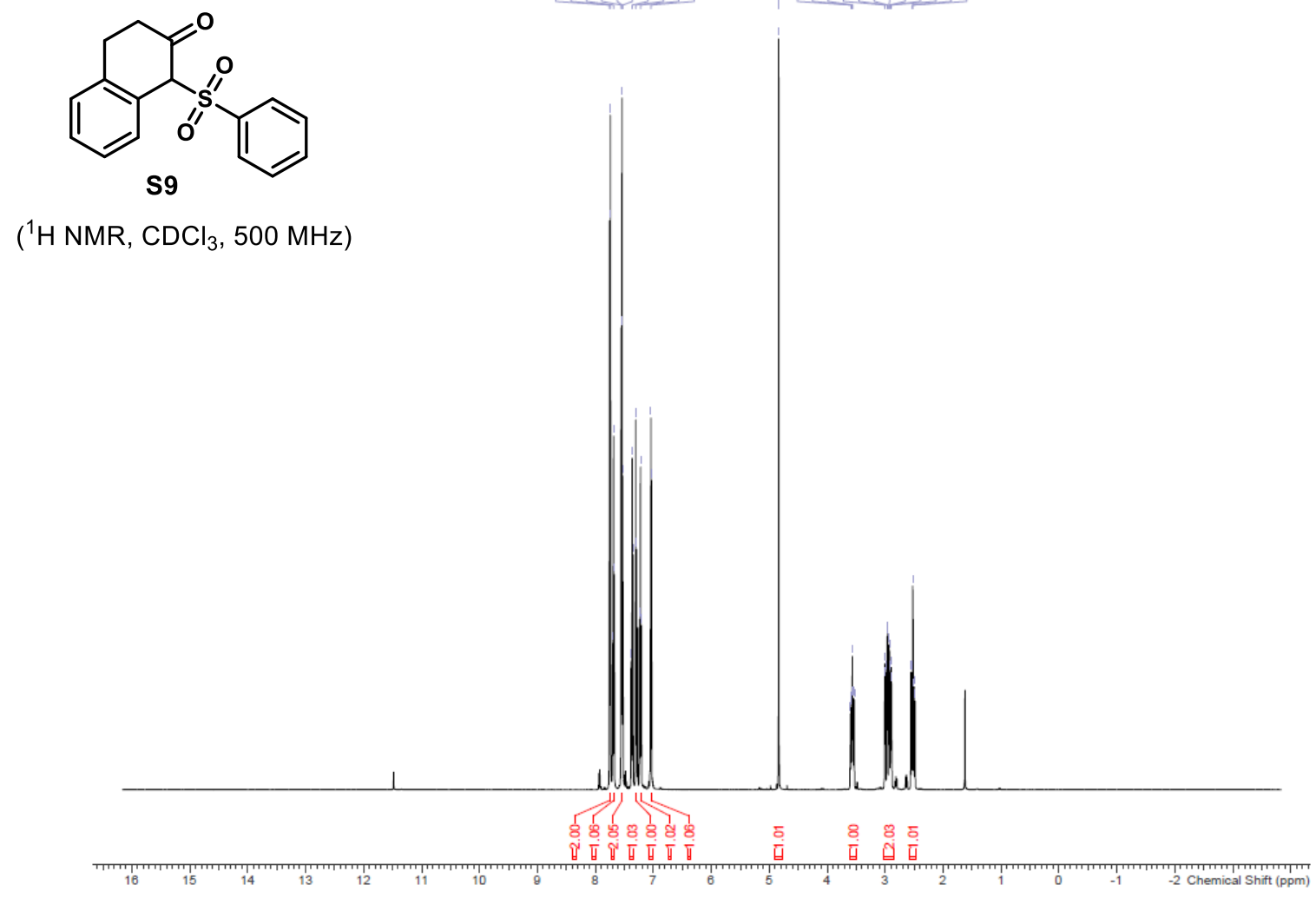

( ${ }^{1} \mathrm{H} \mathrm{NMR}, \mathrm{CDCl}_{3}, 500 \mathrm{MHz}$ )

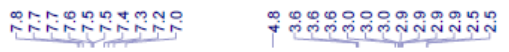

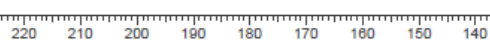

(1mpm)

S5 


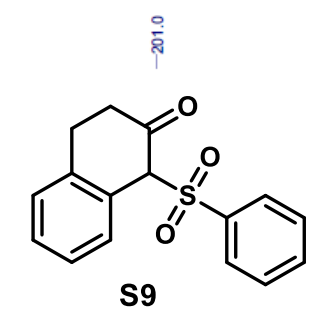

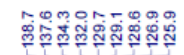

$\stackrel{\infty}{\uparrow}$

节

$\left({ }^{13} \mathrm{C}\left\{{ }^{1} \mathrm{H}\right\} \mathrm{NMR}, \mathrm{CDCl} 3,126 \mathrm{MHz}\right)$


\section{๓⿴囗十}

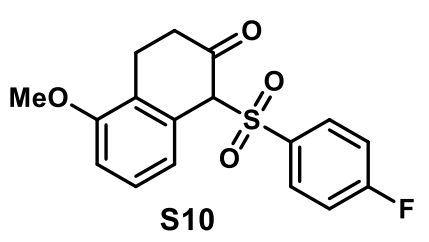

$\left({ }^{1} \mathrm{H} \mathrm{NMR}, \mathrm{CDCl}_{3}, 500 \mathrm{MHz}\right)$

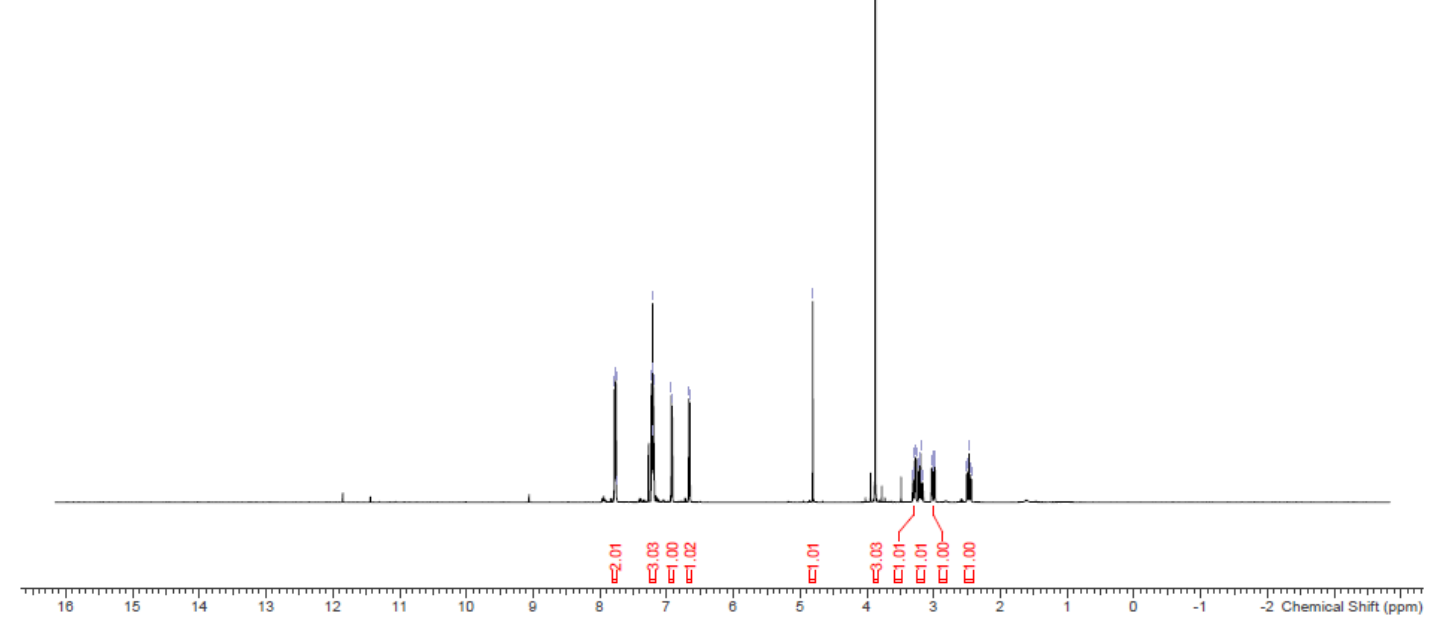



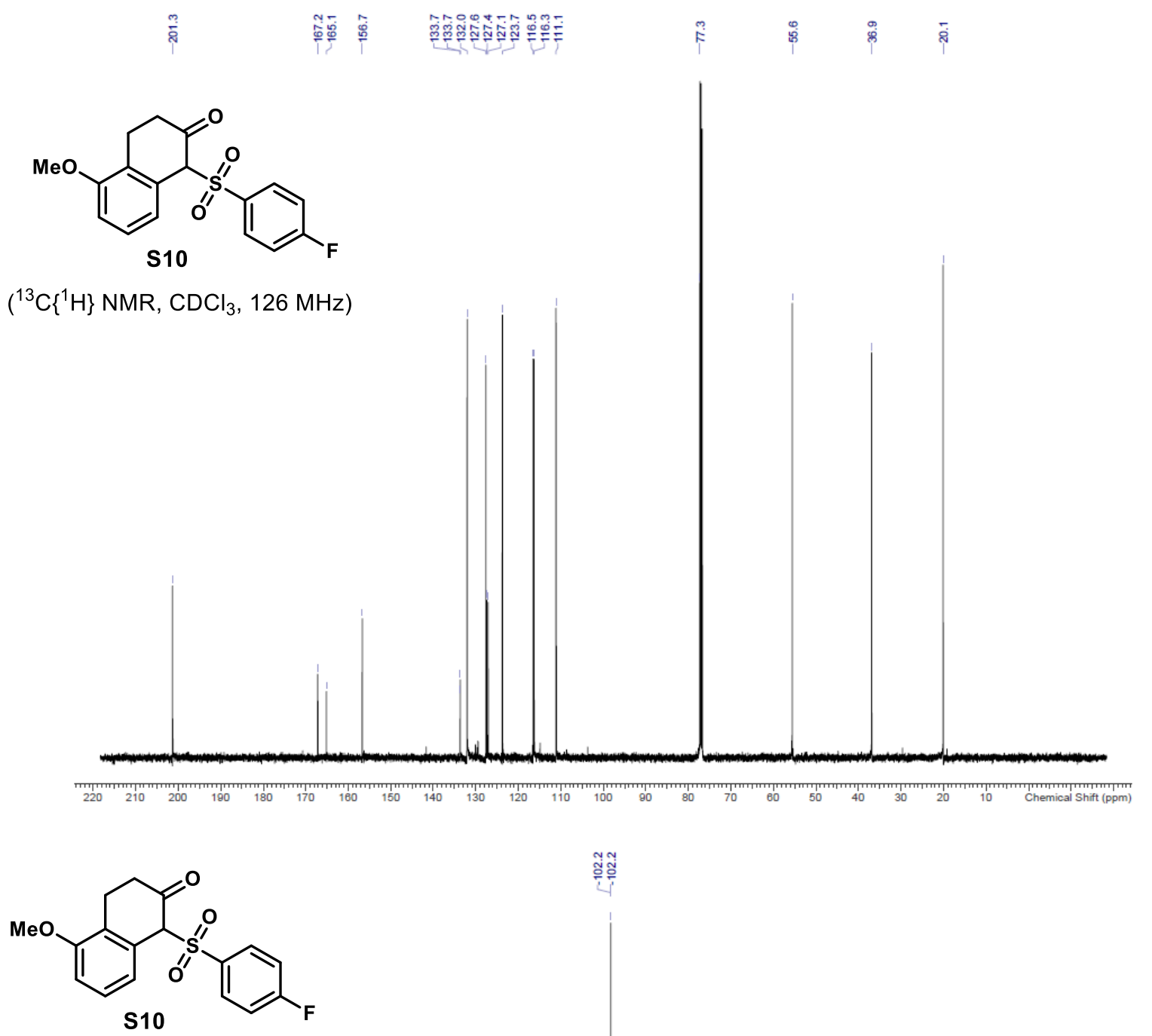

$\left({ }^{19} \mathrm{~F} \mathrm{NMR}, \mathrm{CDCl}_{3}, 376 \mathrm{MHz}\right)$

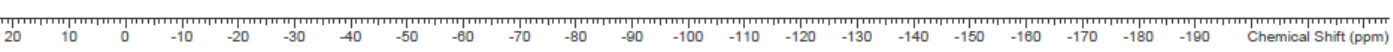



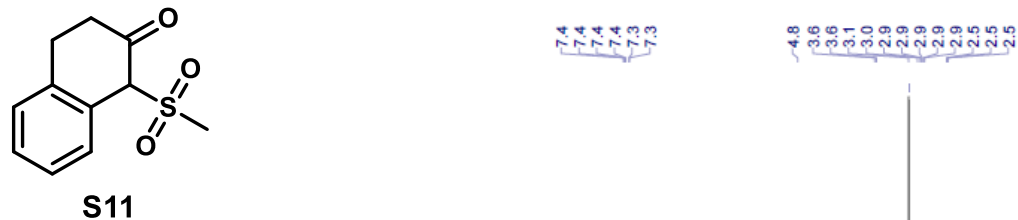

$\left({ }^{1} \mathrm{H} \mathrm{NMR}, \mathrm{CDCl}_{3}, 500 \mathrm{MHz}\right)$

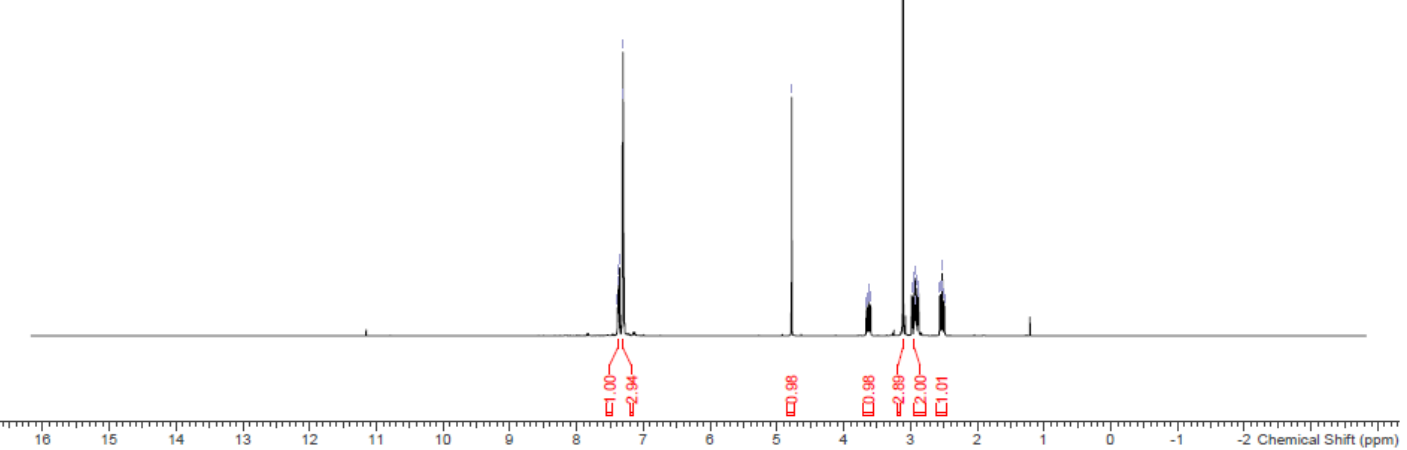

๙ึ่

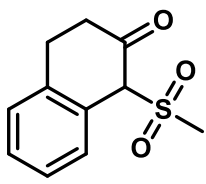

S11

$\left({ }^{13} \mathrm{C}\left\{{ }^{1} \mathrm{H}\right\} \mathrm{NMR}, \mathrm{CDCl}_{3}, 126 \mathrm{MHz}\right)$
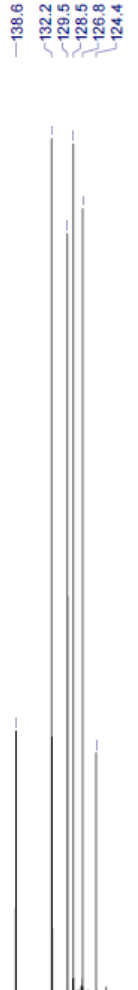

F
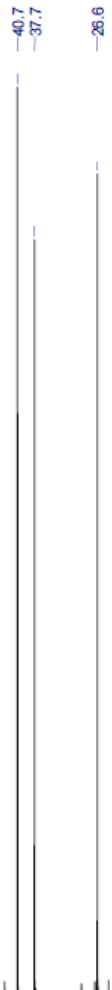

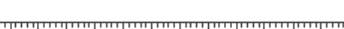

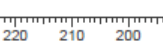

.

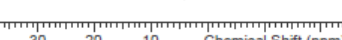




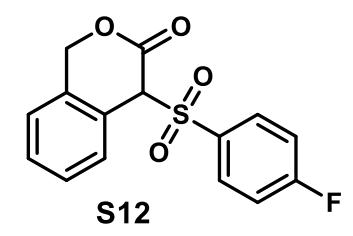



$\left({ }^{1} \mathrm{H}\right.$ NMR, $\left.\mathrm{CDCl}_{3}, 500 \mathrm{MHz}\right)$

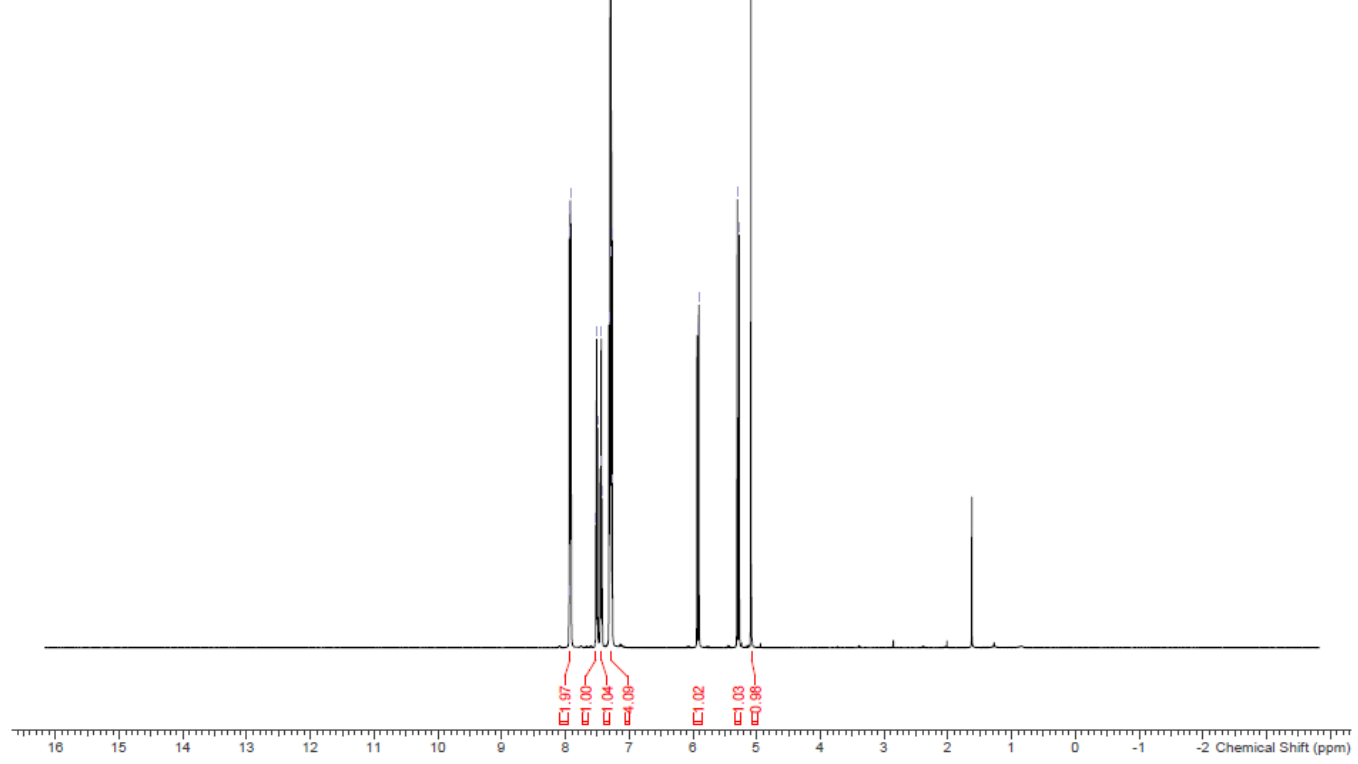

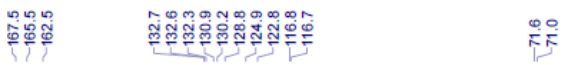

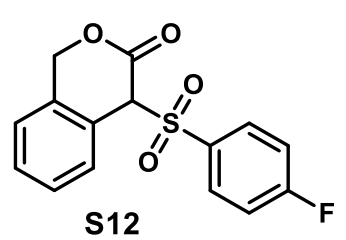

$\left({ }^{13} \mathrm{C}\left\{{ }^{1} \mathrm{H}\right\} \mathrm{NMR}, \mathrm{CDCl}_{3}, 126 \mathrm{MHz}\right)$
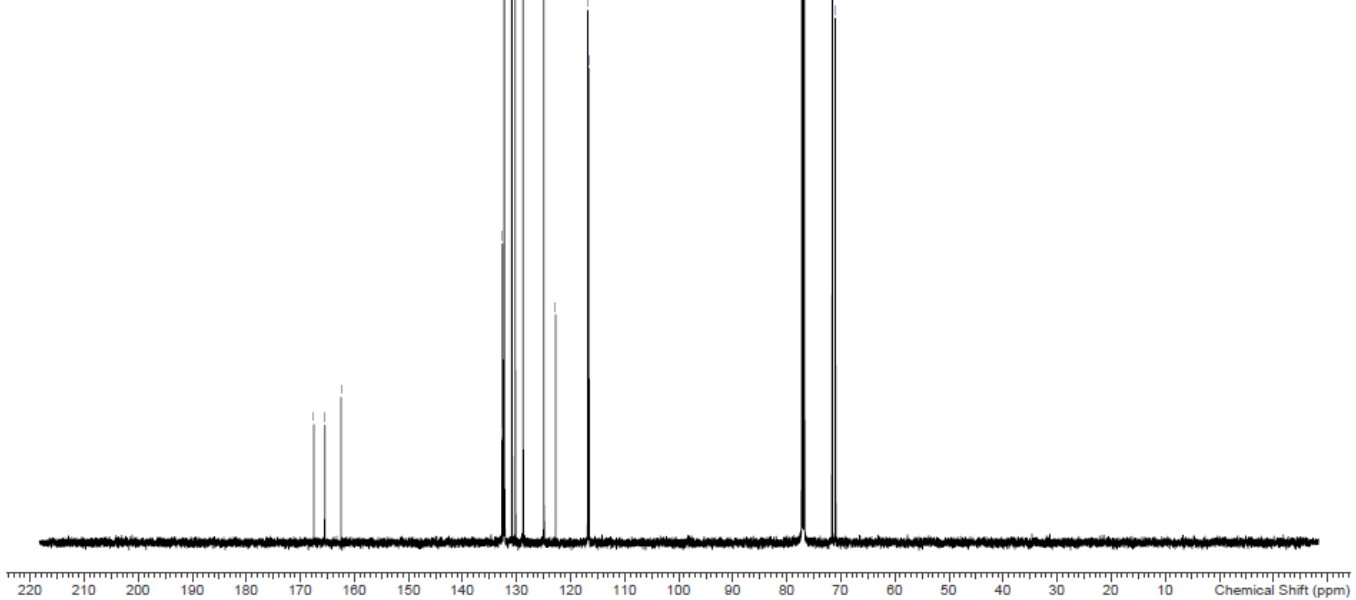


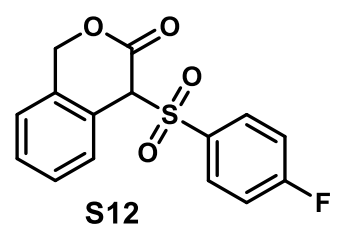

$\left({ }^{19} \mathrm{~F} \mathrm{NMR}, \mathrm{CDCl}_{3}, 376 \mathrm{MHz}\right)$

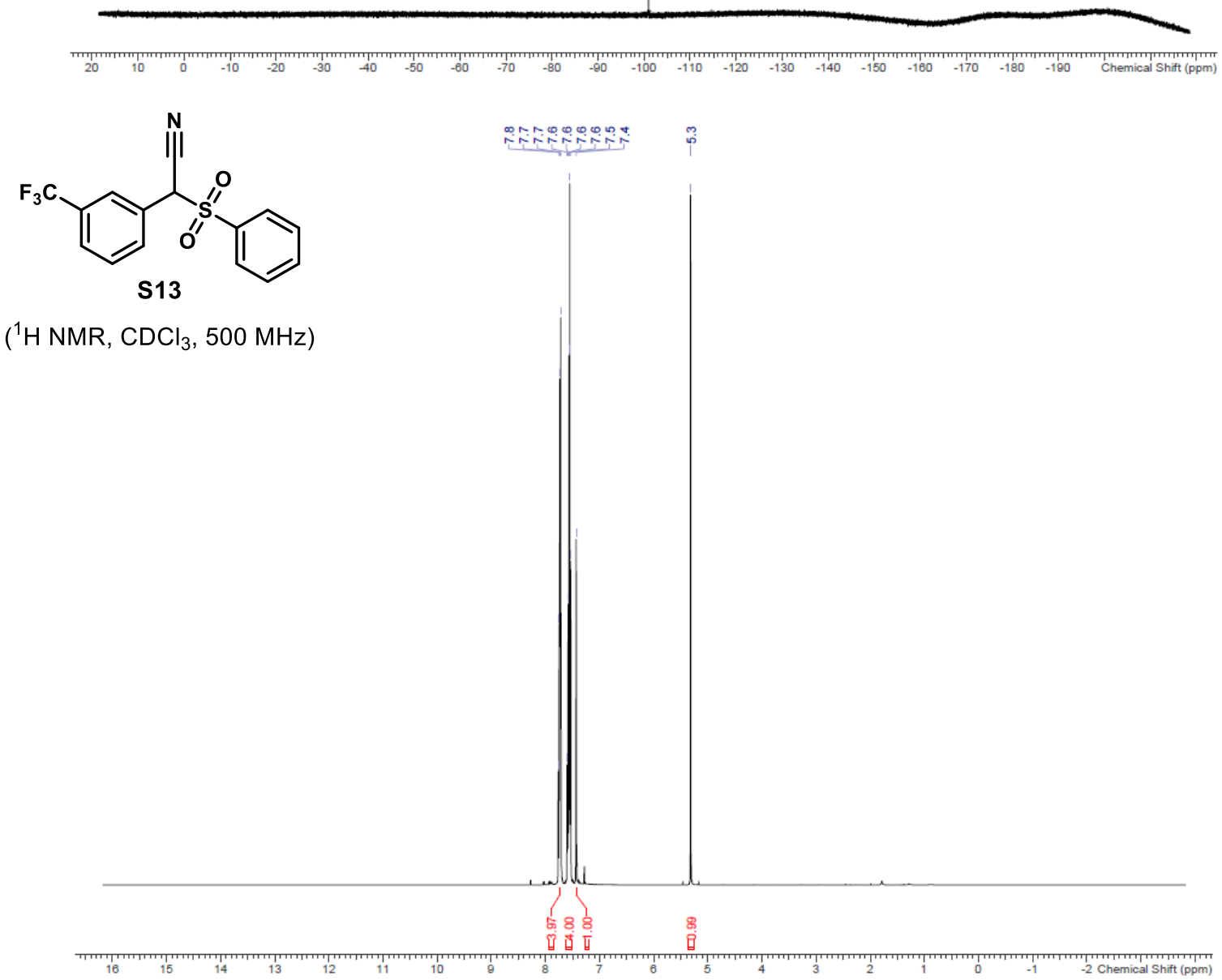




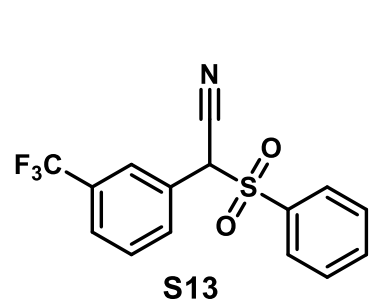

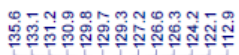

ซึ

$\left({ }^{13} \mathrm{C}\left\{{ }^{1} \mathrm{H}\right\}\right.$ NMR, $\left.\mathrm{CDCl}_{3}, 126 \mathrm{MHz}\right)$
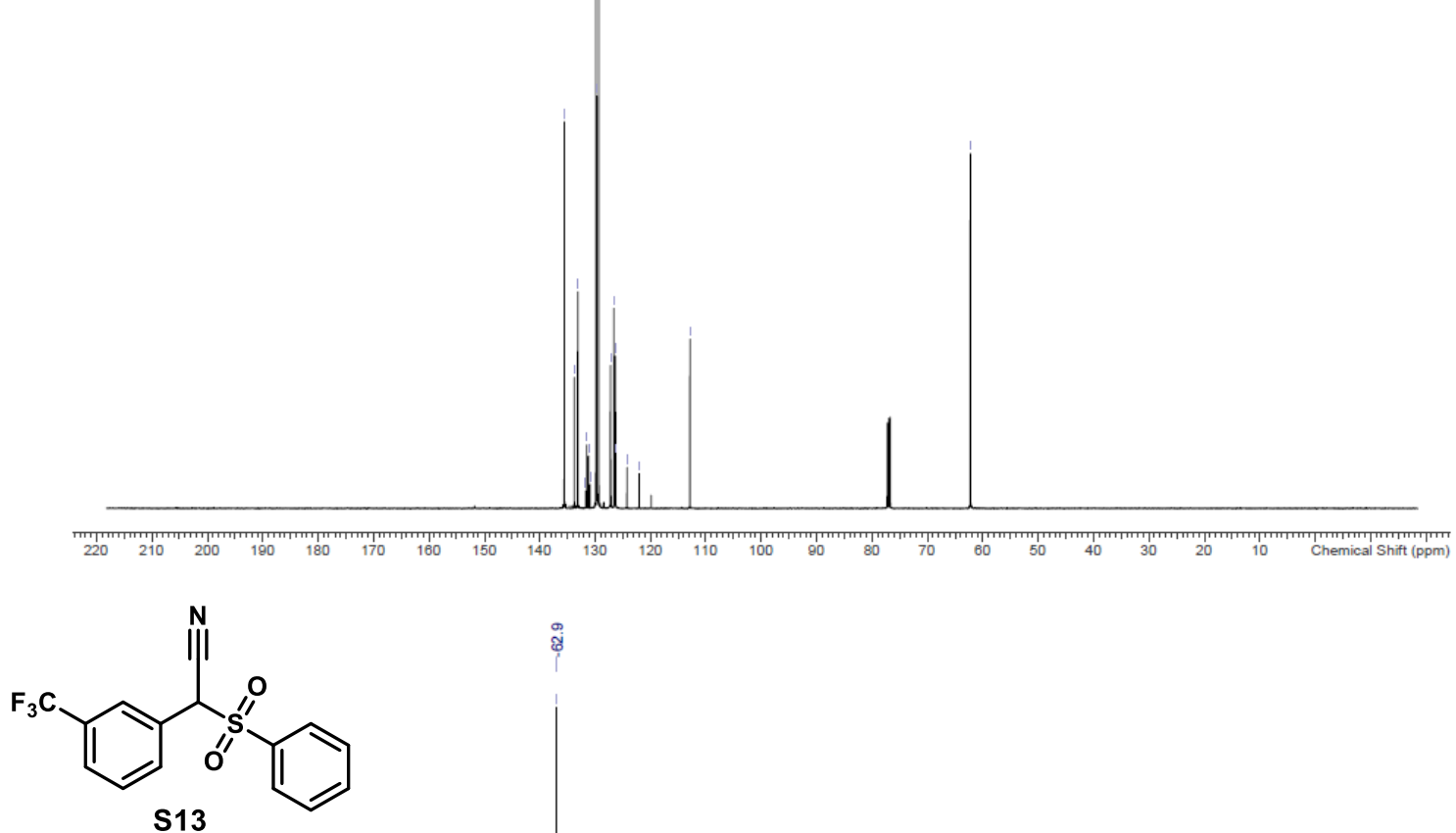

$\left({ }^{19} \mathrm{~F} \mathrm{NMR}, \mathrm{CDCl}_{3}, 376 \mathrm{MHz}\right)$

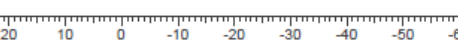

ซึ่ 






$\left({ }^{1} \mathrm{H} \mathrm{NMR}, \mathrm{CDCl}_{3}, 500 \mathrm{MHz}\right)$
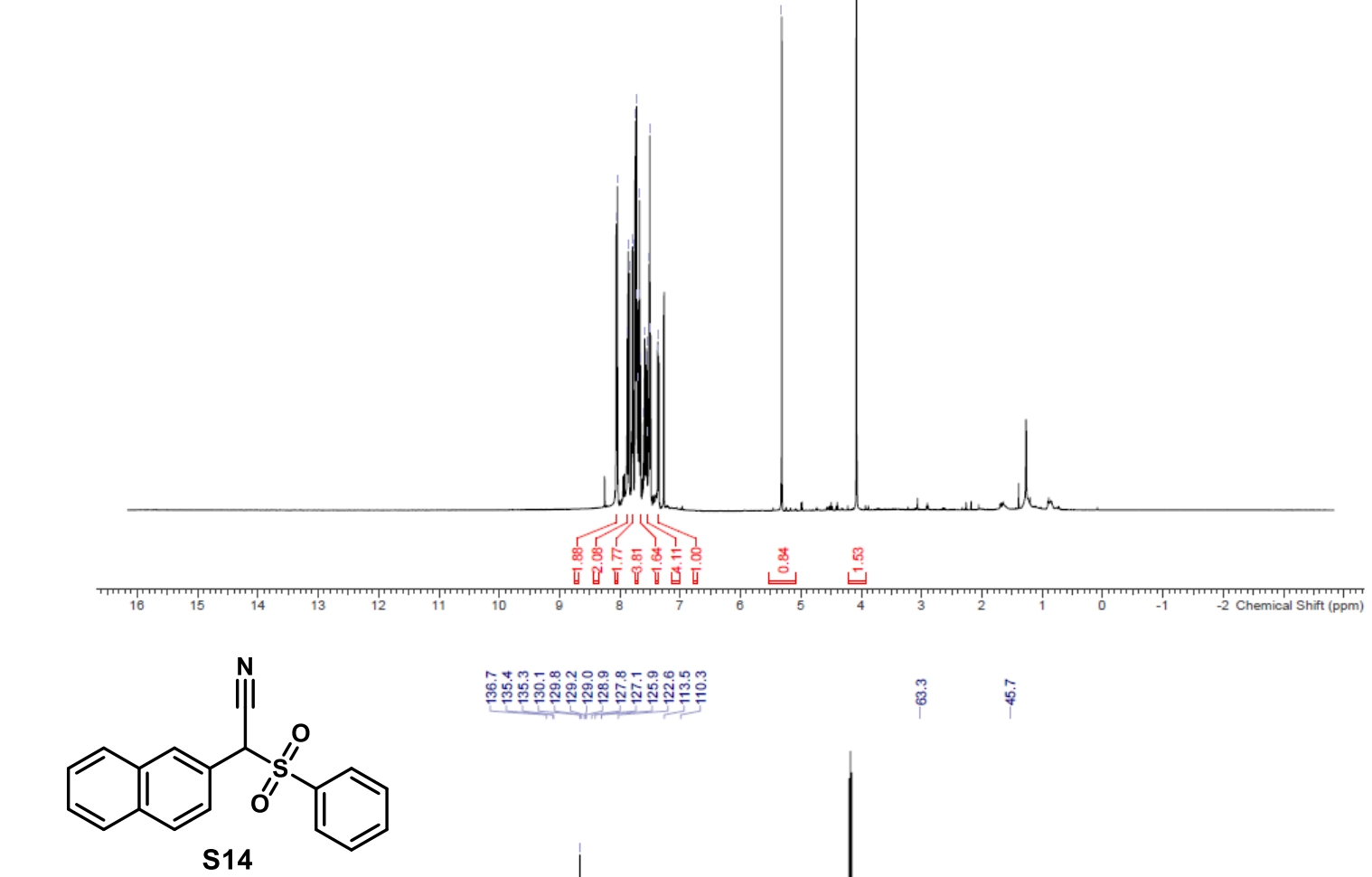

$\left({ }^{13} \mathrm{C}\left\{{ }^{1} \mathrm{H}\right\} \mathrm{NMR}, \mathrm{CDCl}_{3}, 126 \mathrm{MHz}\right)$



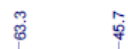

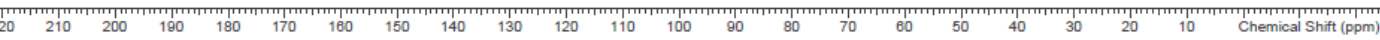




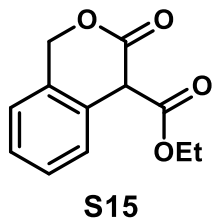

$\left({ }^{1} \mathrm{H} \mathrm{NMR}, \mathrm{CDCl}_{3}, 500 \mathrm{MHz}\right)$
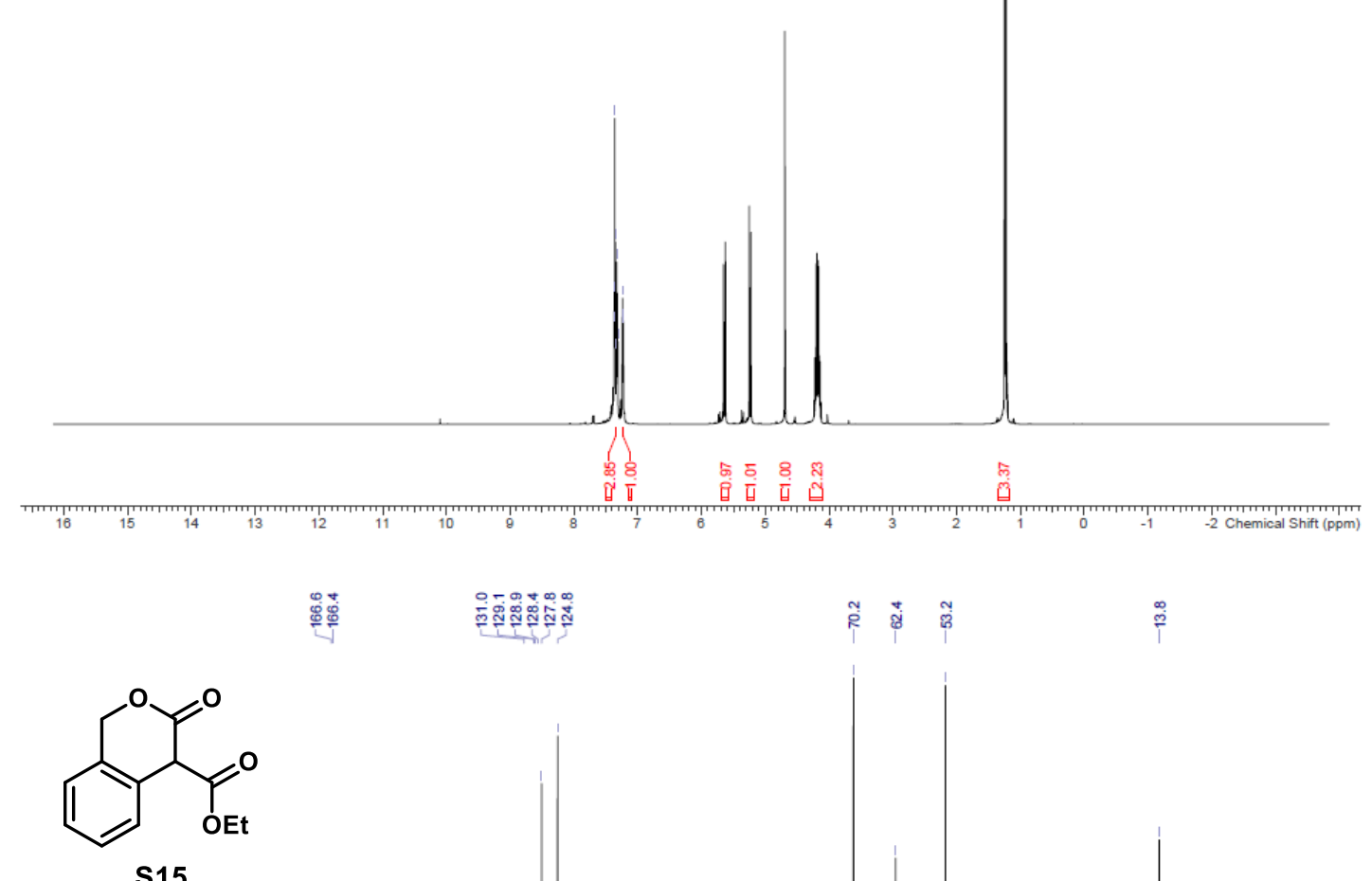

$\left({ }^{13} \mathrm{C}\left\{{ }^{1} \mathrm{H}\right\} \mathrm{NMR}, \mathrm{CDCl}_{3}, 126 \mathrm{MHz}\right)$
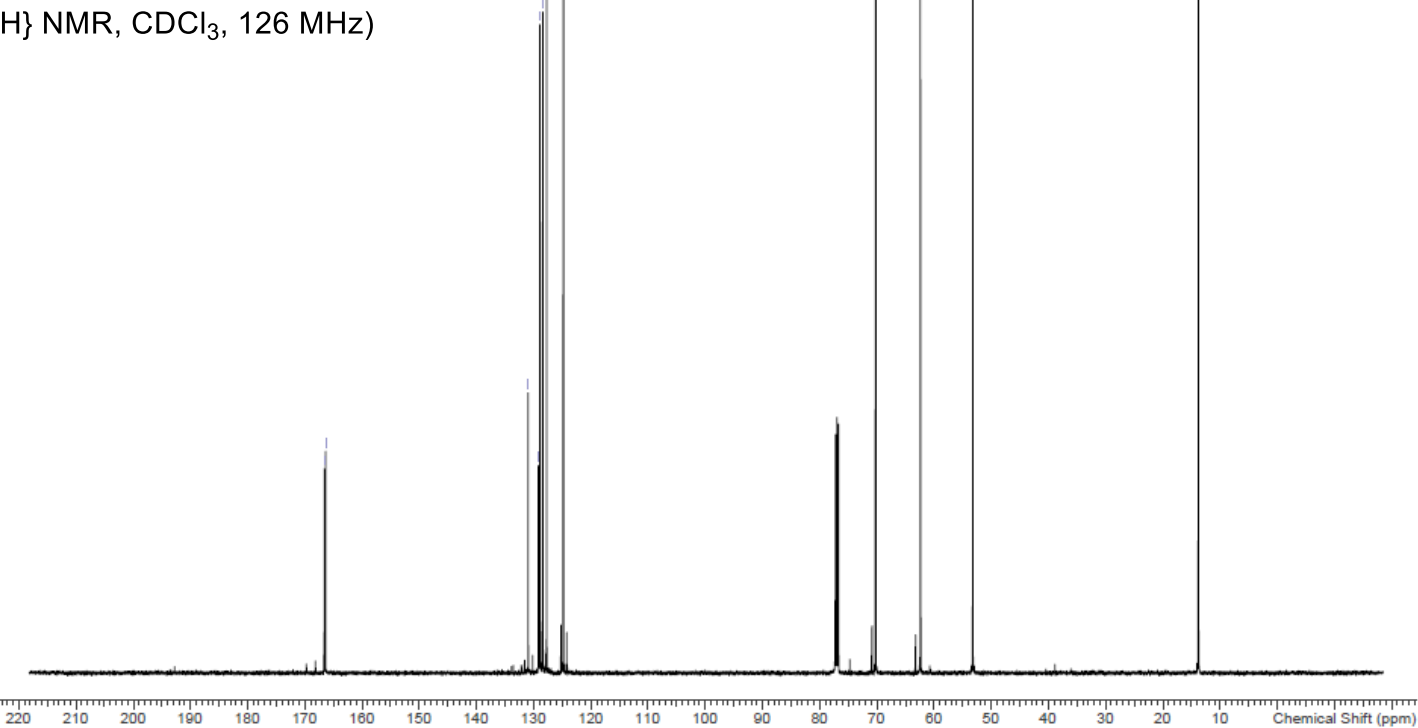

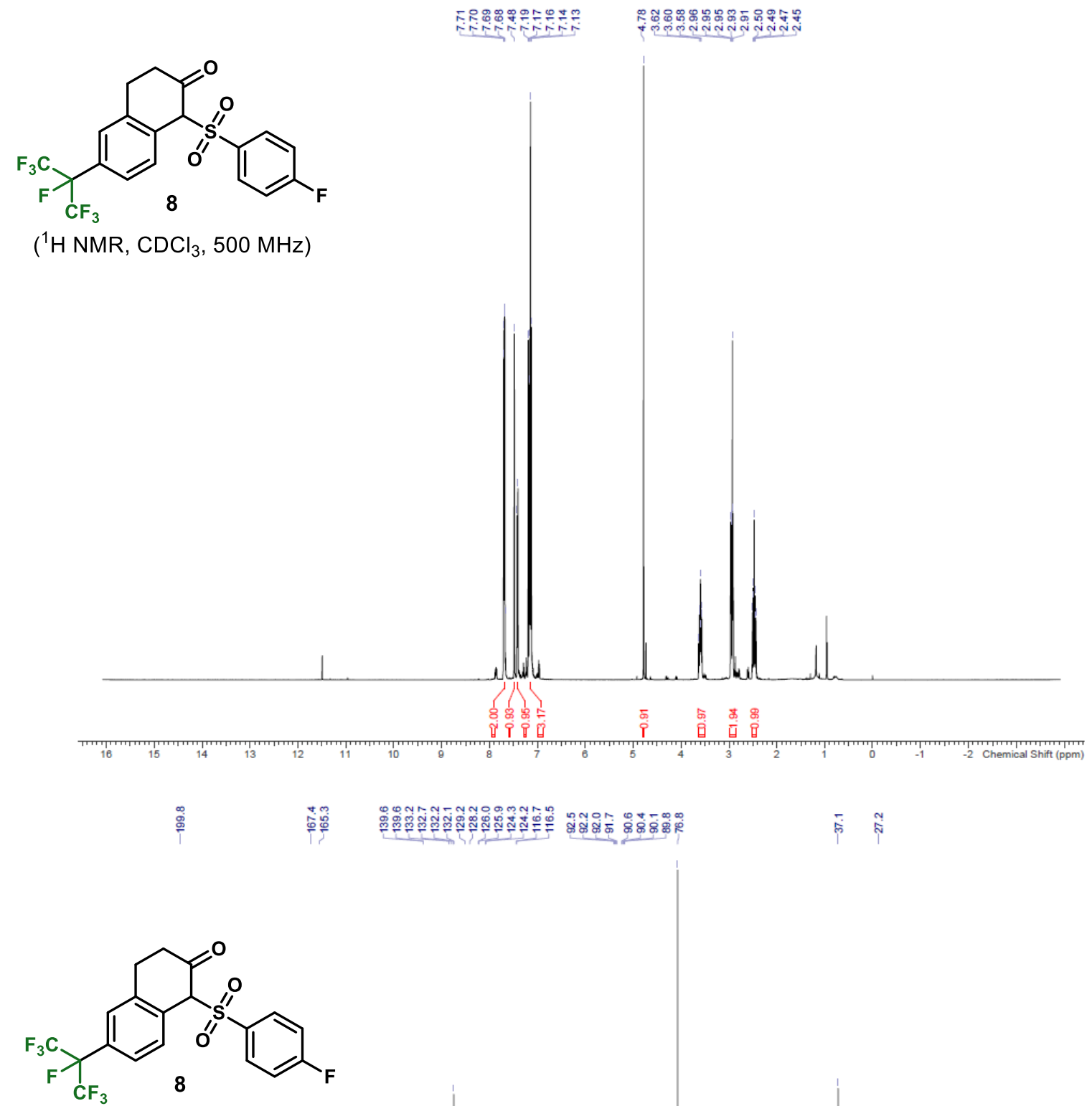

$\left({ }^{13} \mathrm{C}\left\{{ }^{1} \mathrm{H}\right\} \mathrm{NMR}, \mathrm{CDCl}_{3}, 126 \mathrm{MHz}\right)$

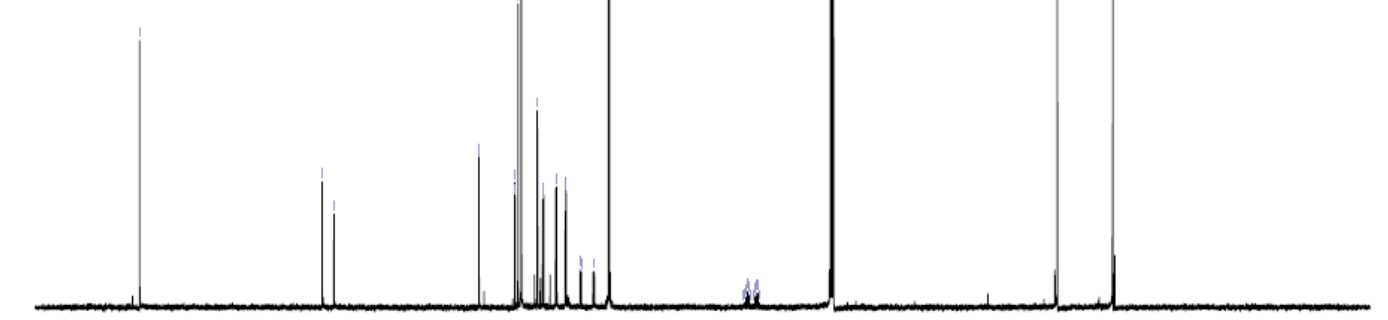

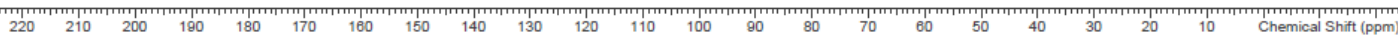




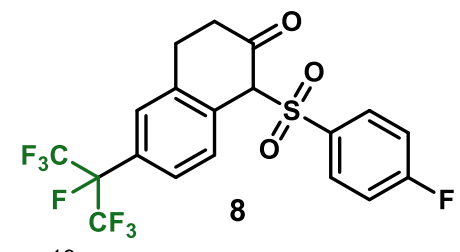

กั

움

$\left({ }^{19} \mathrm{~F} \mathrm{NMR}, \mathrm{CDCl}_{3}, 376 \mathrm{MHz}\right)$
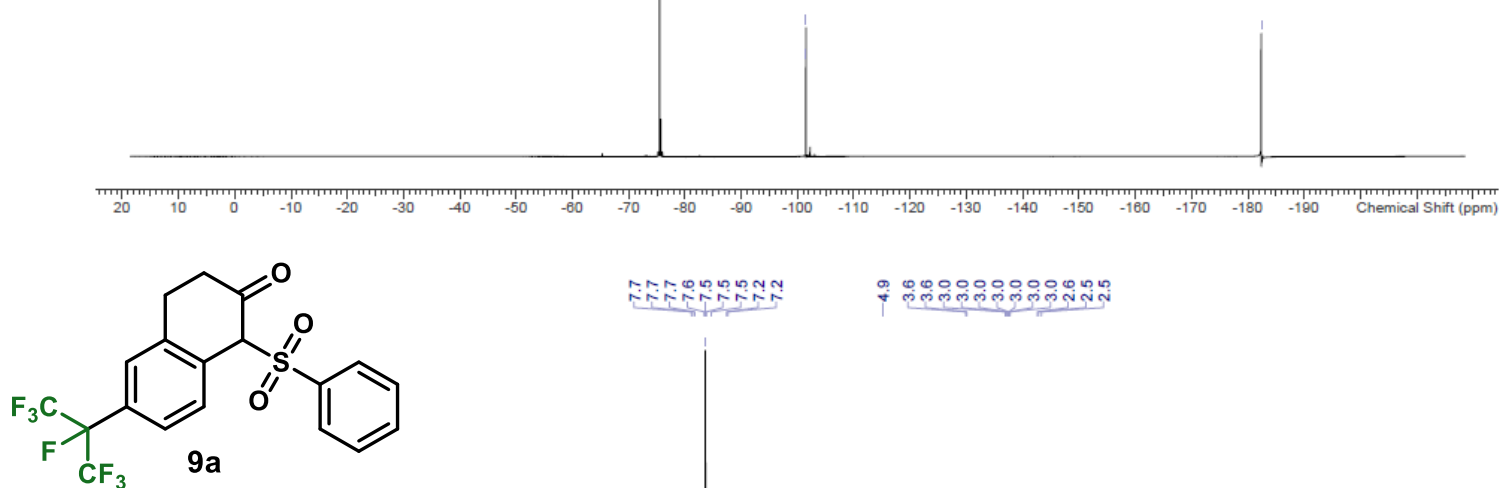

$\left({ }^{1} \mathrm{H}\right.$ NMR, $\left.\mathrm{CDCl}_{3}, 500 \mathrm{MHz}\right)$





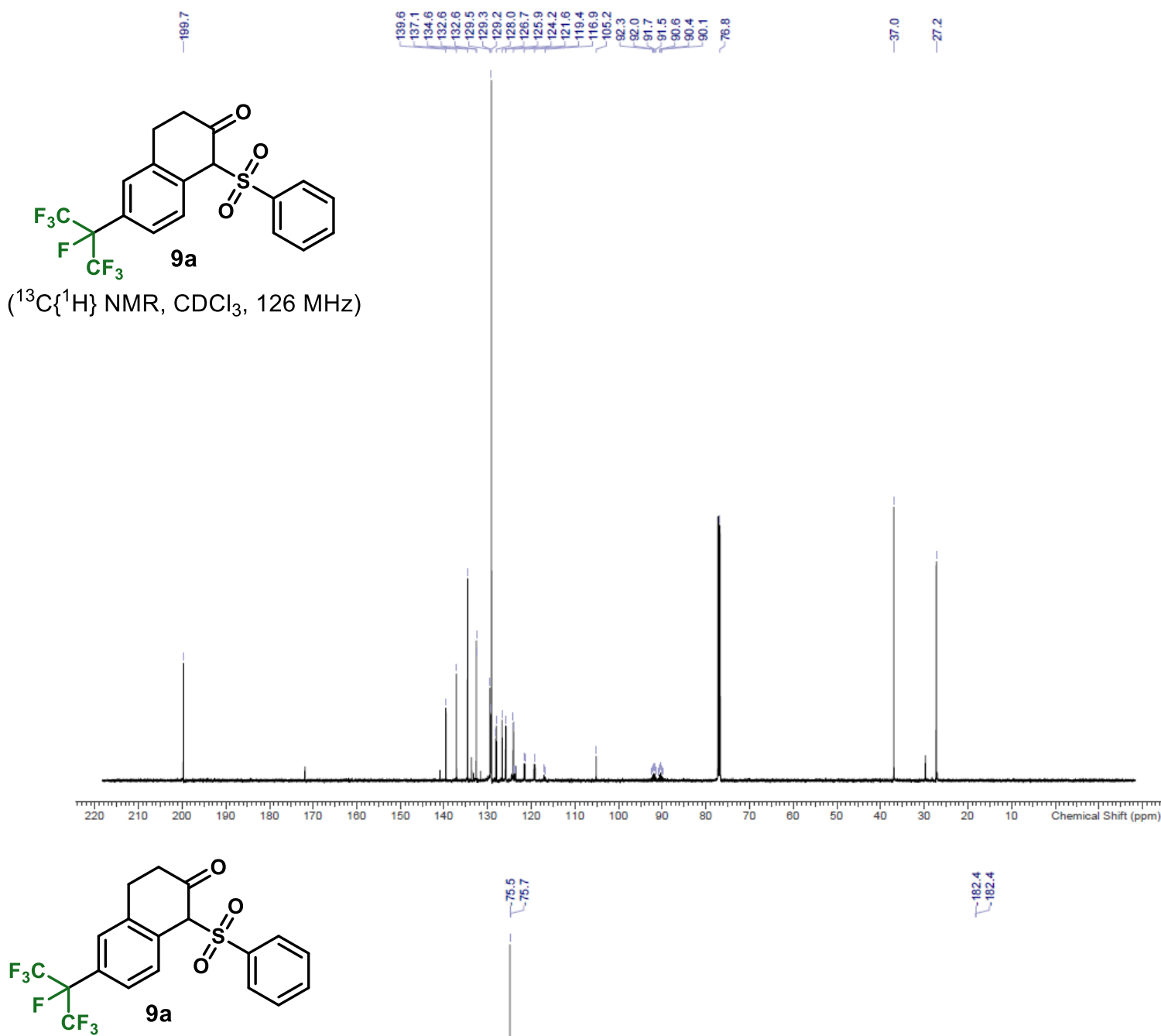

ํํำ

జّن

$\left({ }^{19} \mathrm{~F} \mathrm{NMR}, \mathrm{CDCl}_{3}, 376 \mathrm{MHz}\right)$ 



$\left({ }^{13} \mathrm{C}\left\{{ }^{1} \mathrm{H}\right\} \mathrm{NMR}, \mathrm{CDCl}_{3}, 126 \mathrm{MHz}\right)$
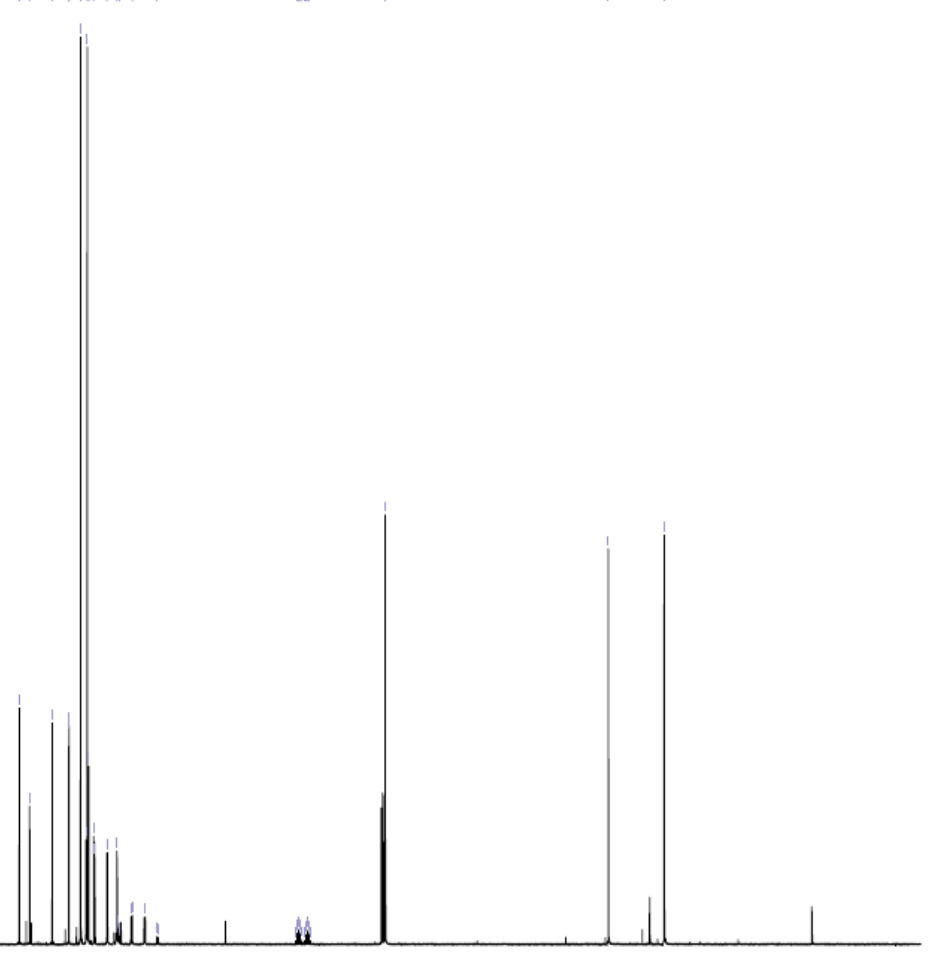

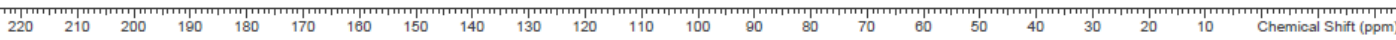



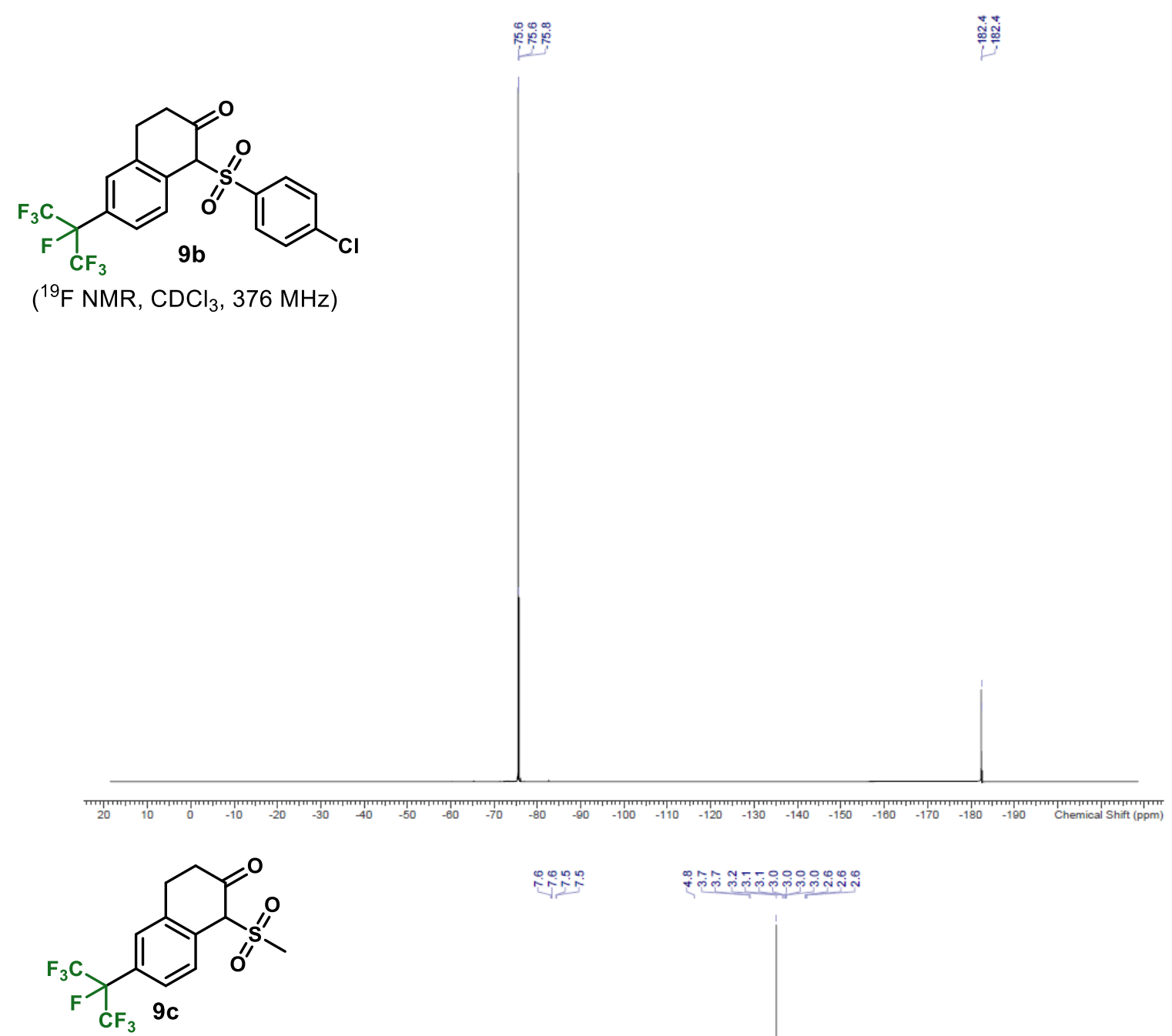

( ${ }^{1} \mathrm{H} \mathrm{NMR}, \mathrm{CDCl}_{3}, 500 \mathrm{MHz}$ )



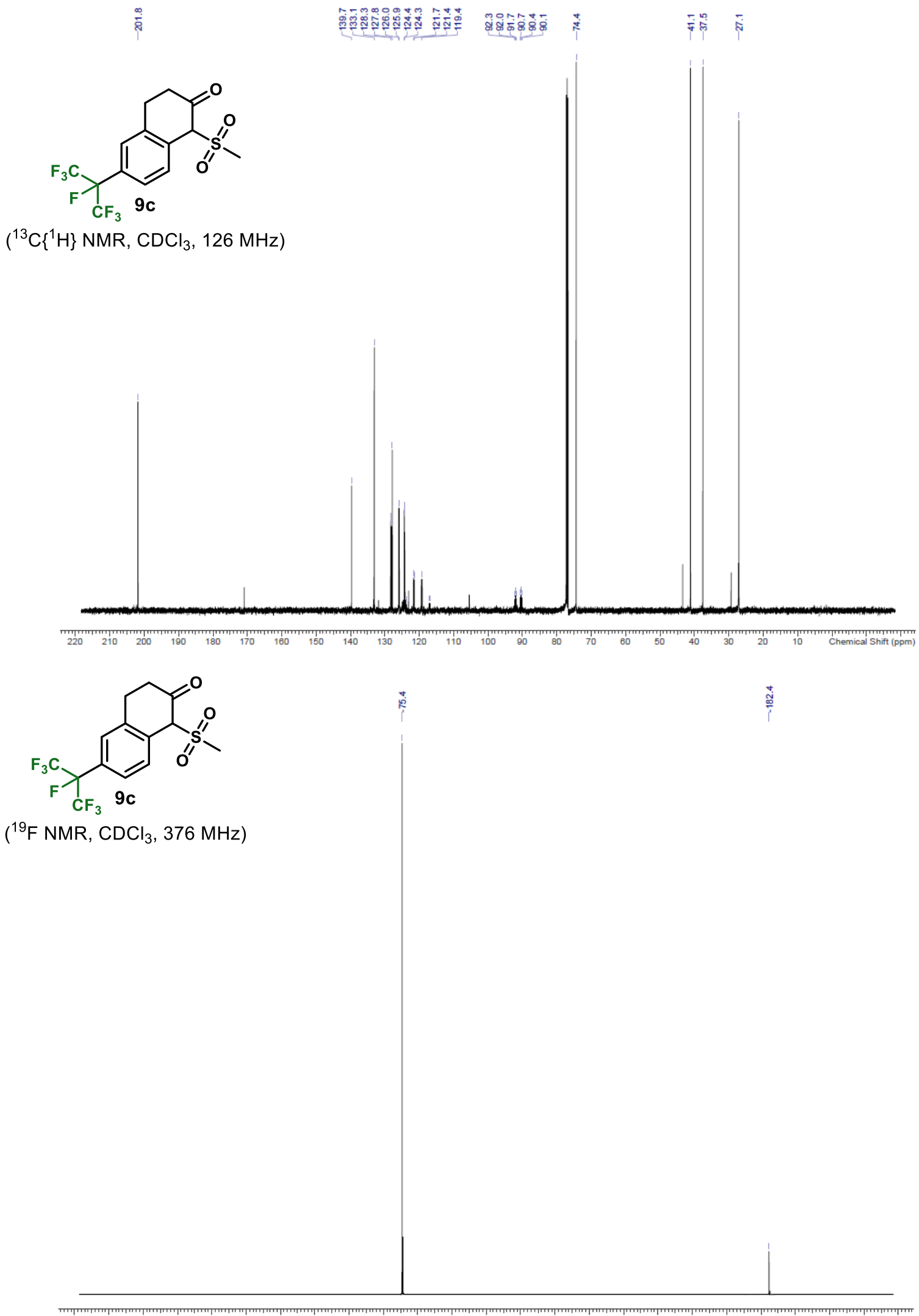

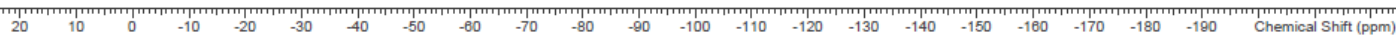



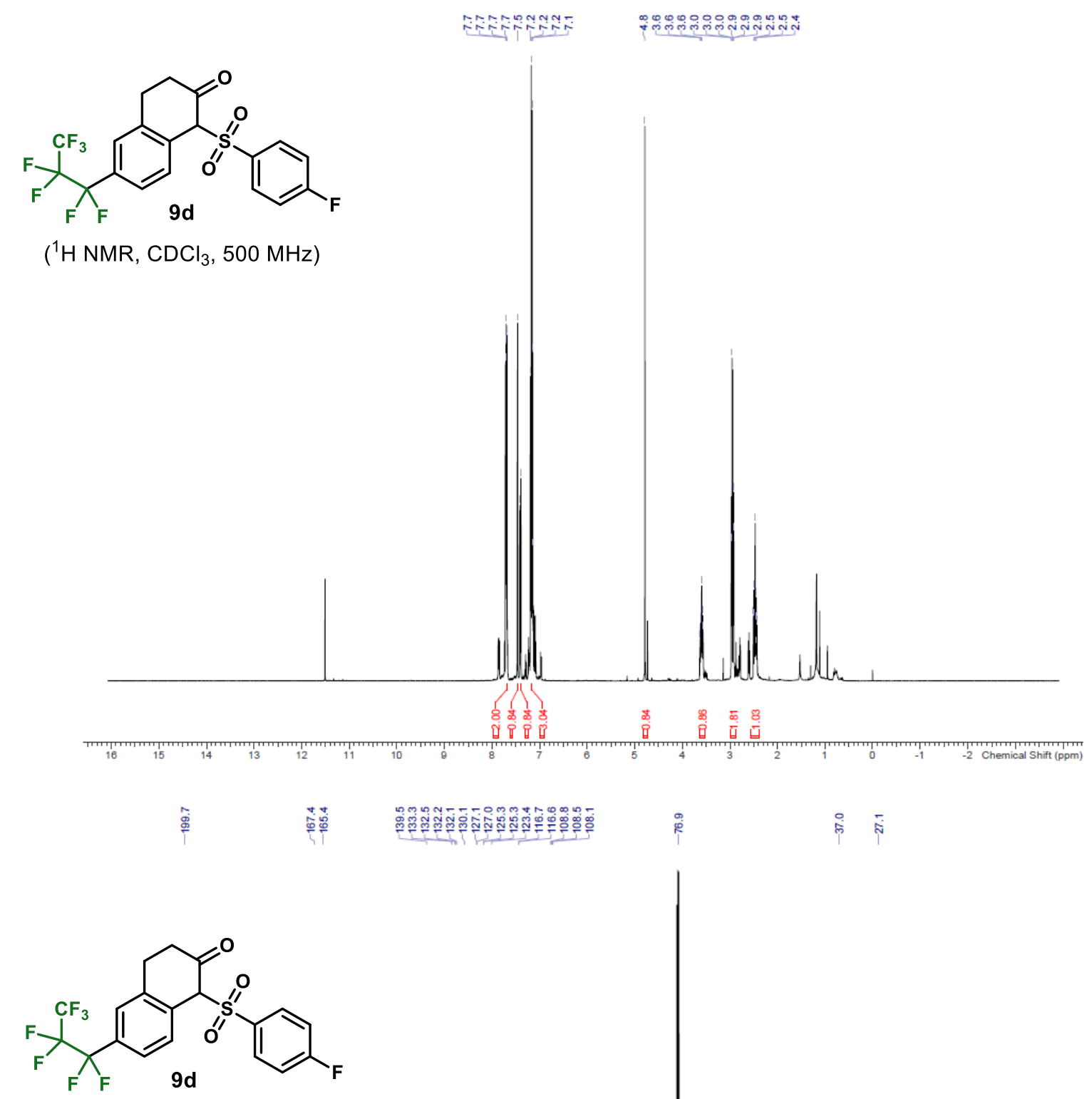

$\left({ }^{13} \mathrm{C}\left\{{ }^{1} \mathrm{H}\right\} \mathrm{NMR}, \mathrm{CDCl}_{3}, 126 \mathrm{MHz}\right)$

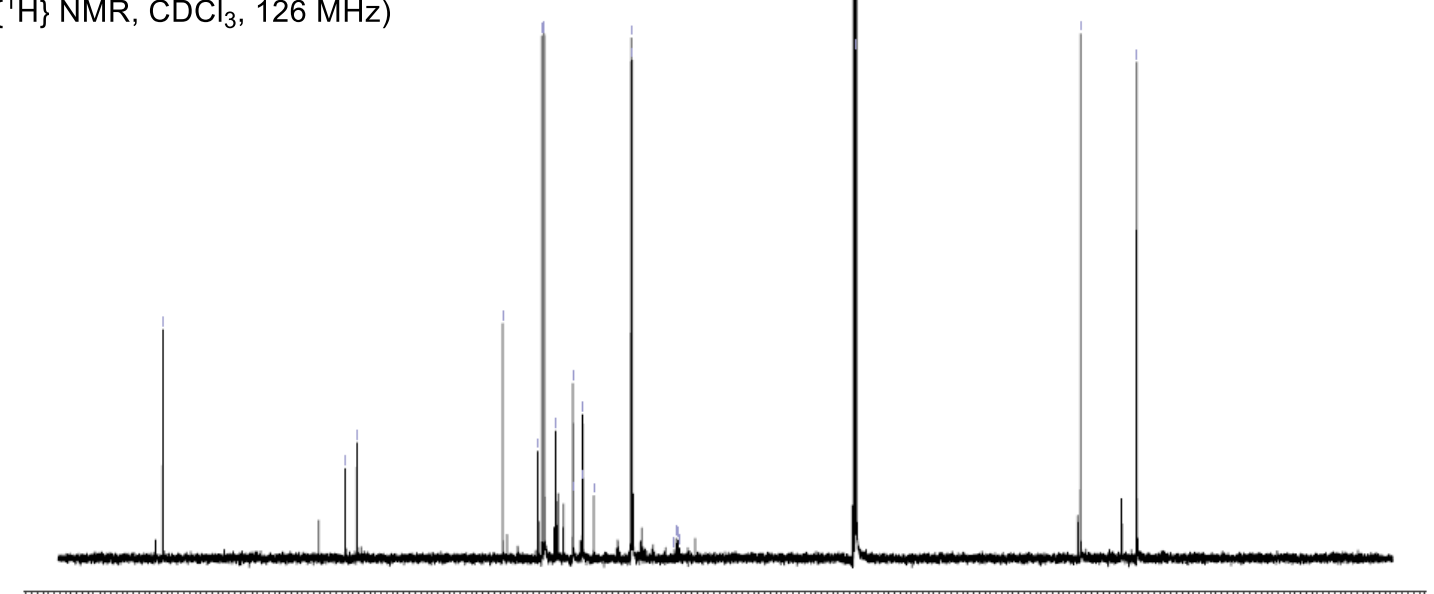

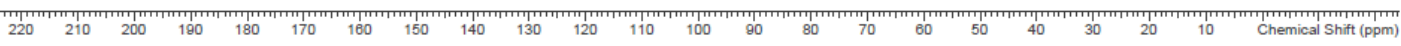




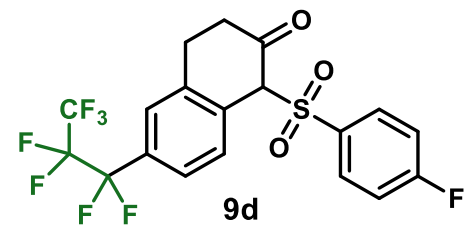

$\left({ }^{19} \mathrm{~F} \mathrm{NMR}, \mathrm{CDCl}_{3}, 376 \mathrm{MHz}\right)$
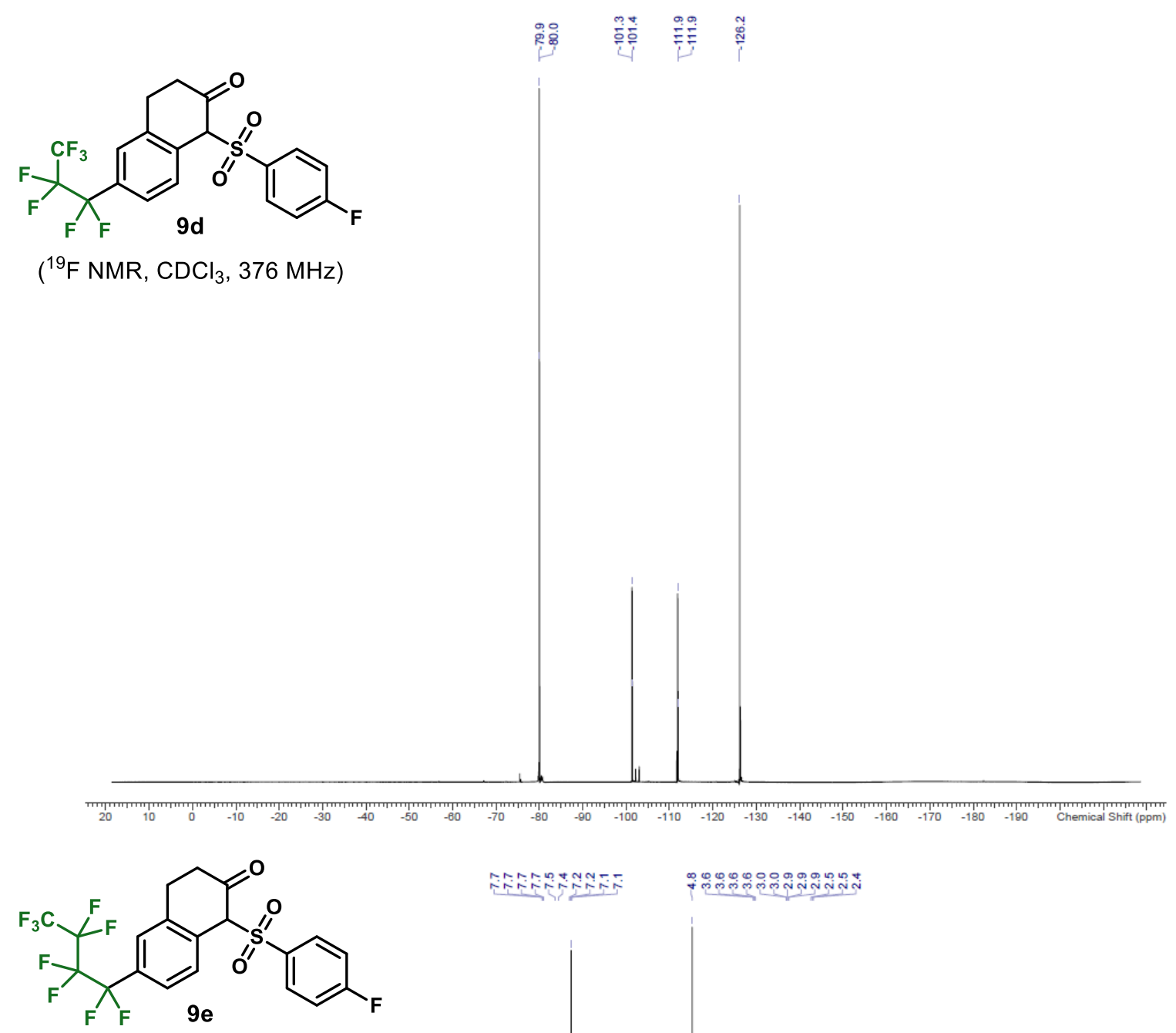

$\left({ }^{1} \mathrm{H} \mathrm{NMR}, \mathrm{CDCl}_{3}, 500 \mathrm{MHz}\right.$ )

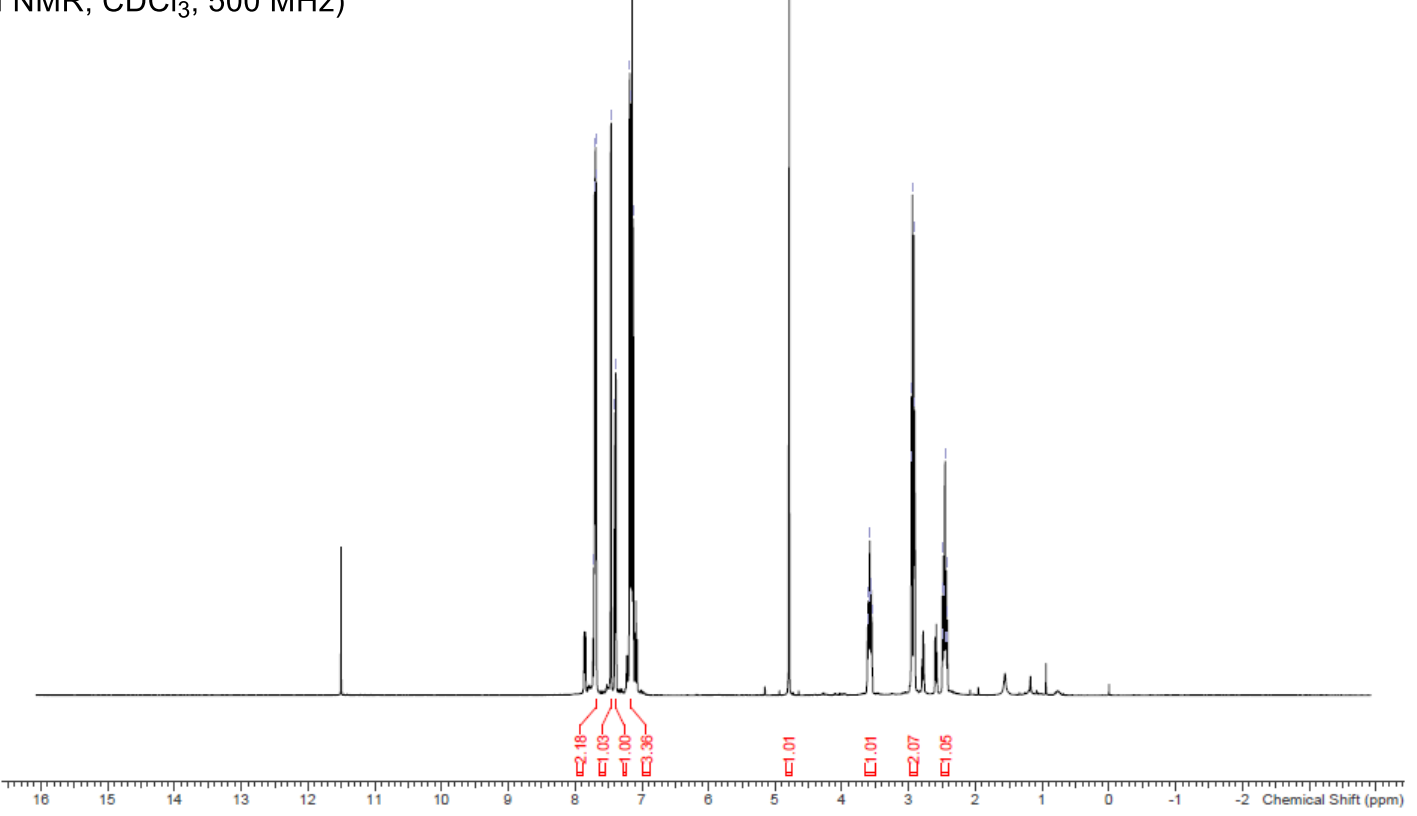



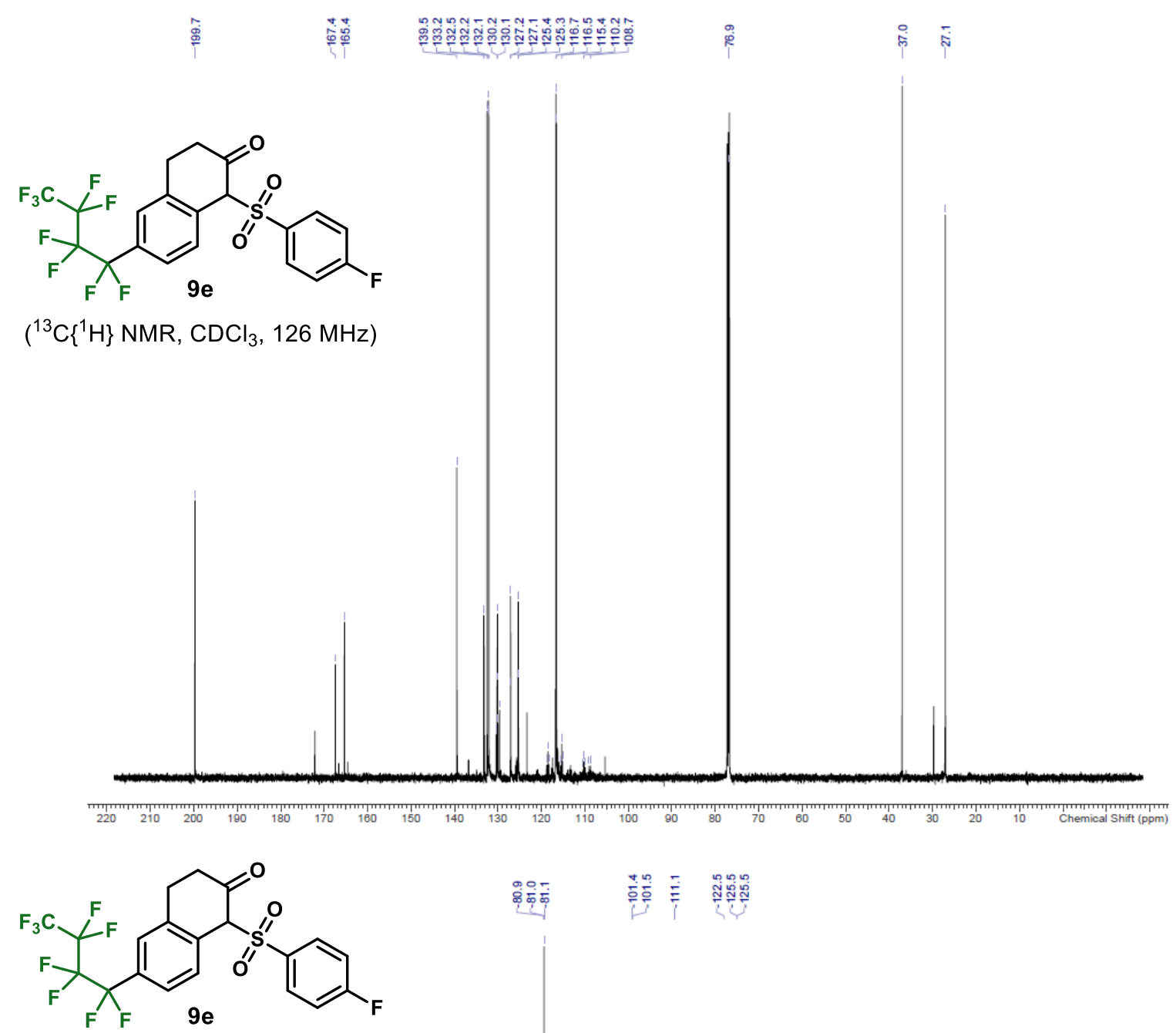

$\left({ }^{19} \mathrm{~F} \mathrm{NMR}, \mathrm{CDCl}_{3}, 376 \mathrm{MHz}\right)$ 

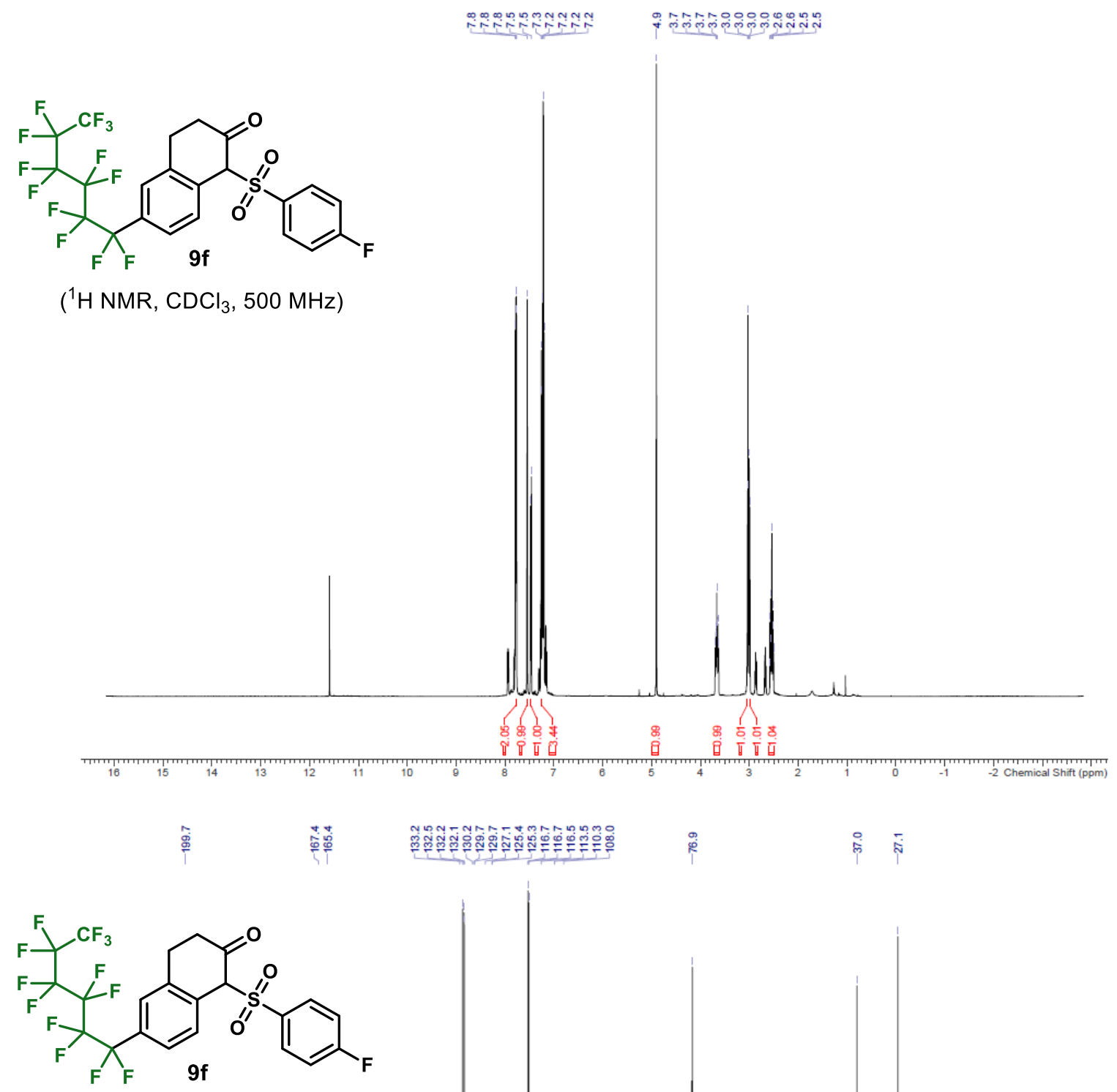

$\left({ }^{13} \mathrm{C}\left\{{ }^{1} \mathrm{H}\right\} \mathrm{NMR}, \mathrm{CDCl}_{3}, 126 \mathrm{MHz}\right)$

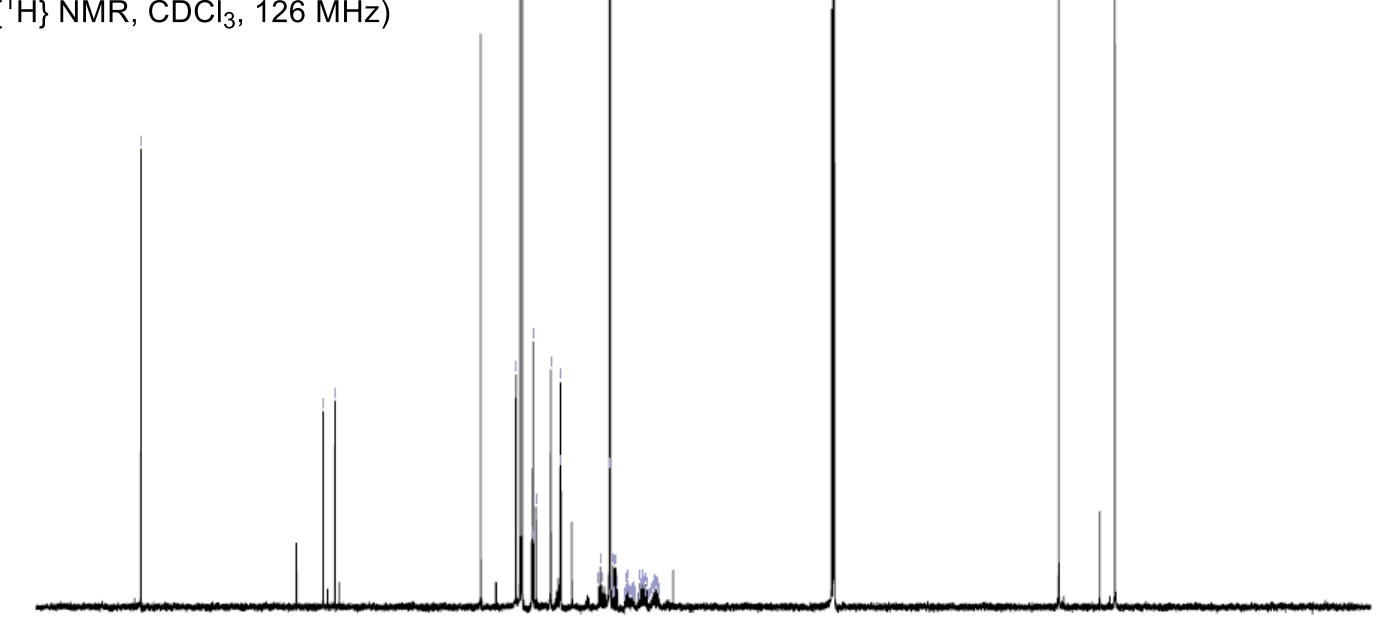

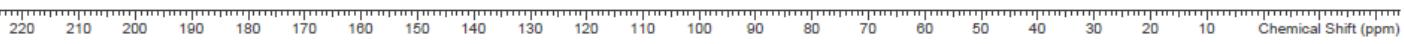




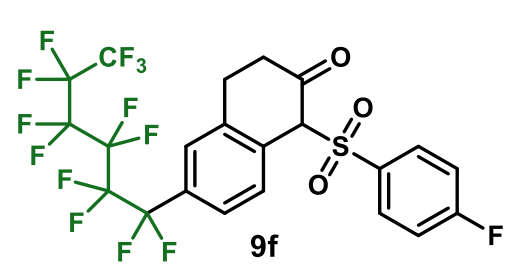

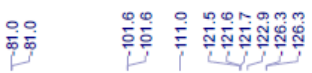

$\left({ }^{19} \mathrm{~F} \mathrm{NMR}, \mathrm{CDCl}_{3}, 376 \mathrm{MHz}\right)$



$\left({ }^{1} \mathrm{H} \mathrm{NMR}, \mathrm{CDCl}_{3}, 500 \mathrm{MHz}\right.$ )

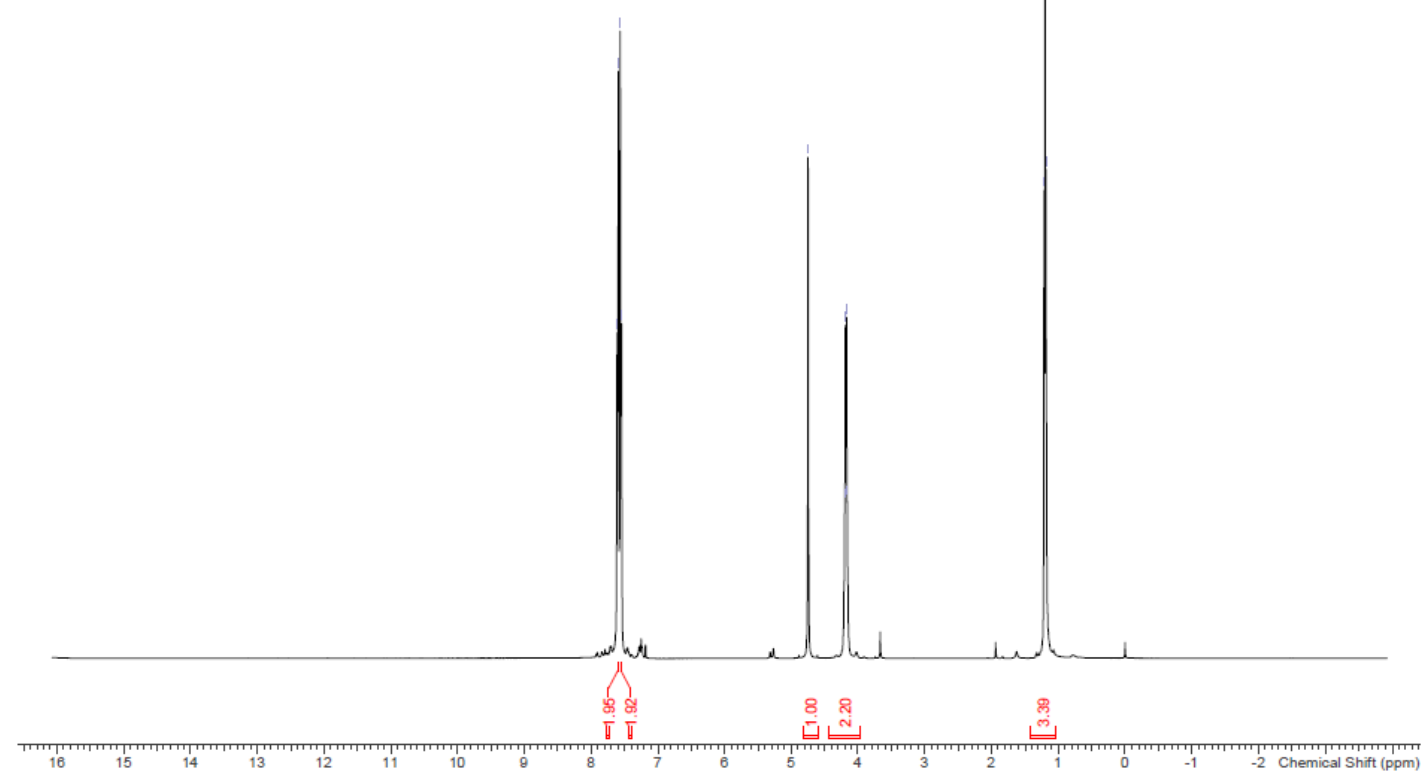




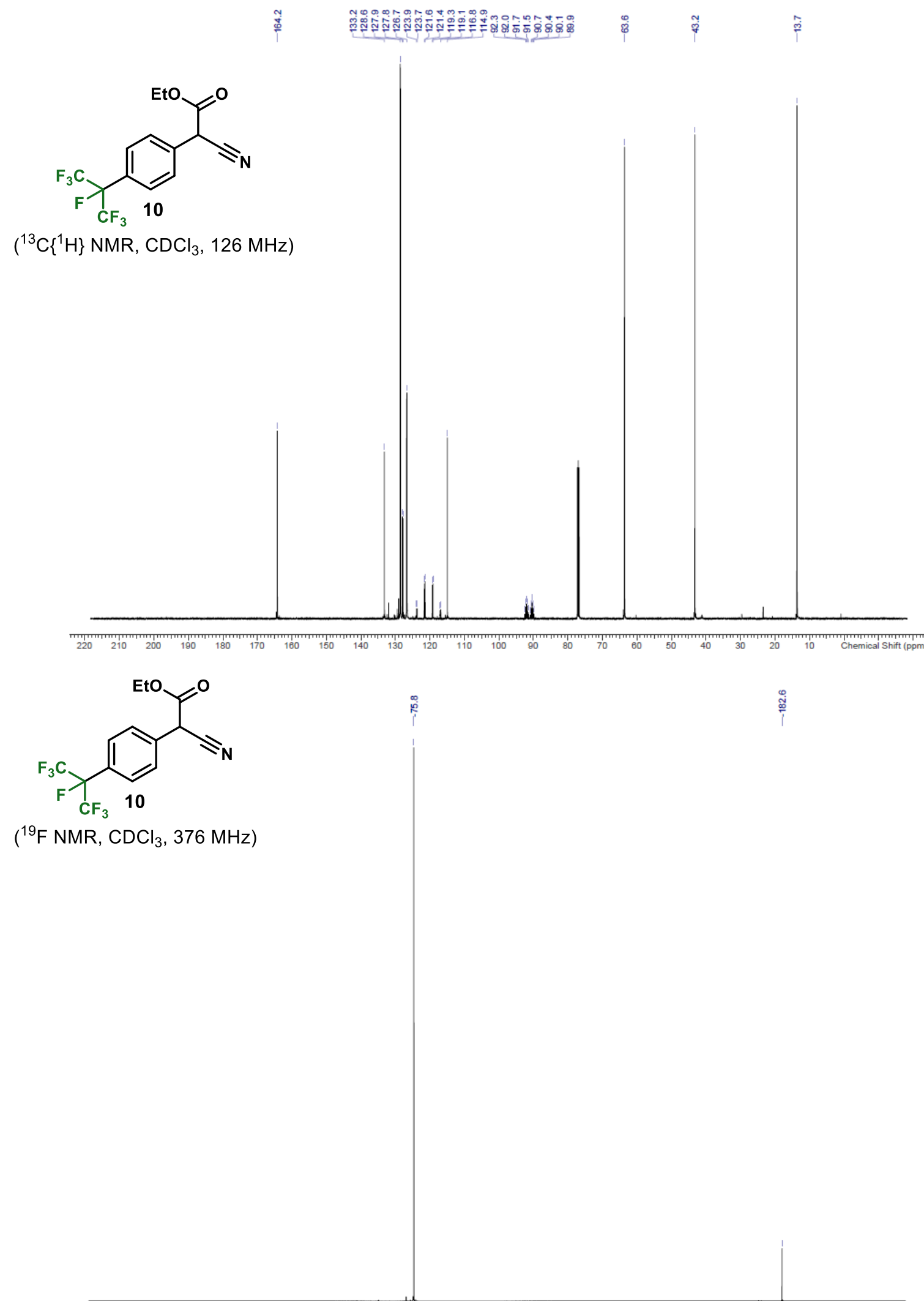

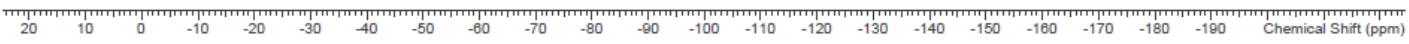




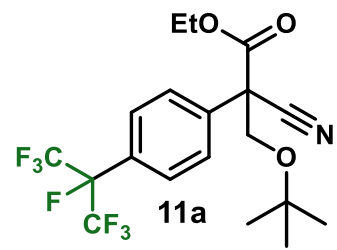

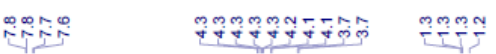

$\left({ }^{1} \mathrm{H} \mathrm{NMR}, \mathrm{CDCl}_{3}, 500 \mathrm{MHz}\right)$
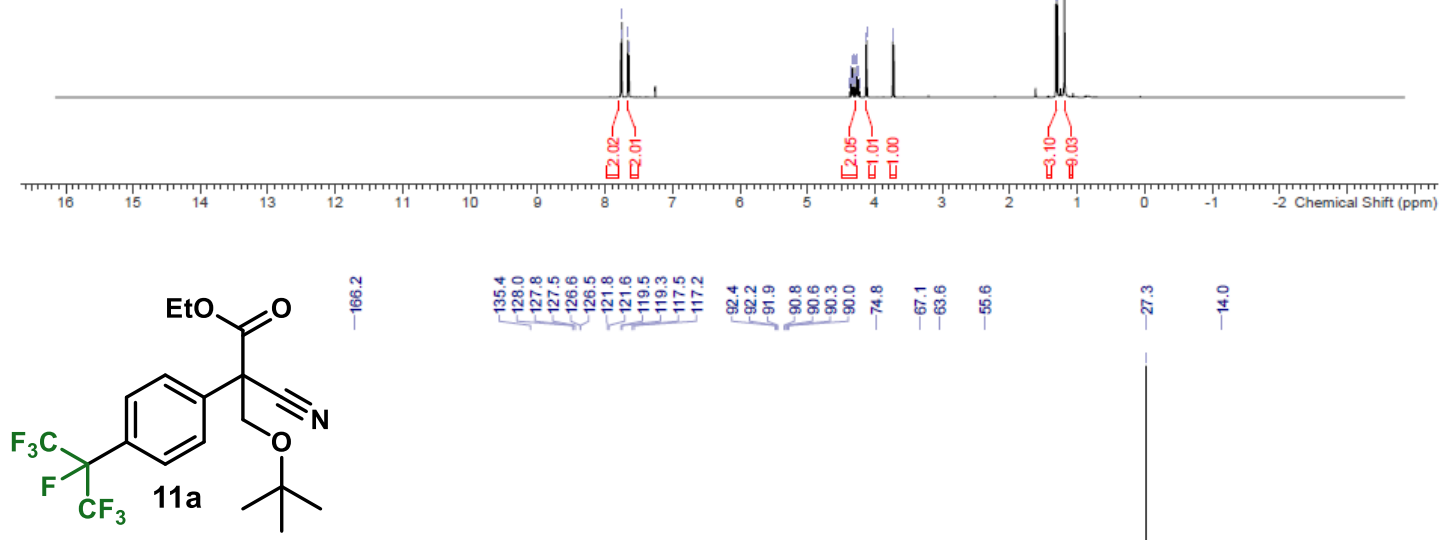

$\left({ }^{13} \mathrm{C}\left\{{ }^{1} \mathrm{H}\right\}\right.$ NMR, $\left.\mathrm{CDCl}_{3}, 126 \mathrm{MHz}\right)$

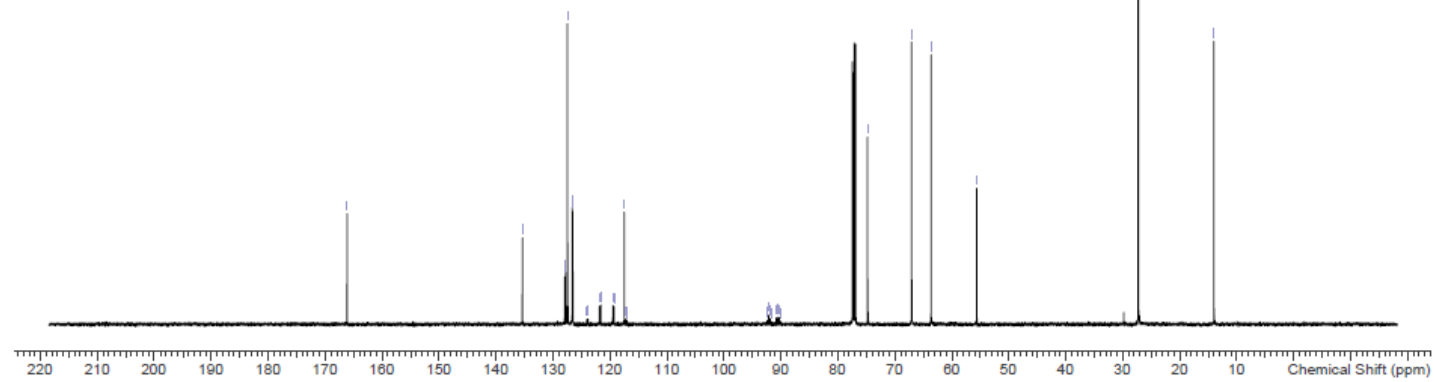




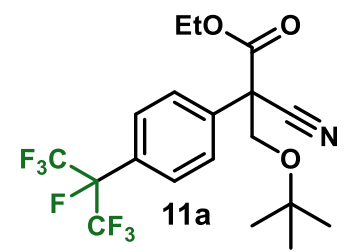

$\left({ }^{19} \mathrm{~F} \mathrm{NMR}, \mathrm{CDCl}_{3}, 376 \mathrm{MHz}\right)$

( $\left.{ }^{\circ} \mathrm{FNMR}, \mathrm{CDCl}_{3}, 376 \mathrm{MHz}\right)$
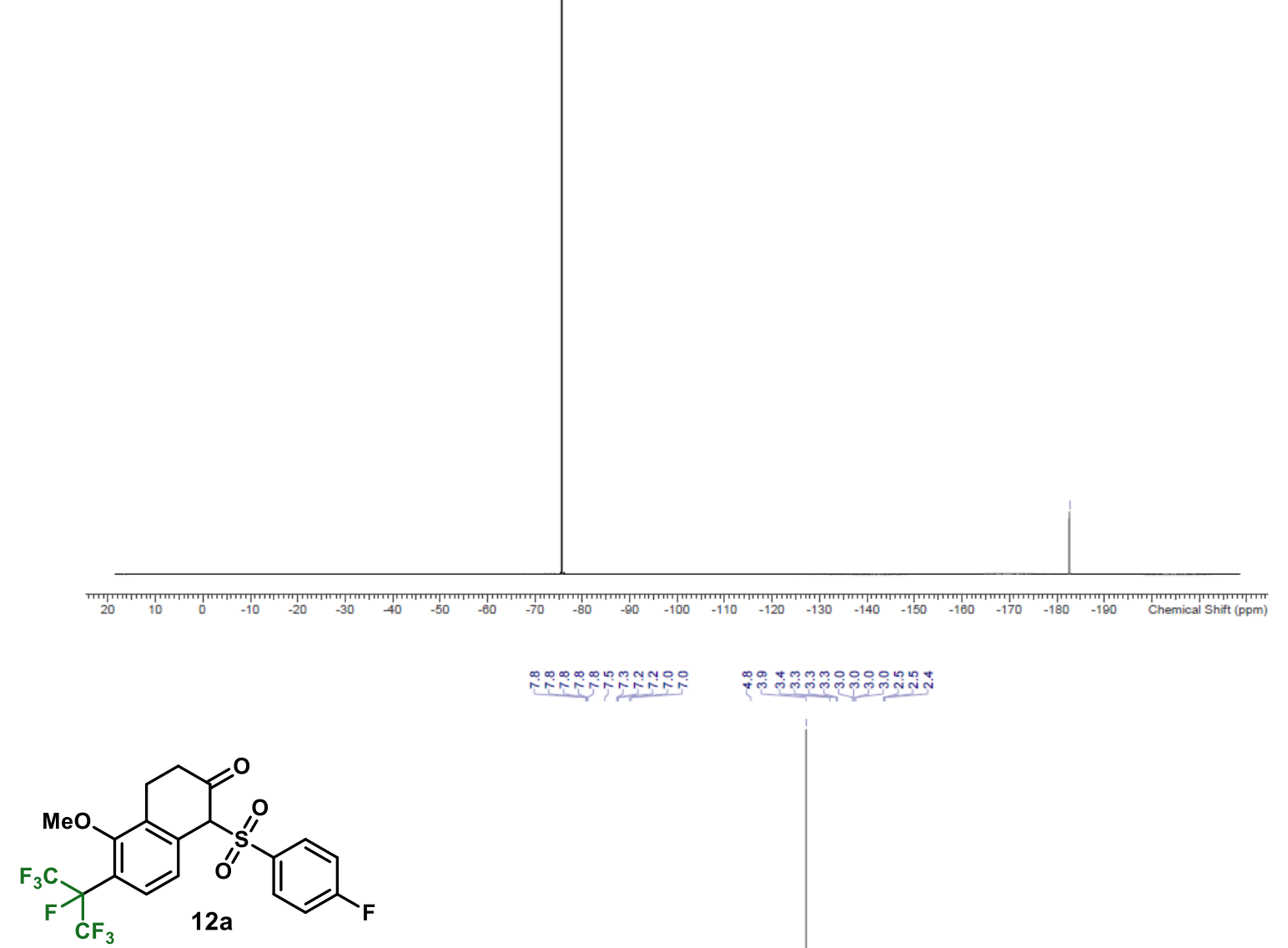

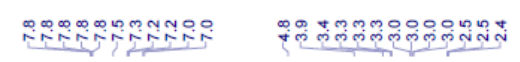

( $\left.{ }^{1} \mathrm{H} \mathrm{NMR}, \mathrm{CDCl}_{3}, 500 \mathrm{MHz}\right)$

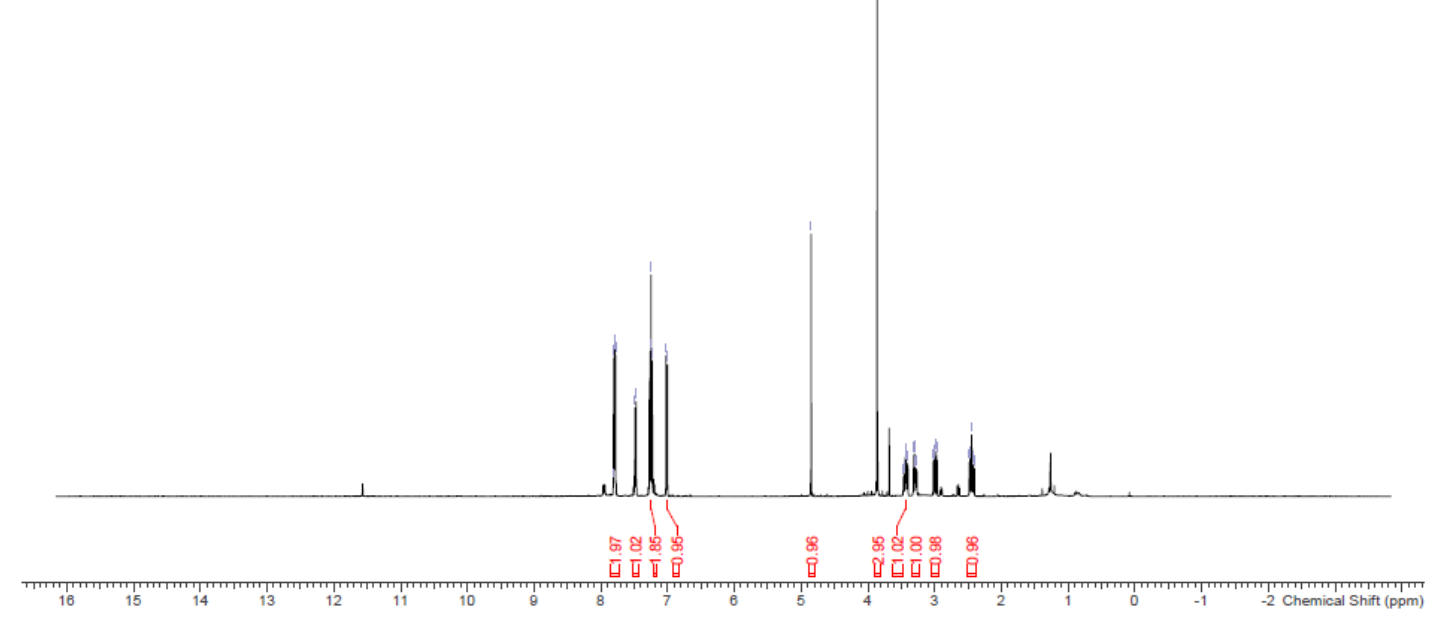



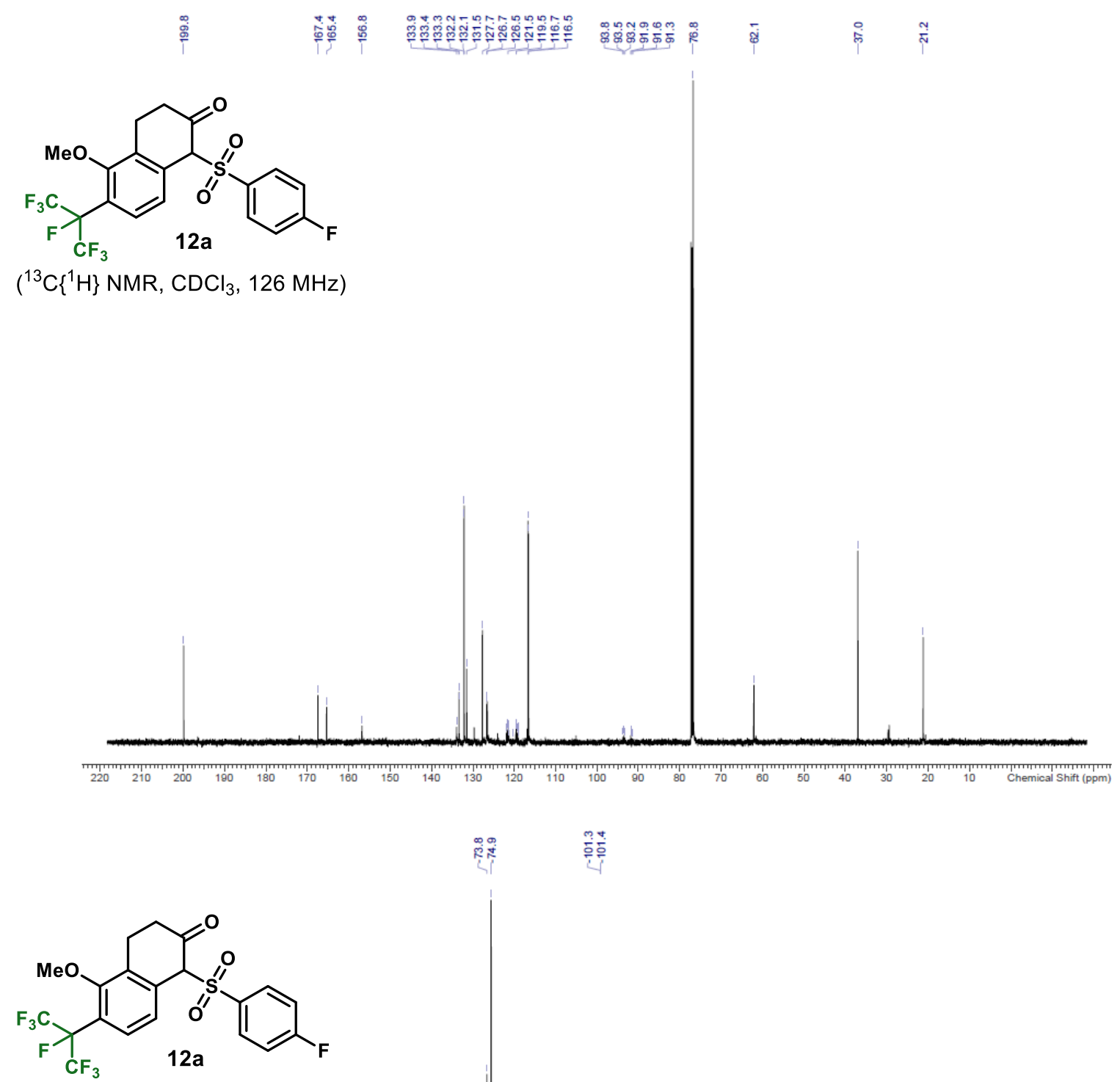

$\left({ }^{19} \mathrm{~F} \mathrm{NMR}, \mathrm{CDCl}_{3}, 376 \mathrm{MHz}\right)$ 


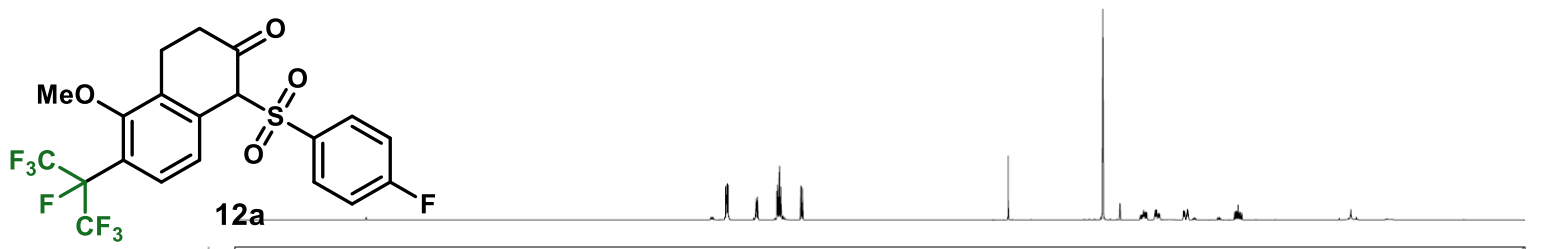

(COSY, $\mathrm{CDCl}_{3}, 500 \mathrm{MHz}$ )

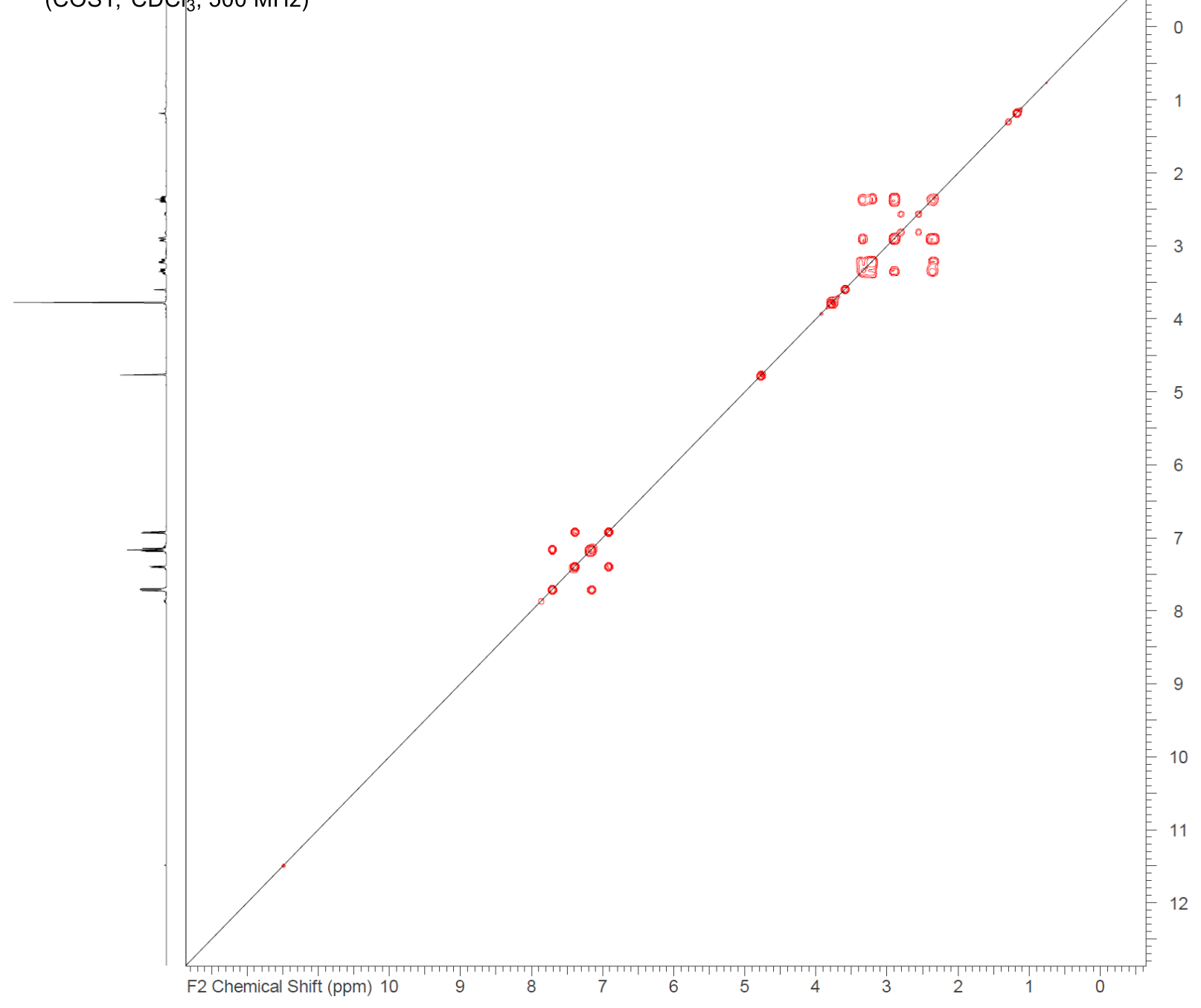



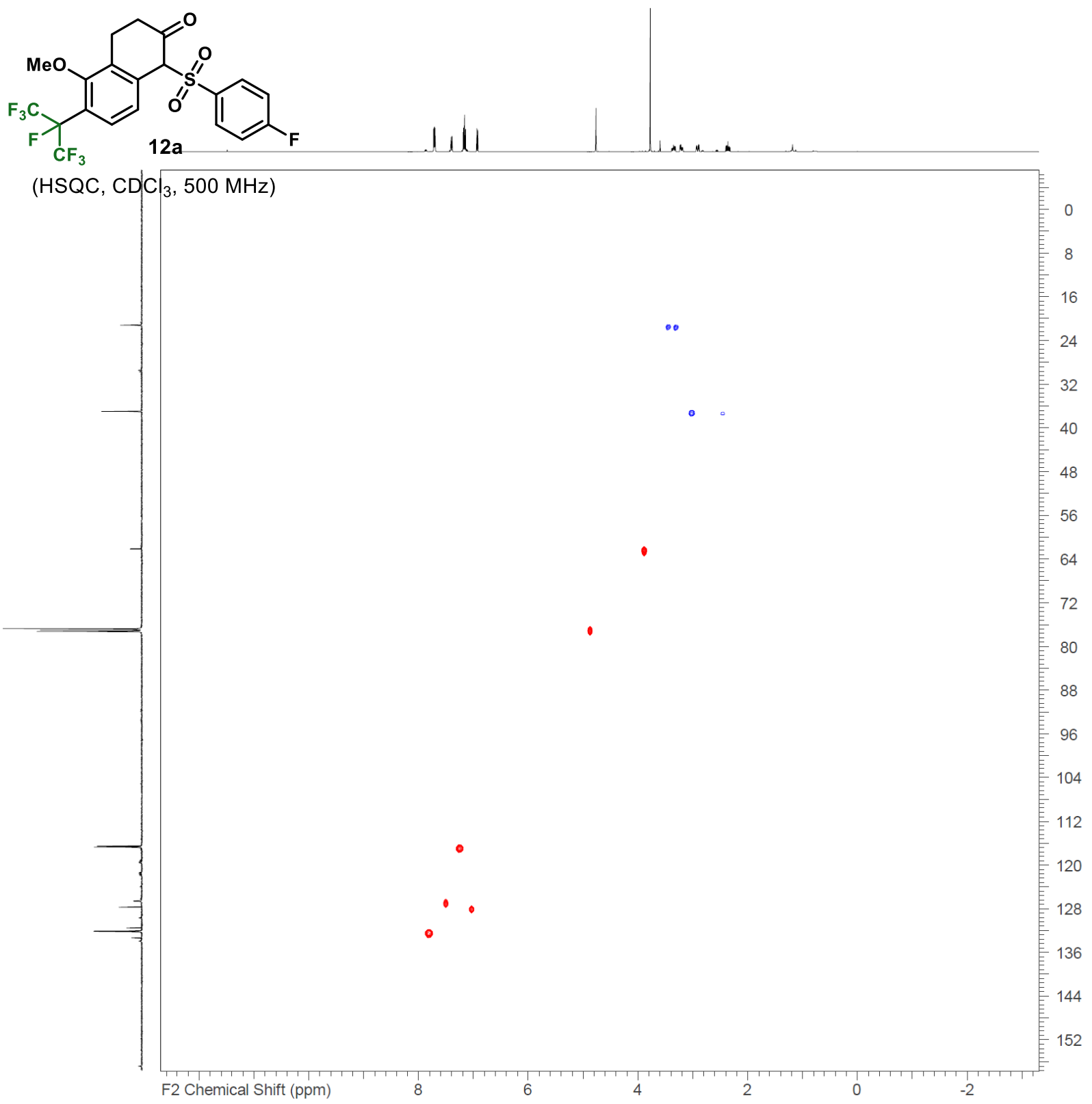


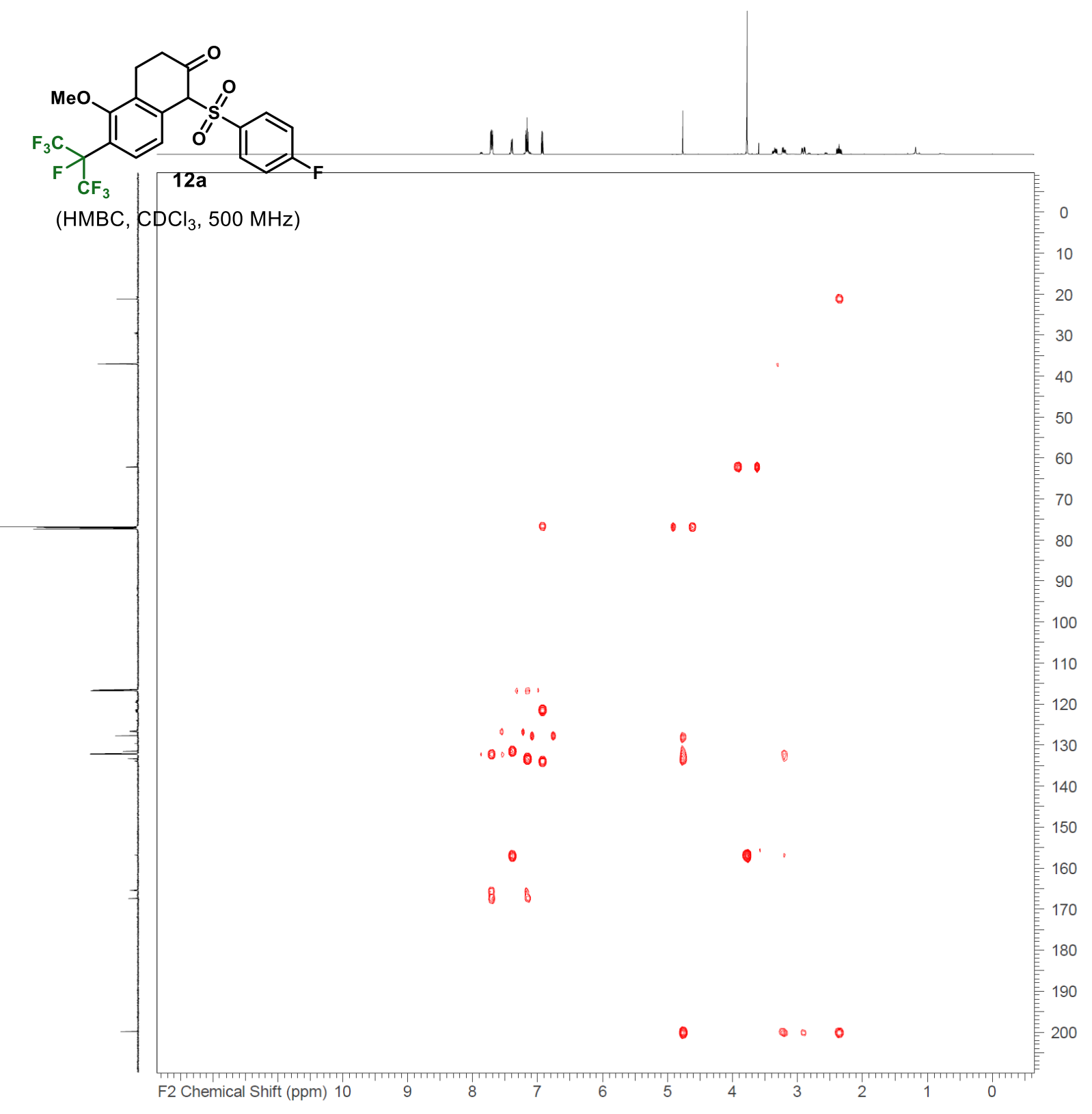




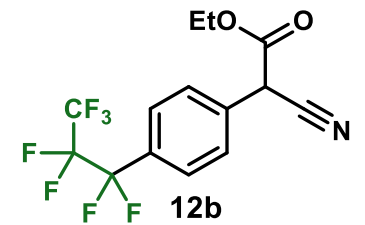

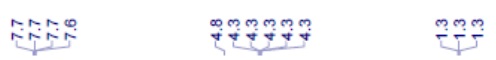

( ${ }^{1} \mathrm{H} \mathrm{NMR}, \mathrm{CDCl}_{3}, 500 \mathrm{MHz}$ )


*



$\left({ }^{13} \mathrm{C}\left\{{ }^{1} \mathrm{H}\right\}\right.$ NMR, $\left.\mathrm{CDCl}_{3}, 126 \mathrm{MHz}\right)$

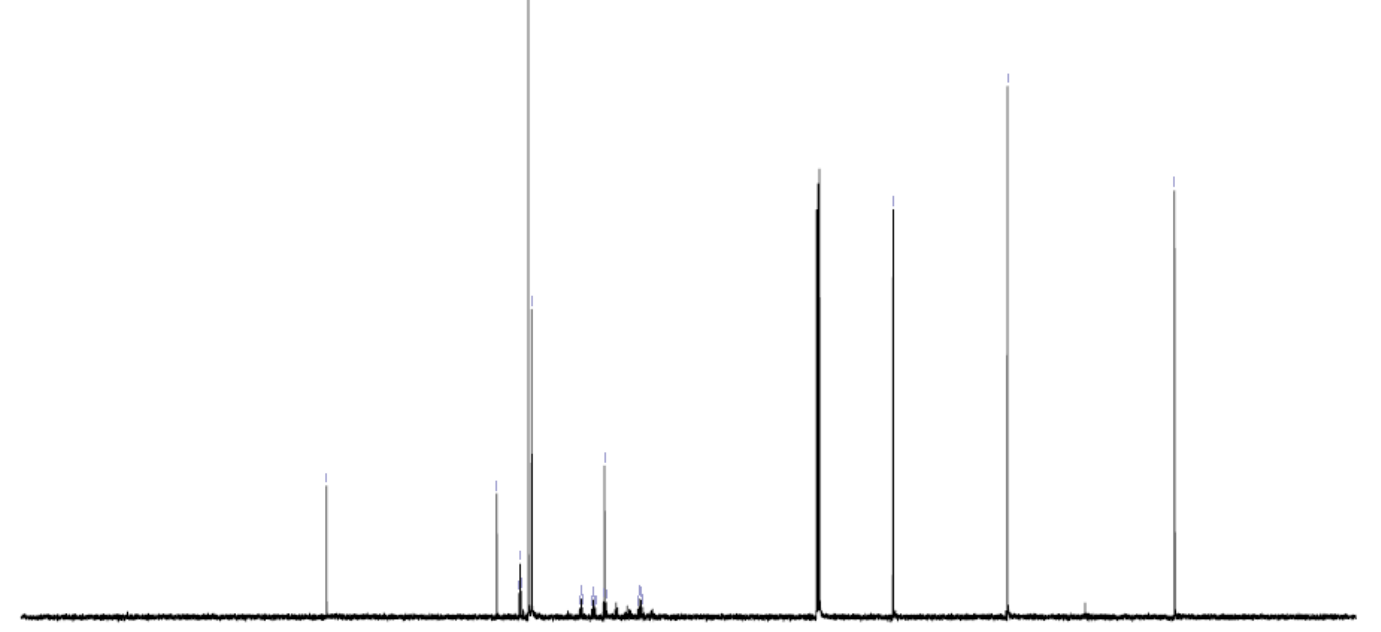

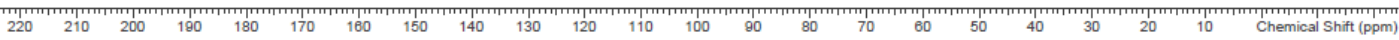




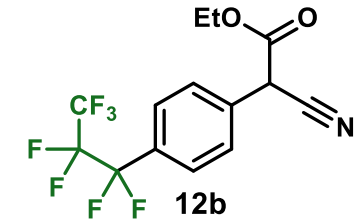

$\left({ }^{19} \mathrm{~F} \mathrm{NMR}, \mathrm{CDCl}_{3}, 376 \mathrm{MHz}\right)$

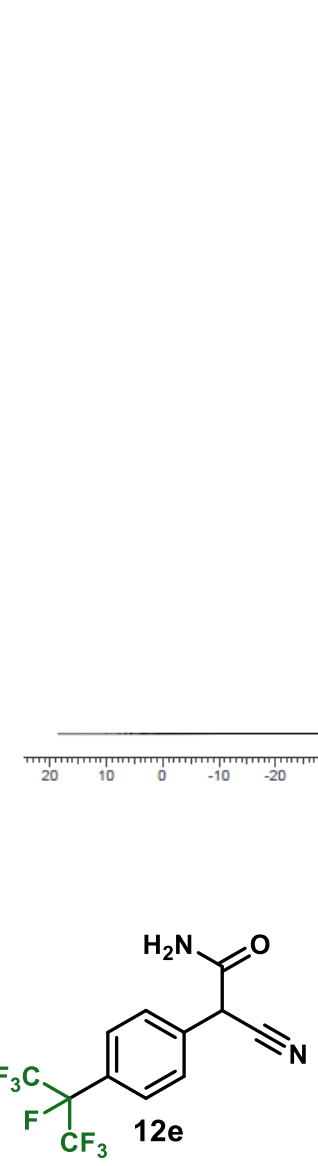

$\left({ }^{1} \mathrm{H}\right.$ NMR, DMSO-d $\left.6,500 \mathrm{MHz}\right)$

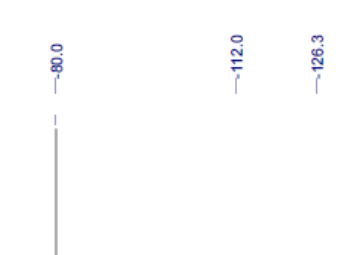



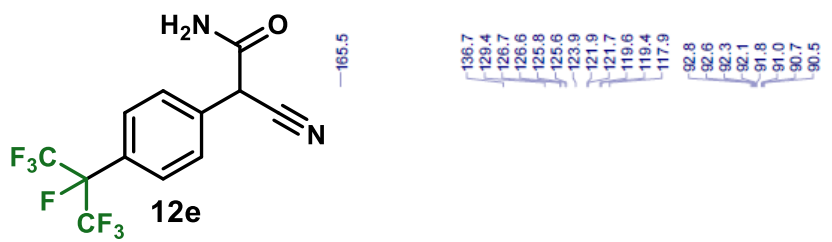

$\left({ }^{13} \mathrm{C}\left\{{ }^{1} \mathrm{H}\right\}\right.$ NMR, DMSO- $\left.\mathrm{d}_{6}, 126 \mathrm{MHz}\right)$


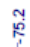

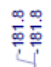

$\left({ }^{19} \mathrm{~F}\right.$ NMR, DMSO- $\left.\mathrm{d}_{6}, 376 \mathrm{MHz}\right)$

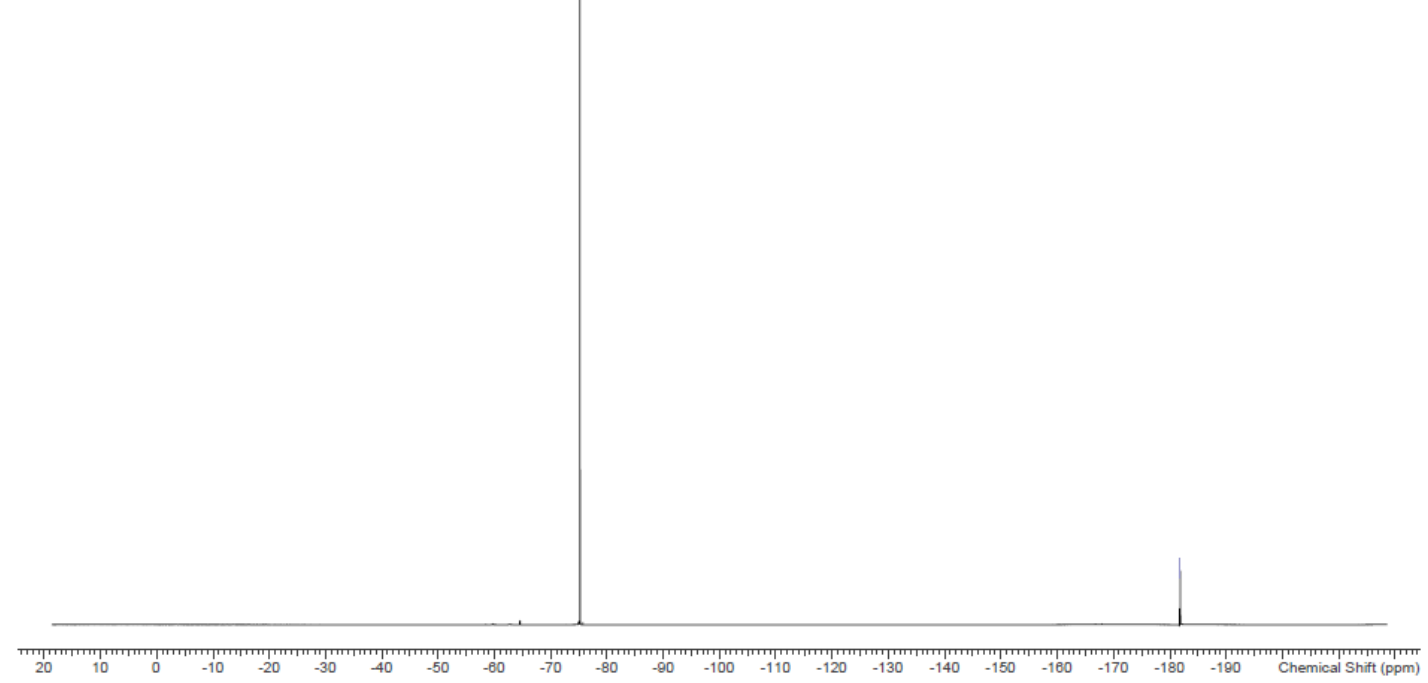




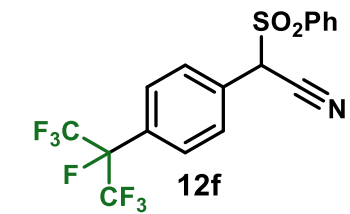

( ${ }^{1} \mathrm{H}$ NMR, $\mathrm{CDCl}_{3}, 500 \mathrm{MHz}$ )
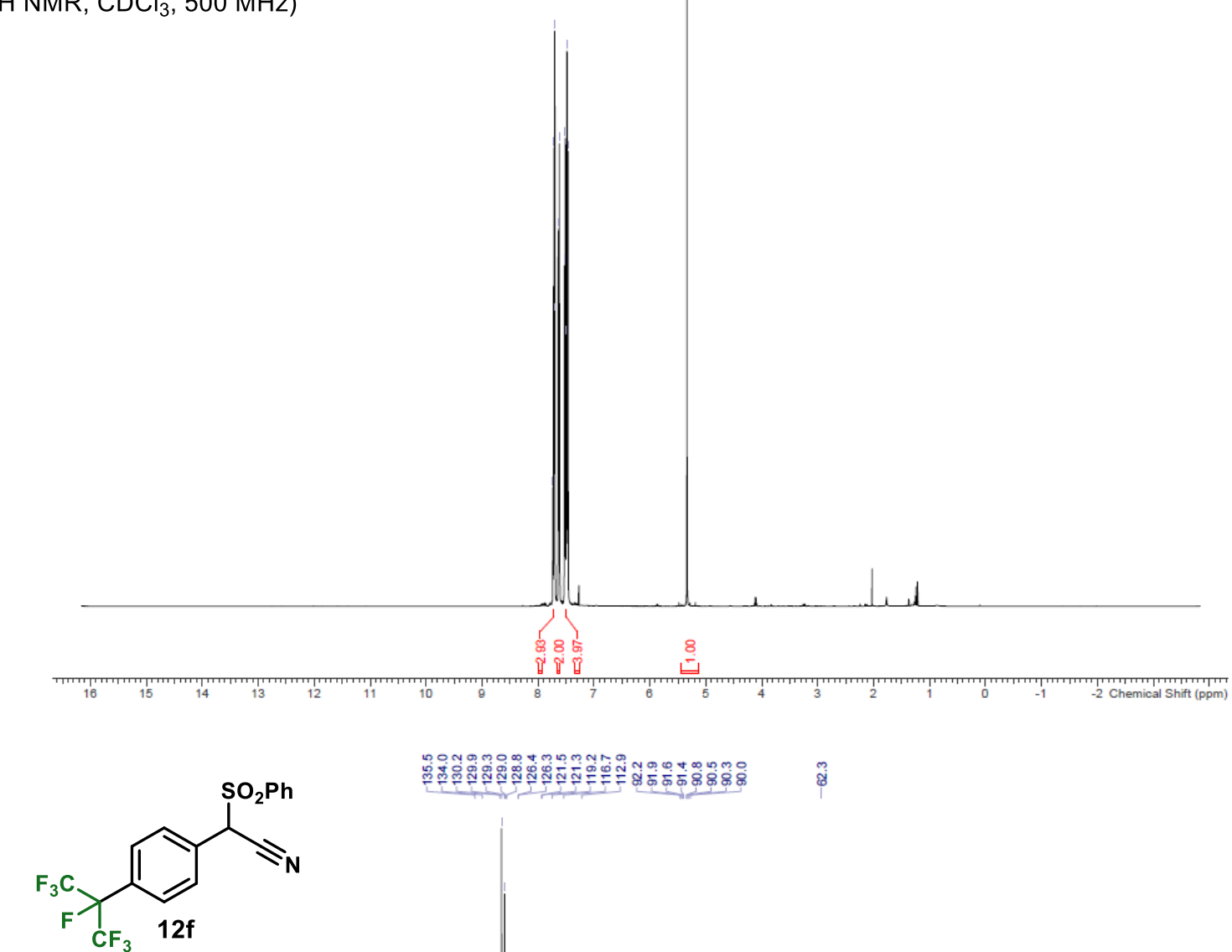

$\left({ }^{13} \mathrm{C}\left\{{ }^{1} \mathrm{H}\right\} \mathrm{NMR}, \mathrm{CDCl}_{3}, 126 \mathrm{MHz}\right)$
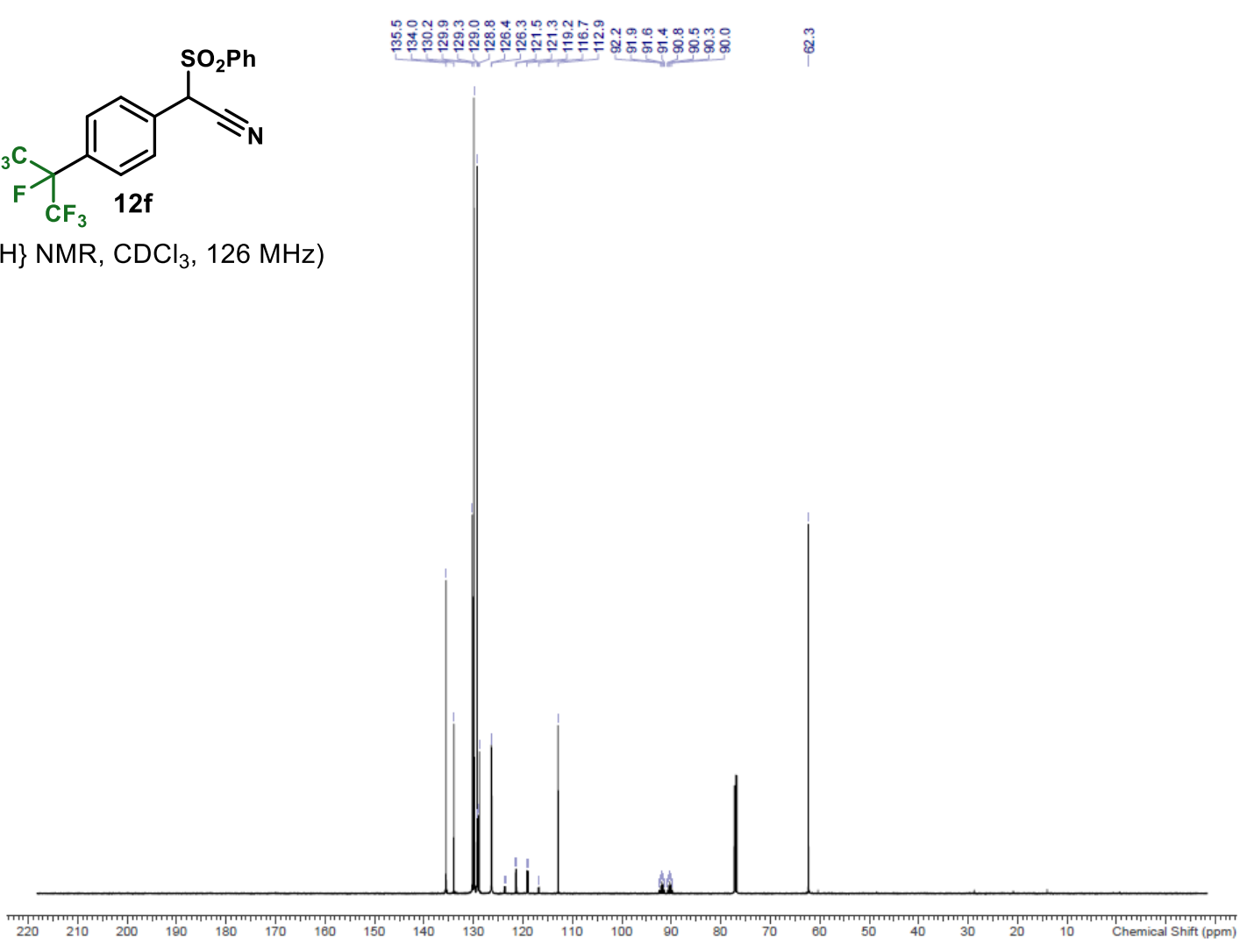


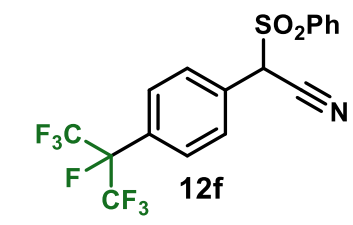

$\left({ }^{19} \mathrm{~F} \mathrm{NMR}, \mathrm{CDCl}_{3}, 376 \mathrm{MHz}\right)$





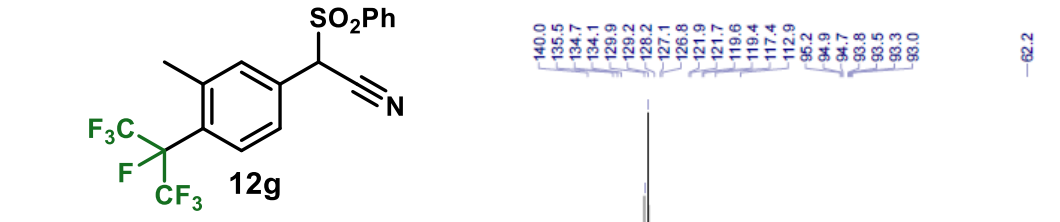

$\stackrel{\min }{\dot{4}}$

$\left({ }^{13} \mathrm{C}\left\{{ }^{1} \mathrm{H}\right\} \mathrm{NMR}, \mathrm{CDCl}_{3}, 126 \mathrm{MHz}\right)$
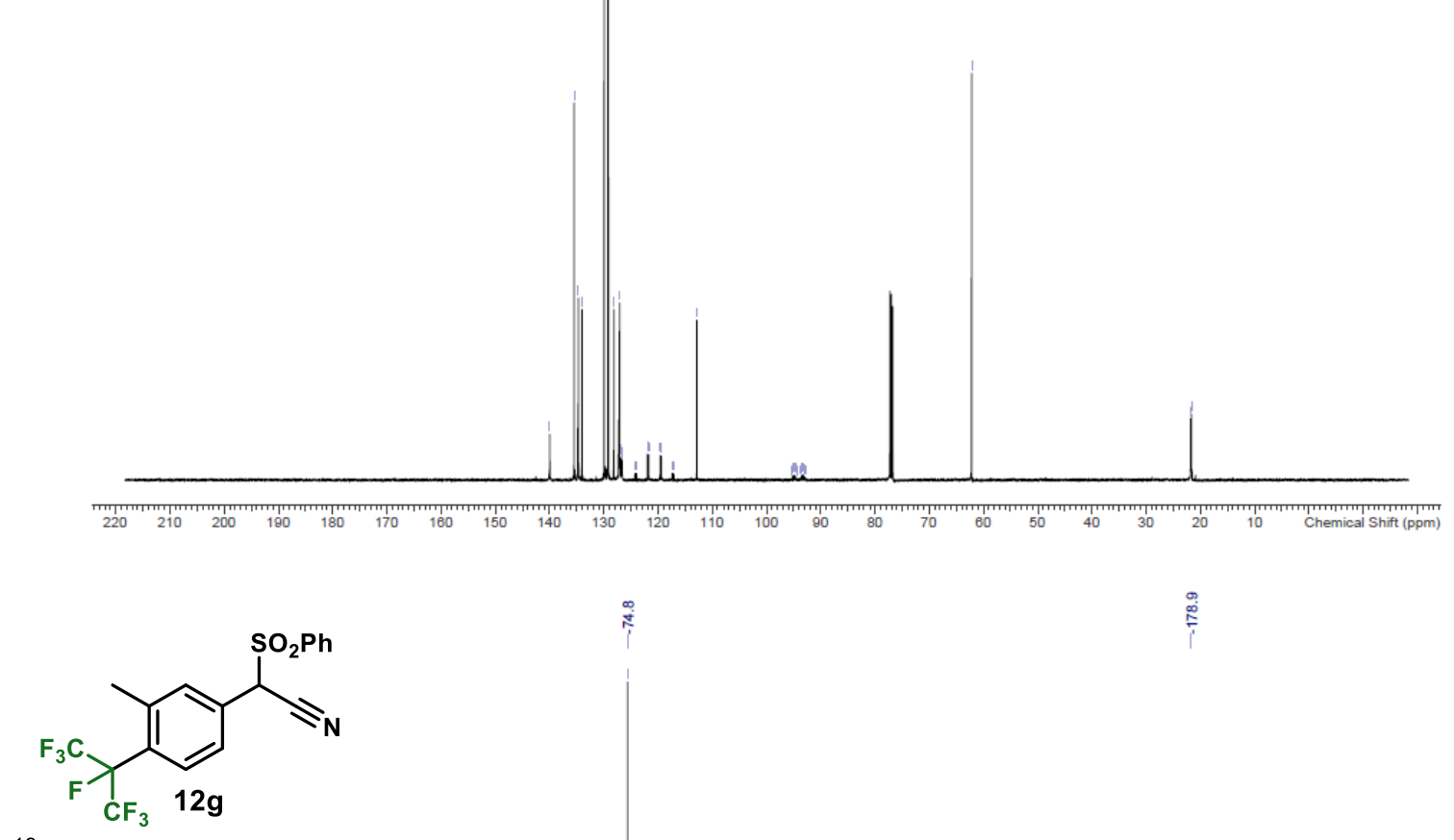

$\left({ }^{19} \mathrm{~F} \mathrm{NMR}, \mathrm{CDCl}_{3}, 376 \mathrm{MHz}\right)$

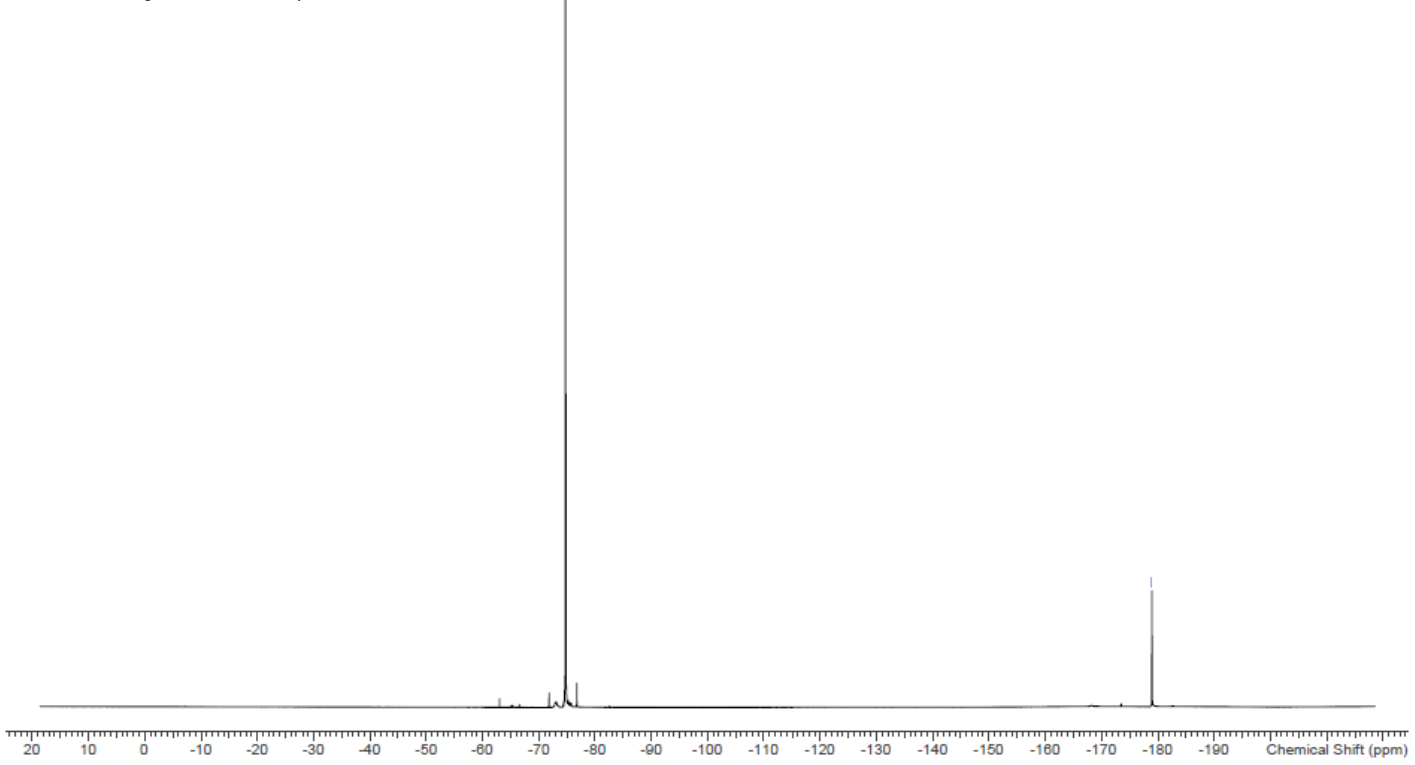



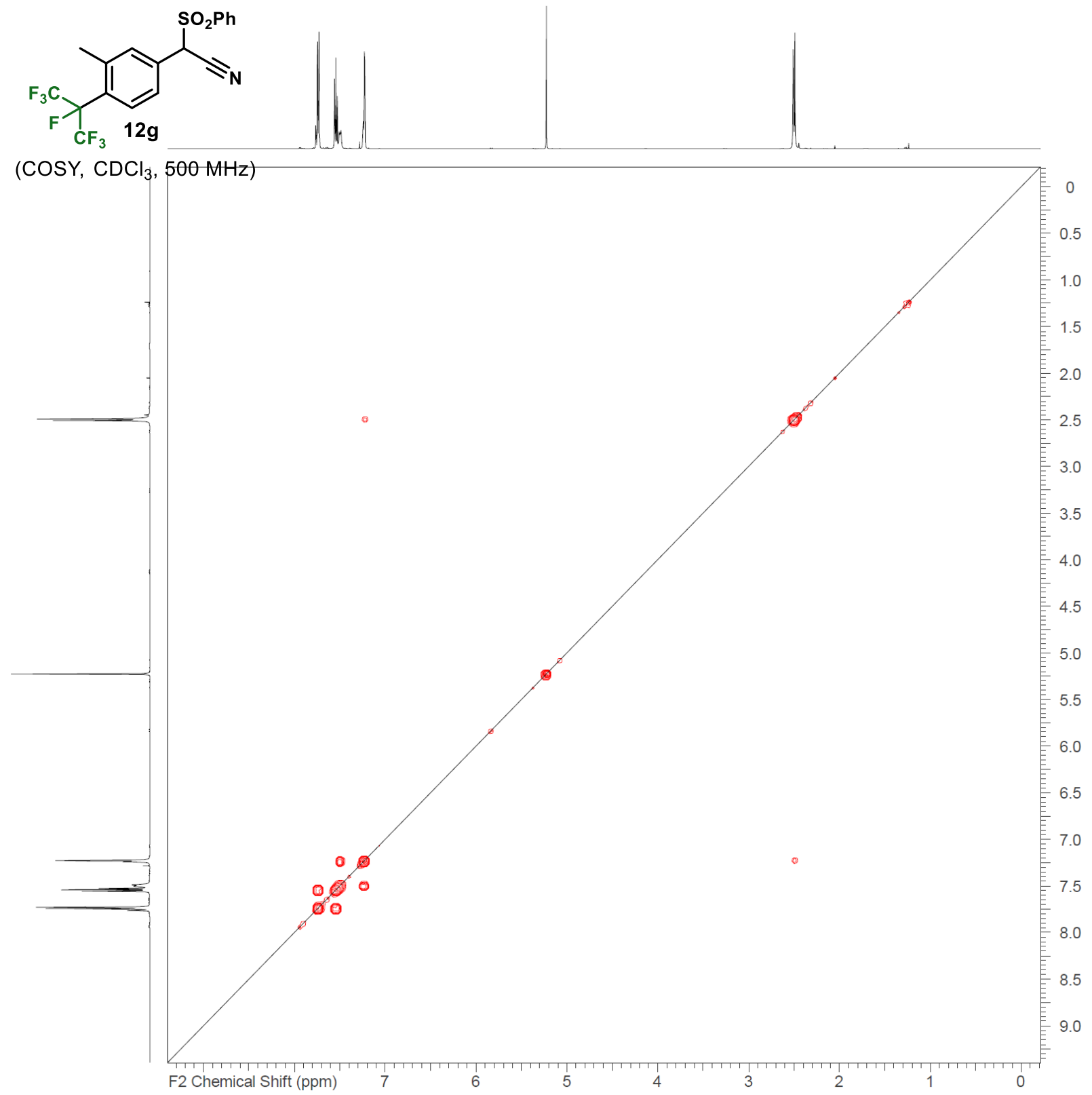

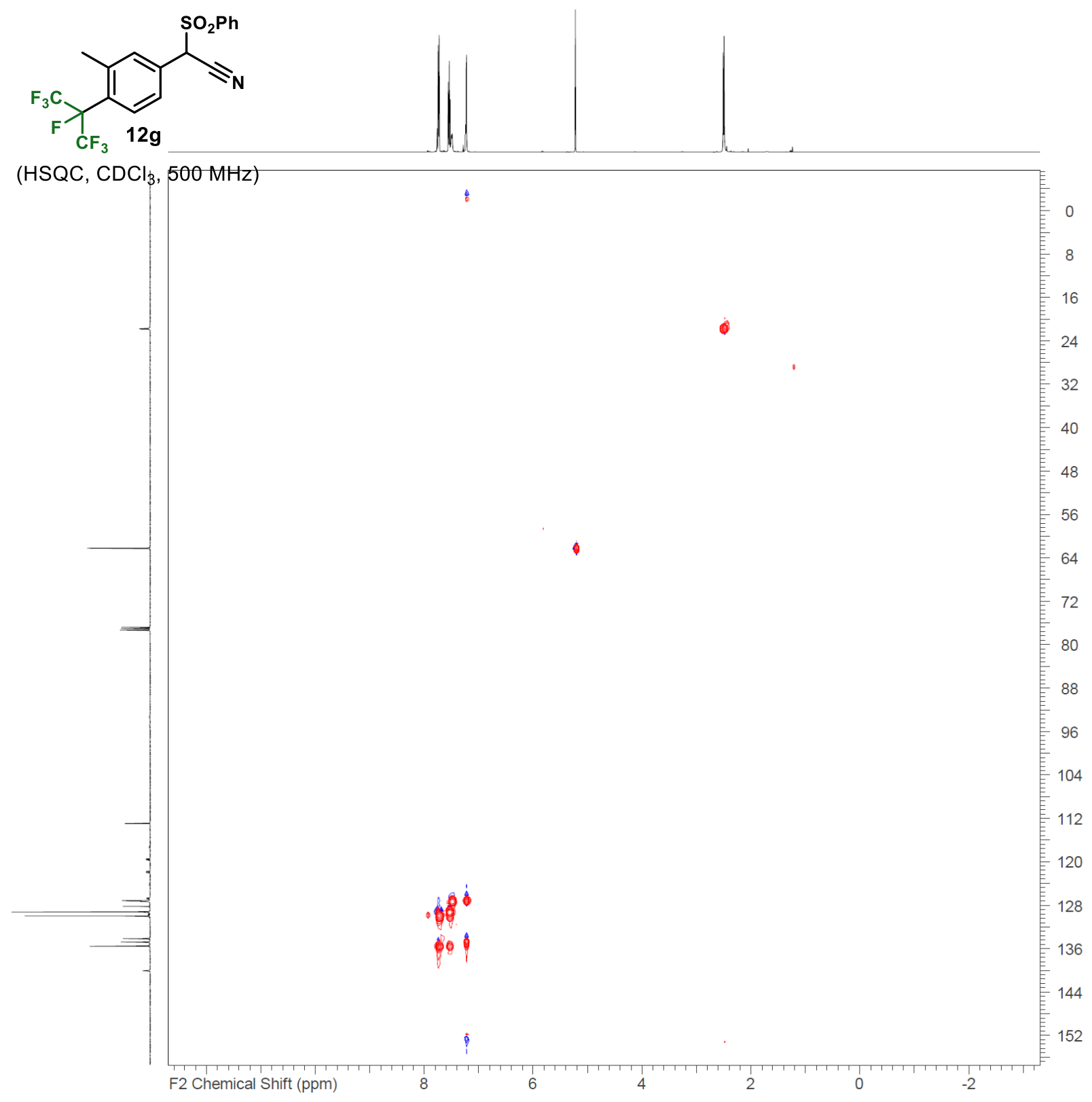


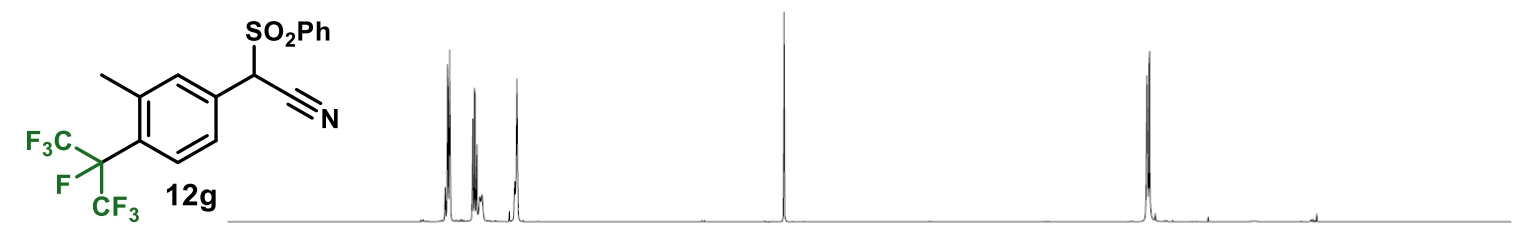

(HMBC, $\mathrm{CDCl}_{3}, 500 \mathrm{MHz}$ )

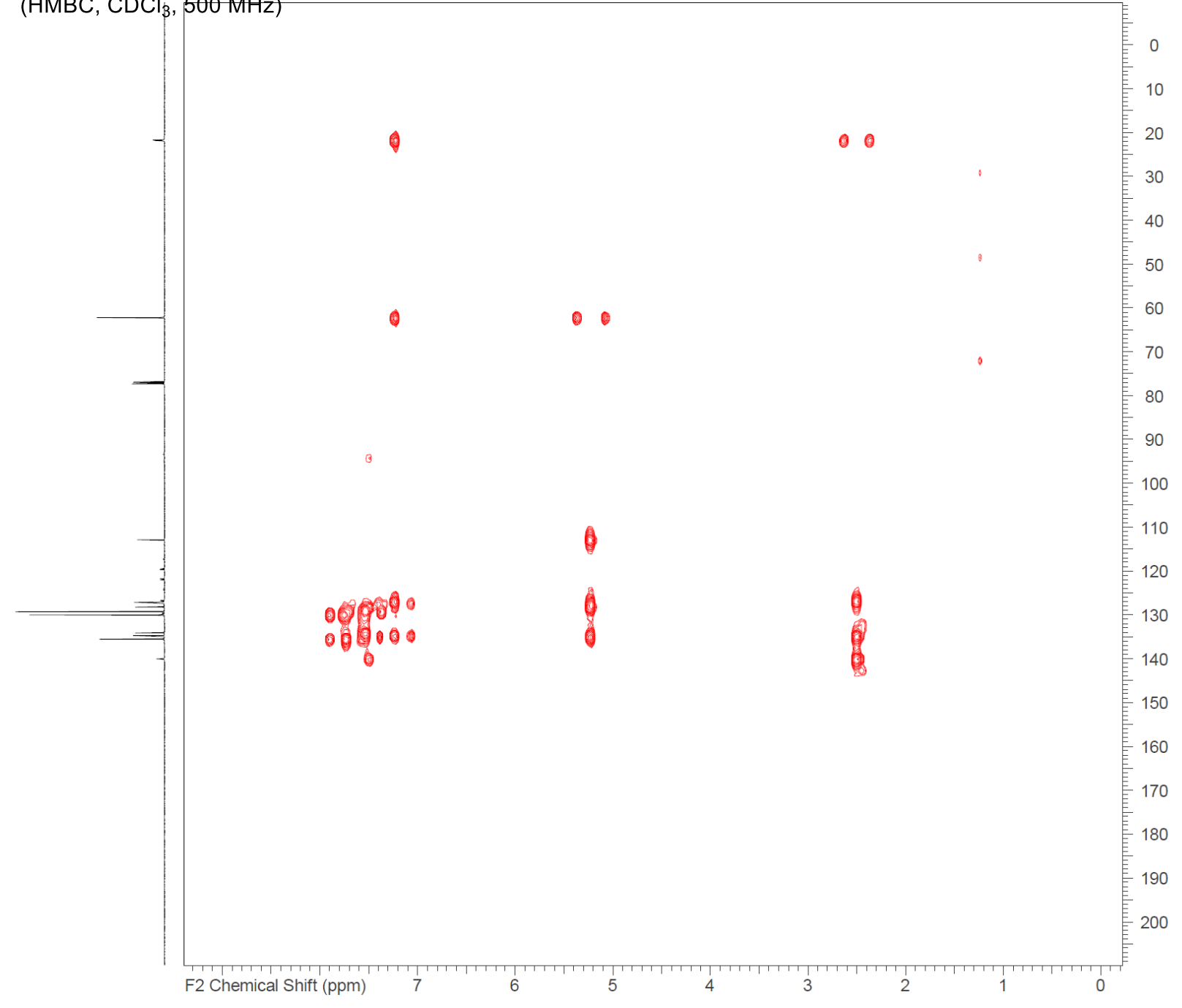




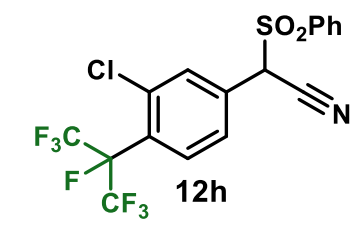

( $\left.{ }^{1} \mathrm{H} \mathrm{NMR}, \mathrm{CDCl}_{3}, 500 \mathrm{MHz}\right)$

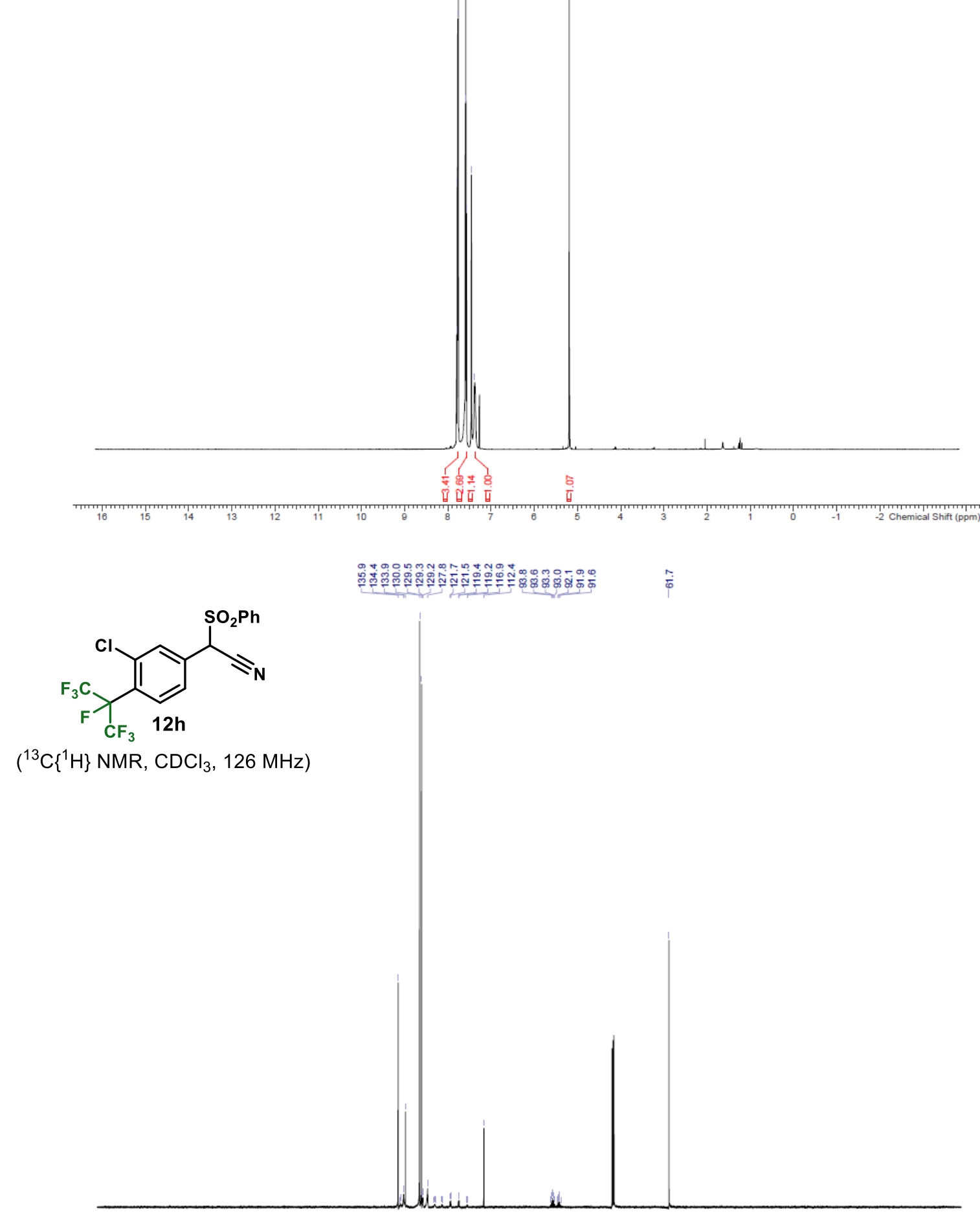

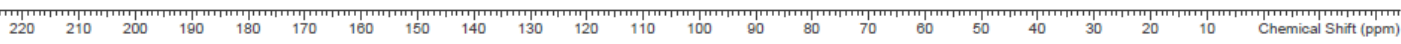




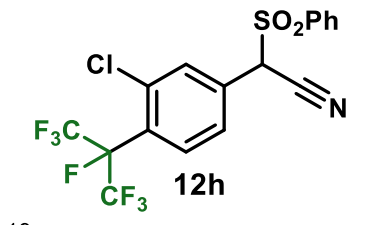

$\left({ }^{19} \mathrm{~F} \mathrm{NMR}, \mathrm{CDCl}_{3}, 376 \mathrm{MHz}\right)$






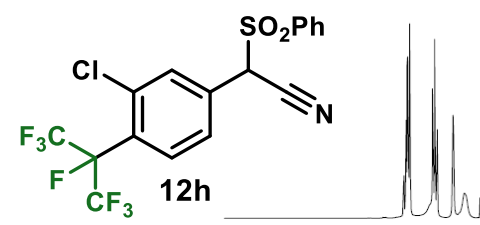

(COSY, $\mathrm{CDCl}_{3}, 500 \mathrm{MHz}$ )

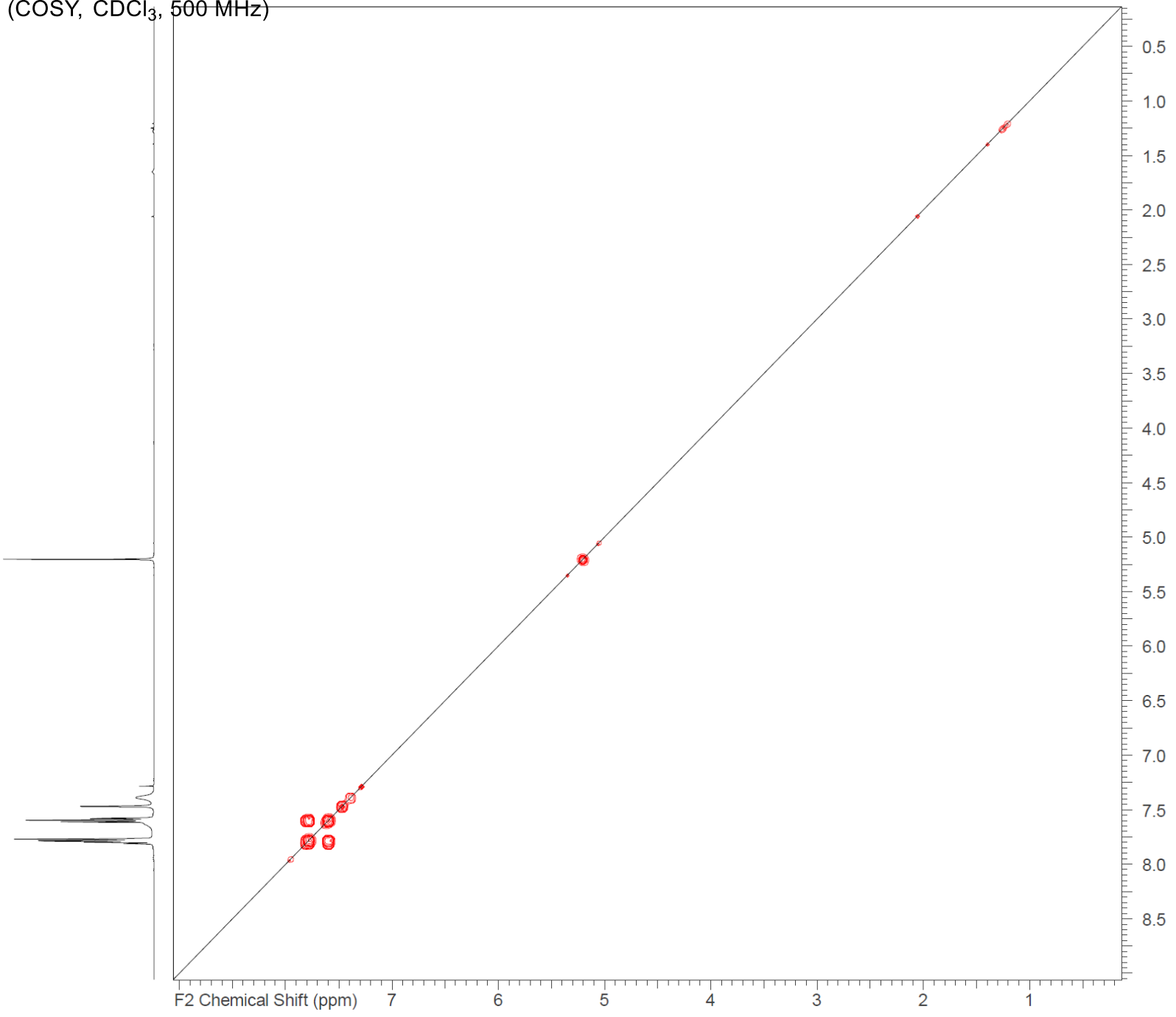



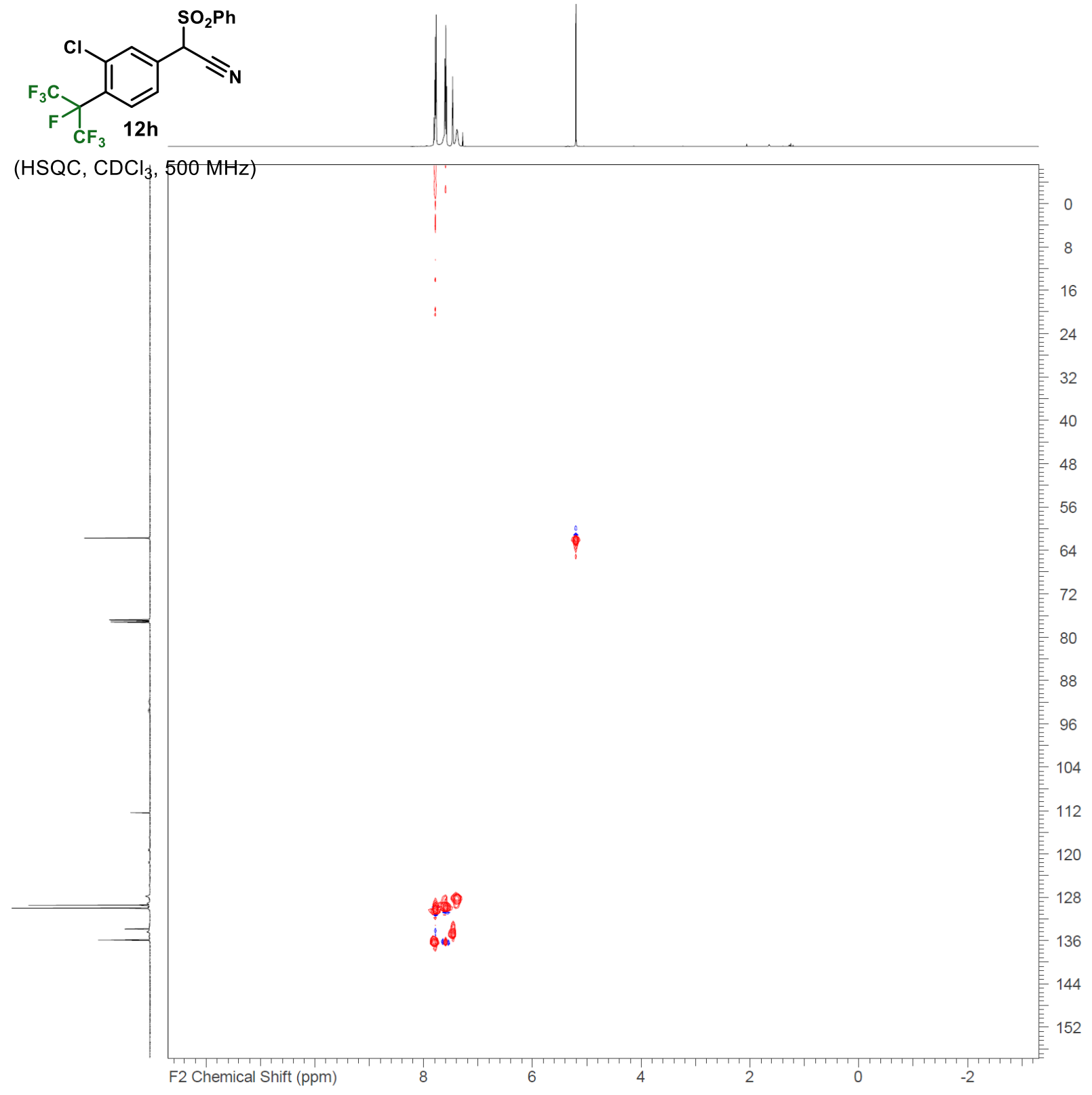


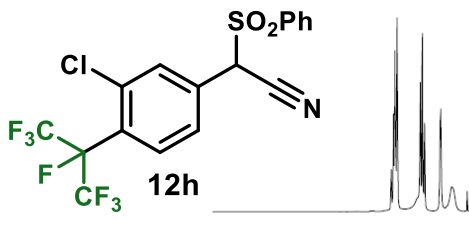

(HMBC, $\left.\mathrm{CDCl}_{\xi}, 500 \mathrm{MHz}\right)$





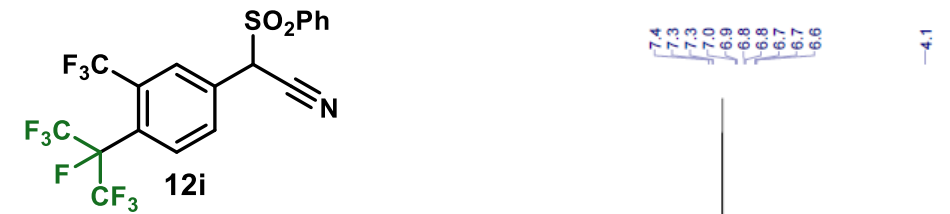

$\left({ }^{1} \mathrm{H} \mathrm{NMR}, \mathrm{C}_{6} \mathrm{D}_{6}, 500 \mathrm{MHz}\right)$

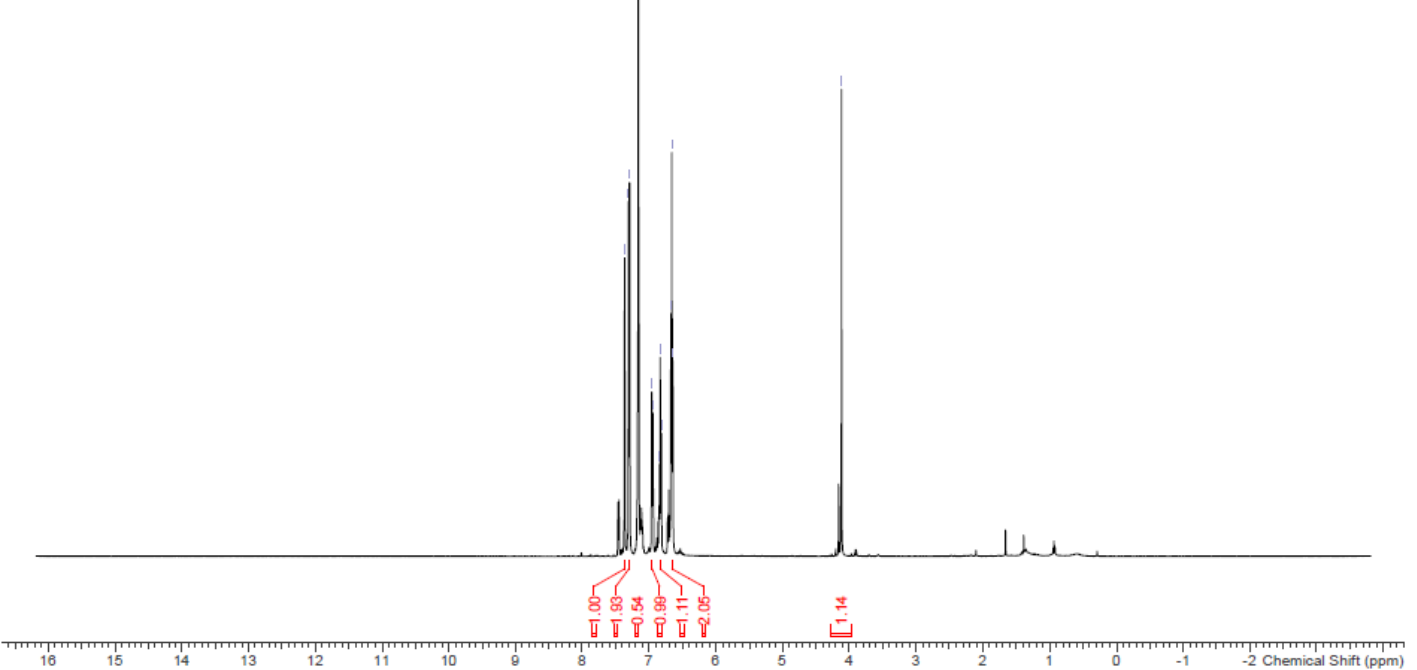



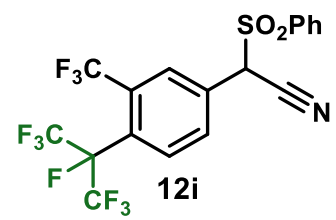

$\left({ }^{13} \mathrm{C}\left\{{ }^{1} \mathrm{H}\right\}\right.$ NMR, $\left.\mathrm{C}_{6} \mathrm{D}_{6}, 126 \mathrm{MHz}\right)$

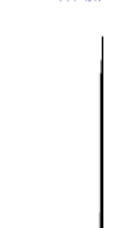

(



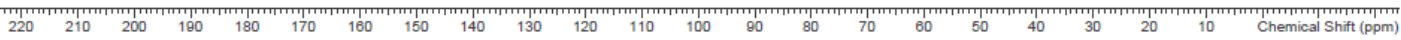




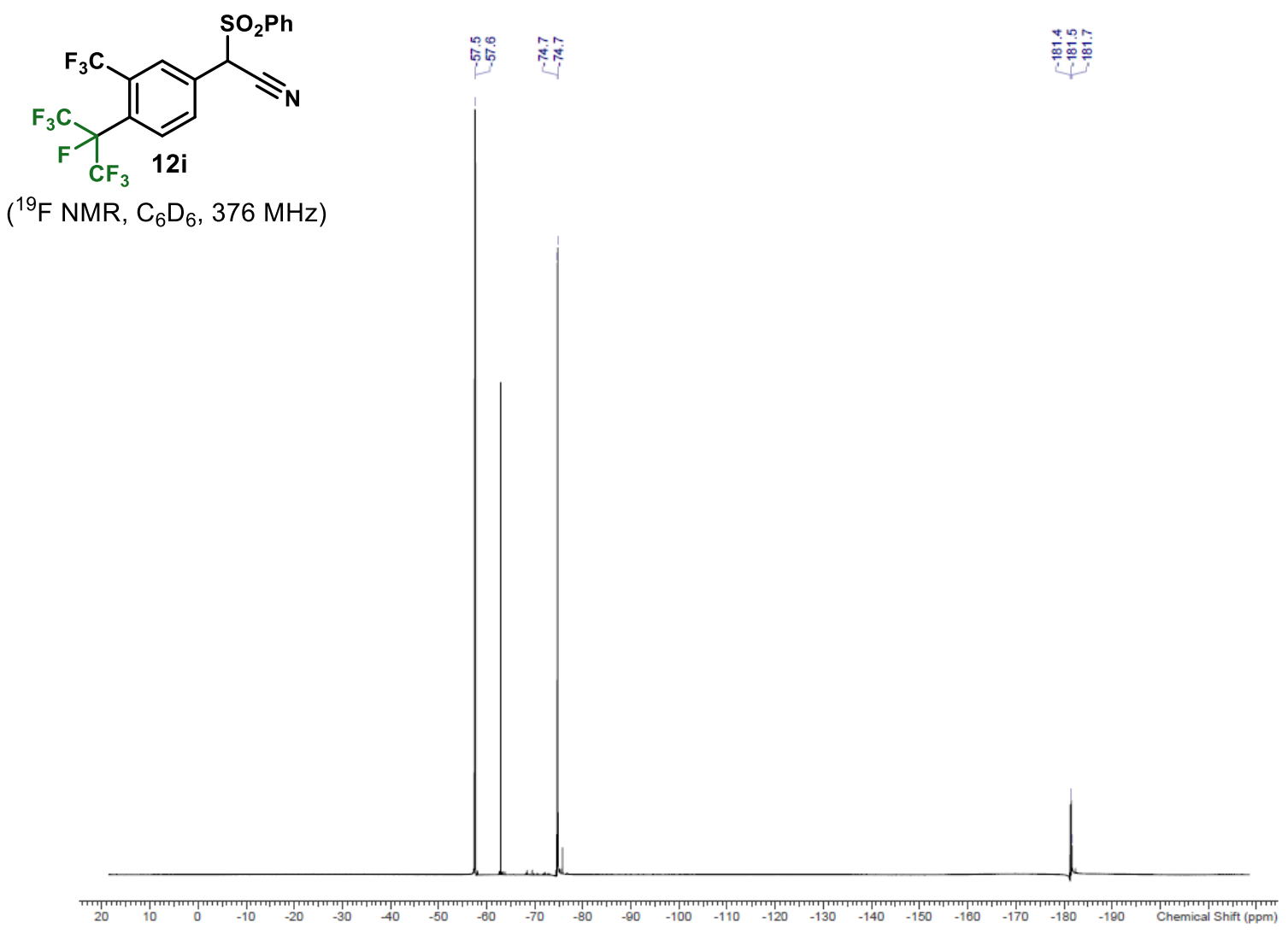




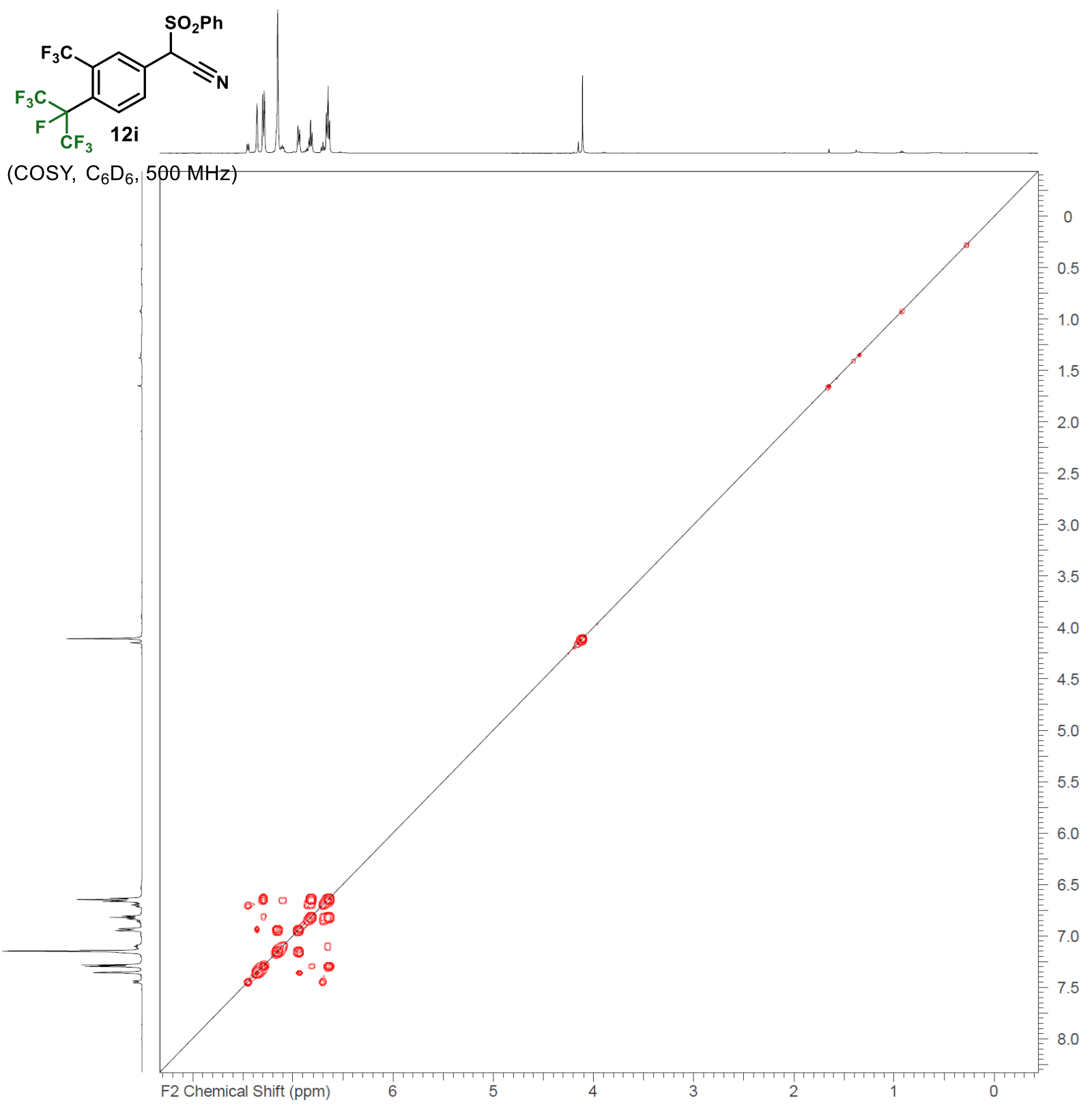




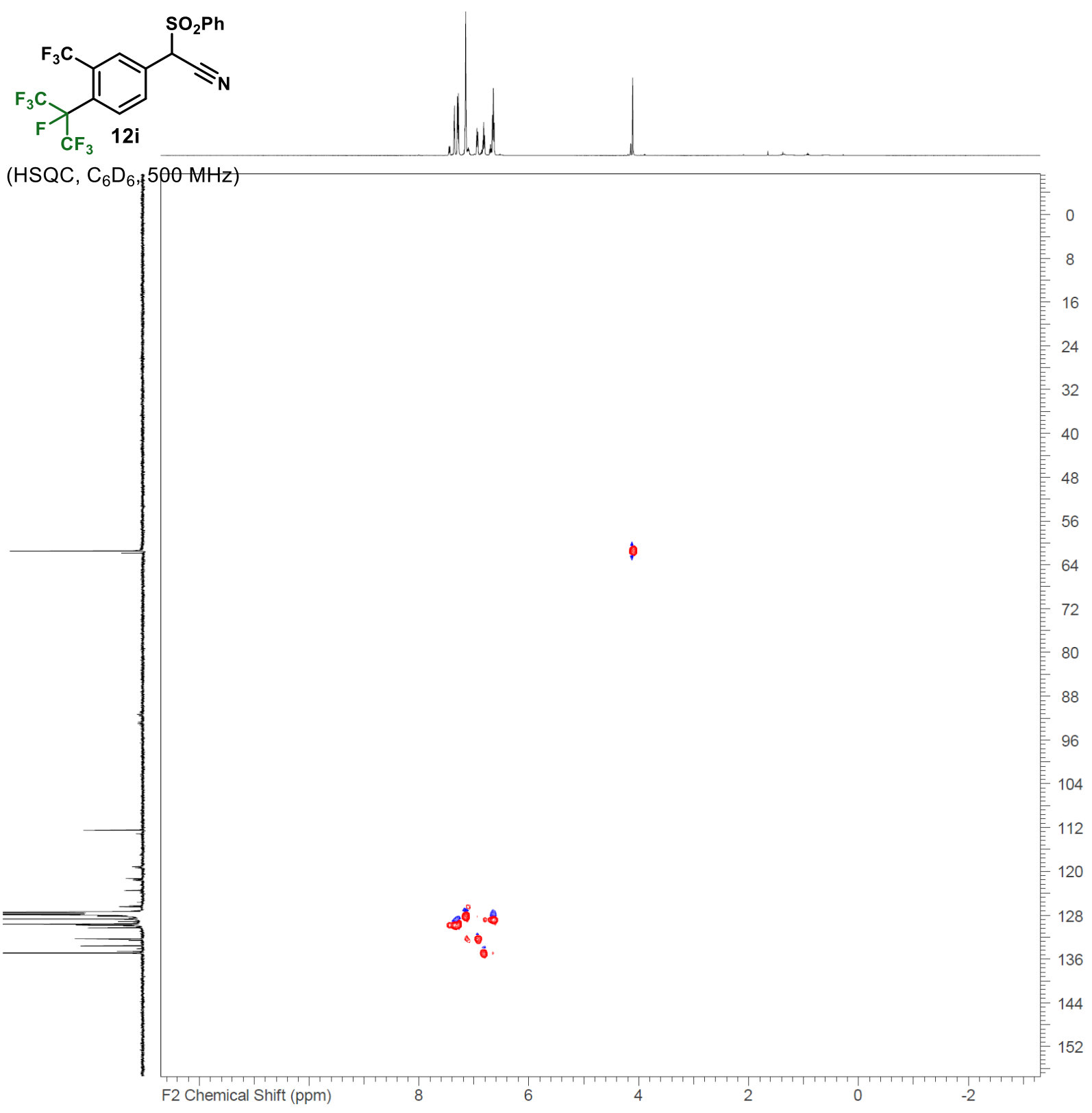




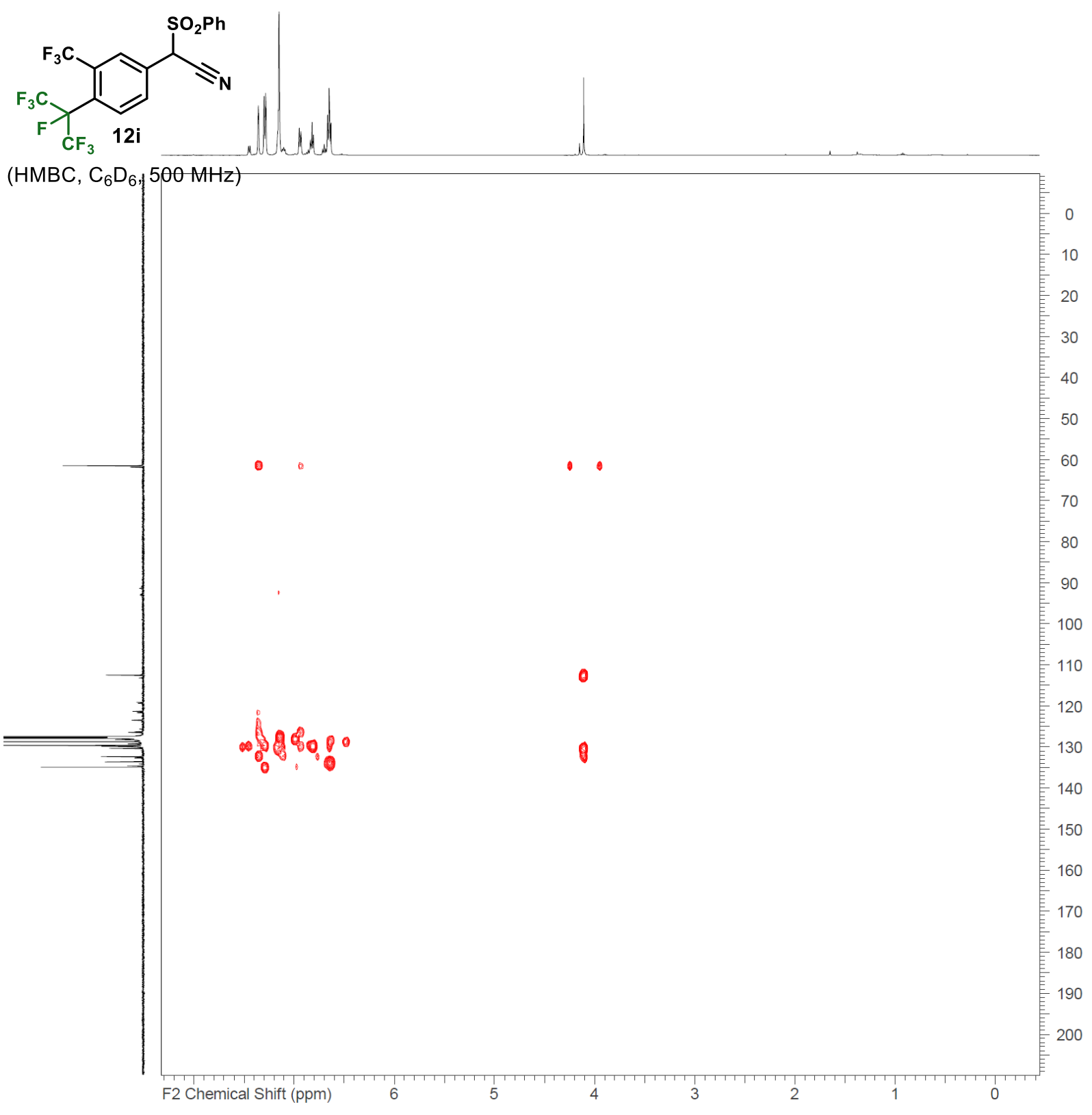



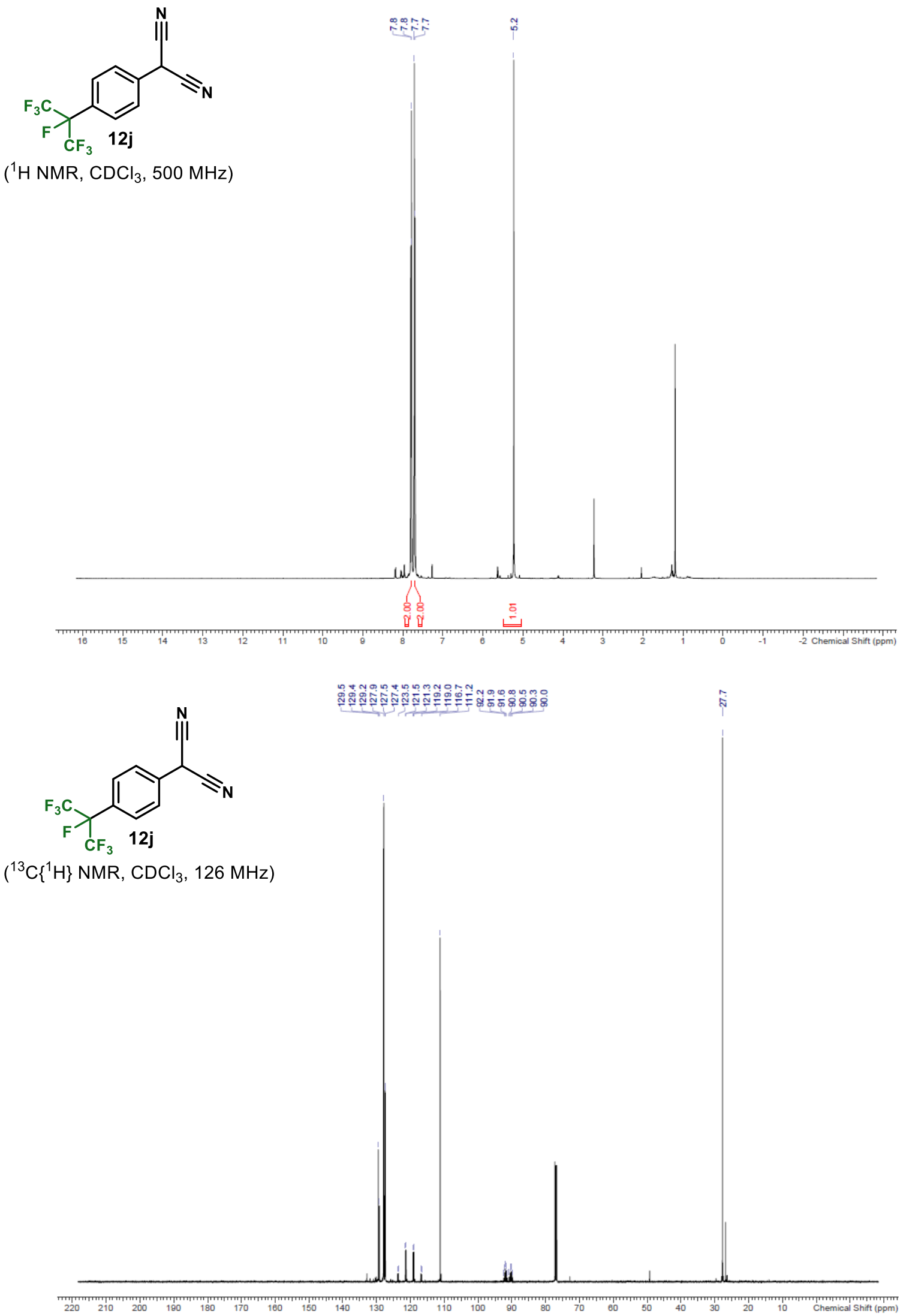


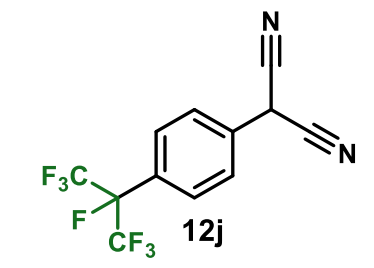

$\left({ }^{19} \mathrm{~F} \mathrm{NMR}, \mathrm{CDCl}_{3}, 376 \mathrm{MHz}\right)$

\section{(19F NMR, $\left.\mathrm{CDCl}_{3}, 376 \mathrm{MHz}\right)$}
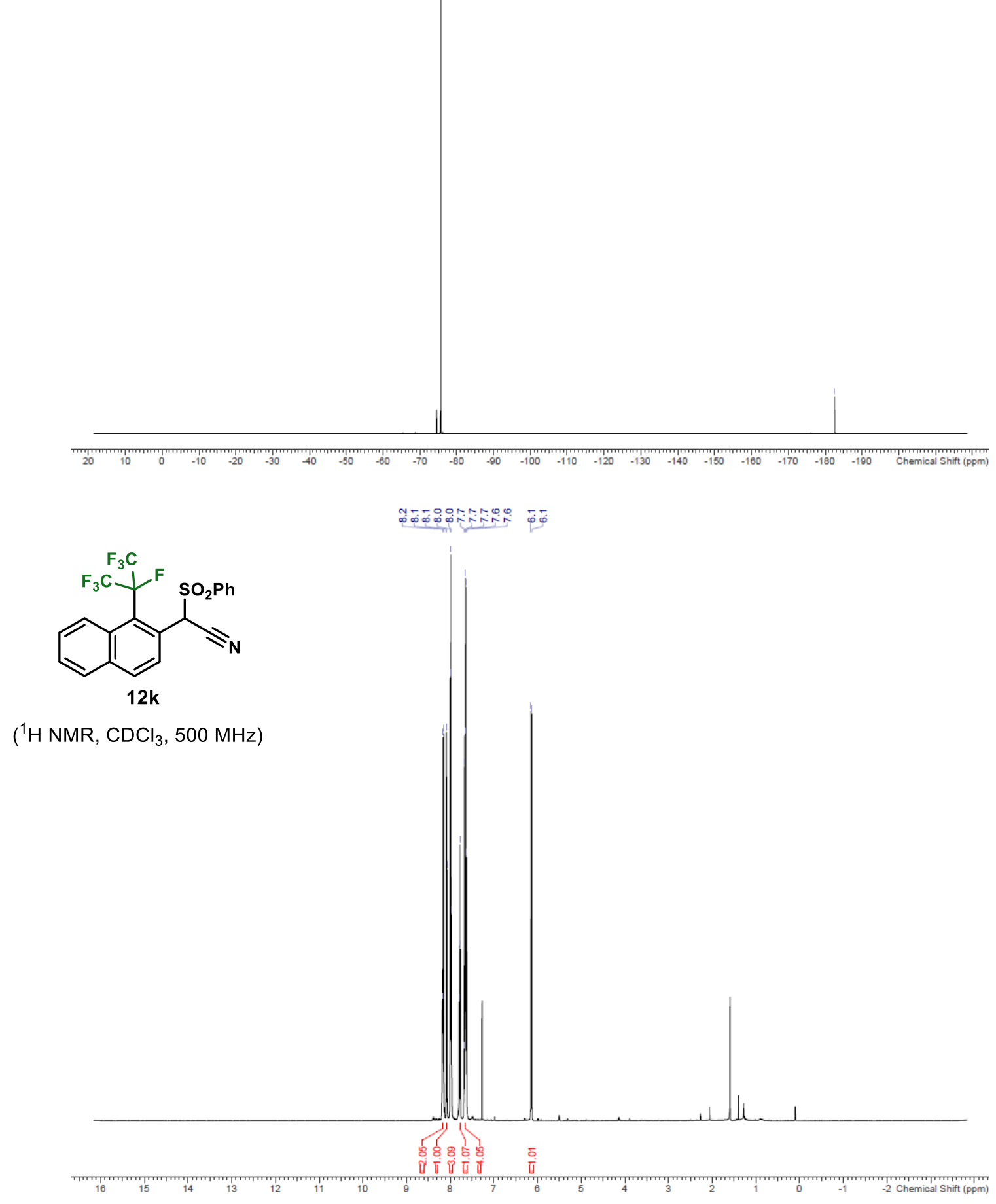

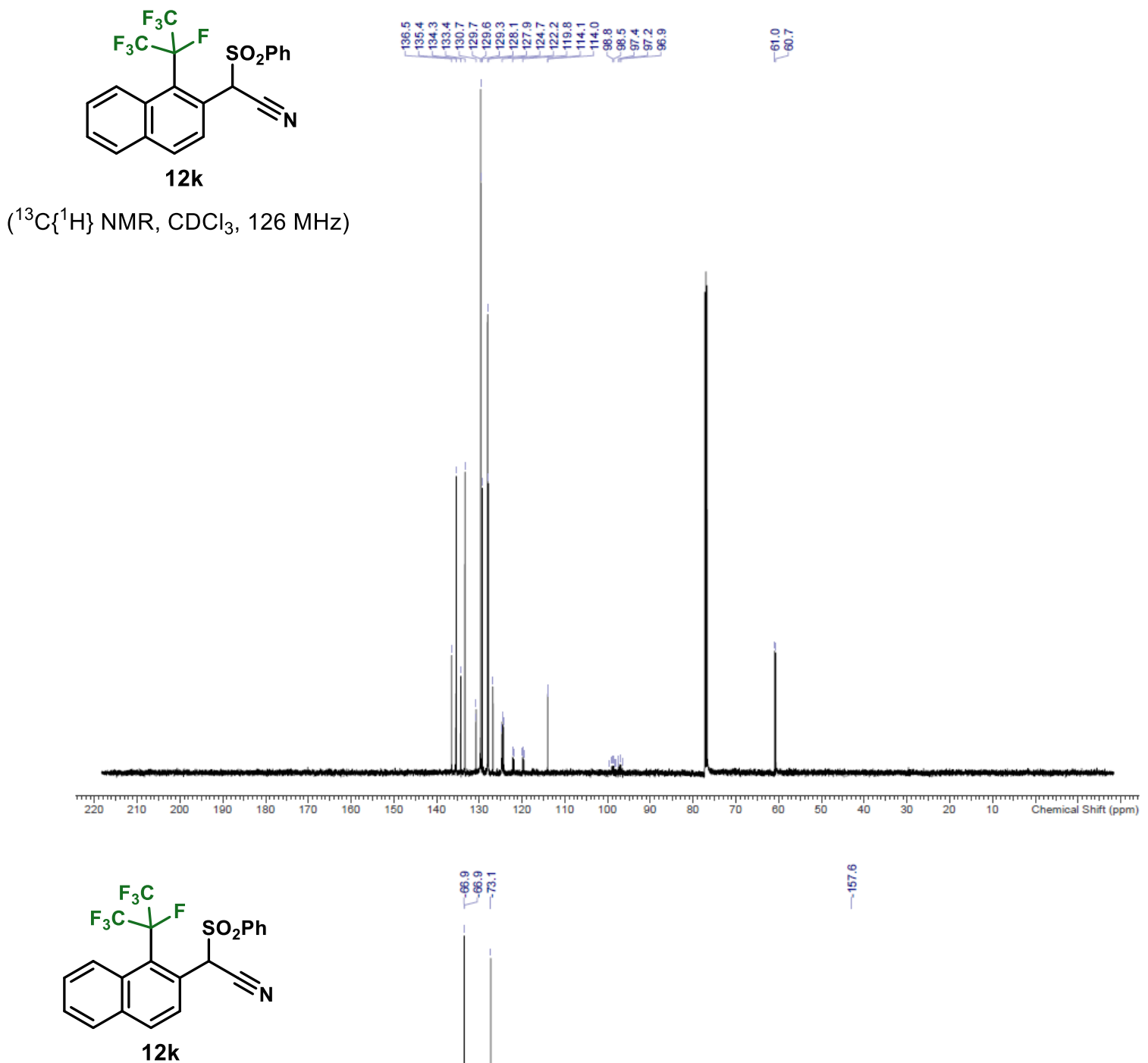

$\left({ }^{19} \mathrm{~F} \mathrm{NMR}, \mathrm{CDCl}_{3}, 376 \mathrm{MHz}\right)$

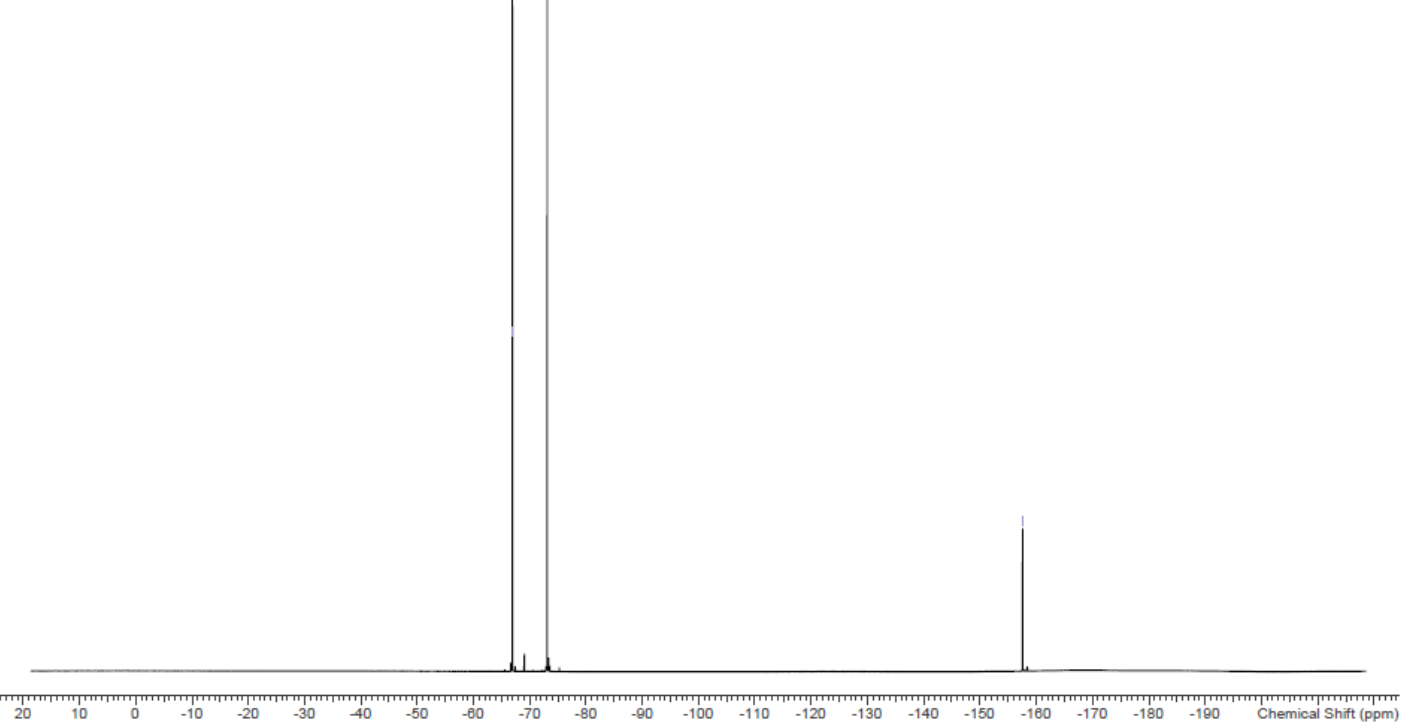



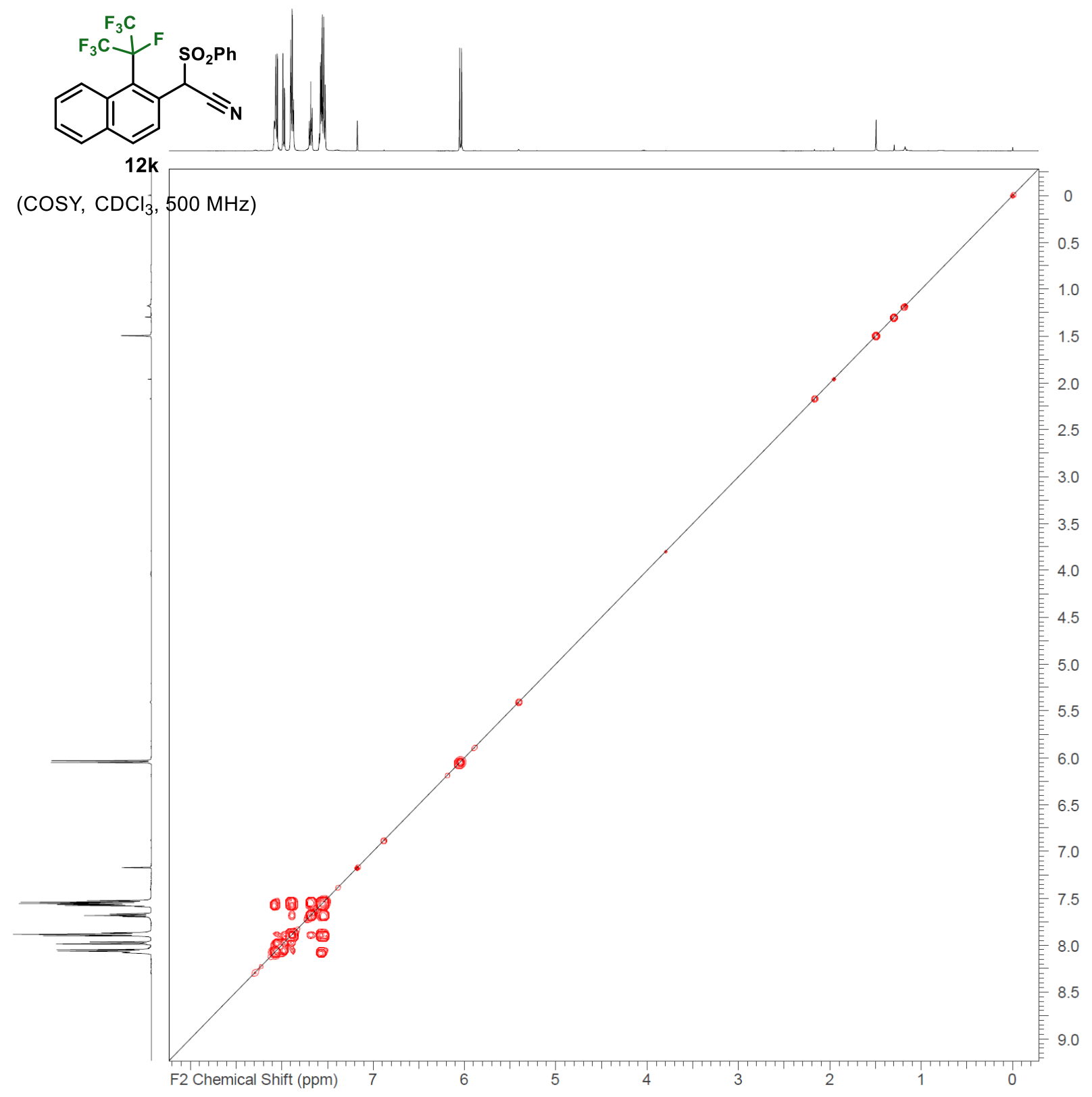

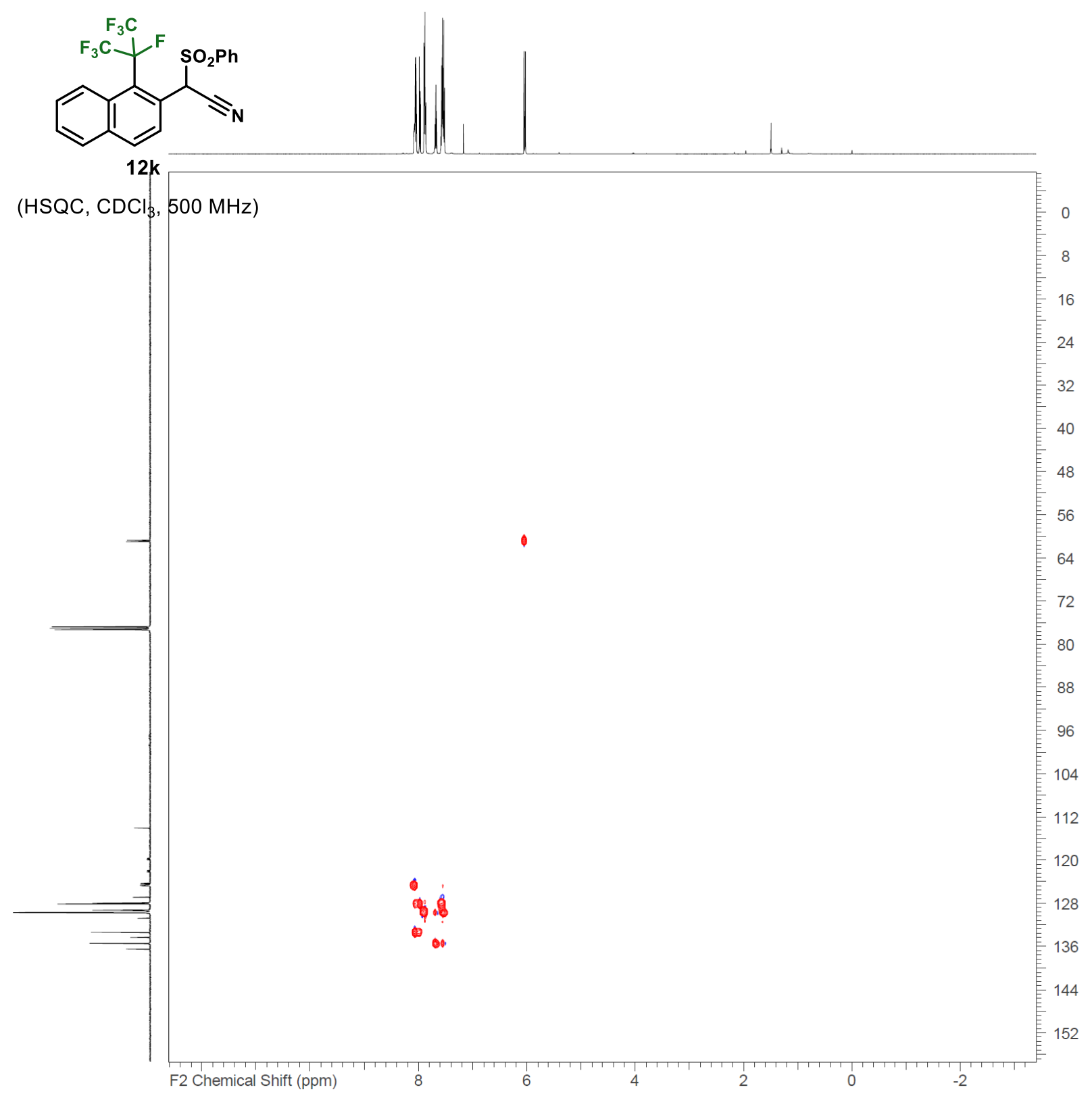


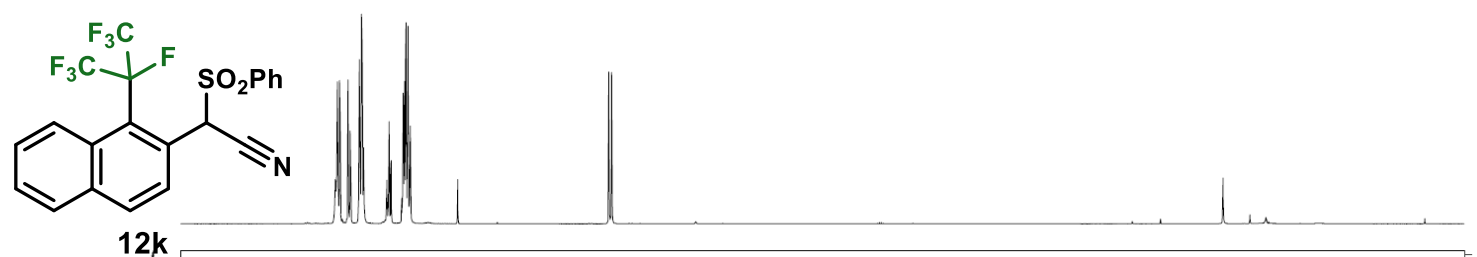

(HMBC, CDCl $3,500 \mathrm{MHz}$ )

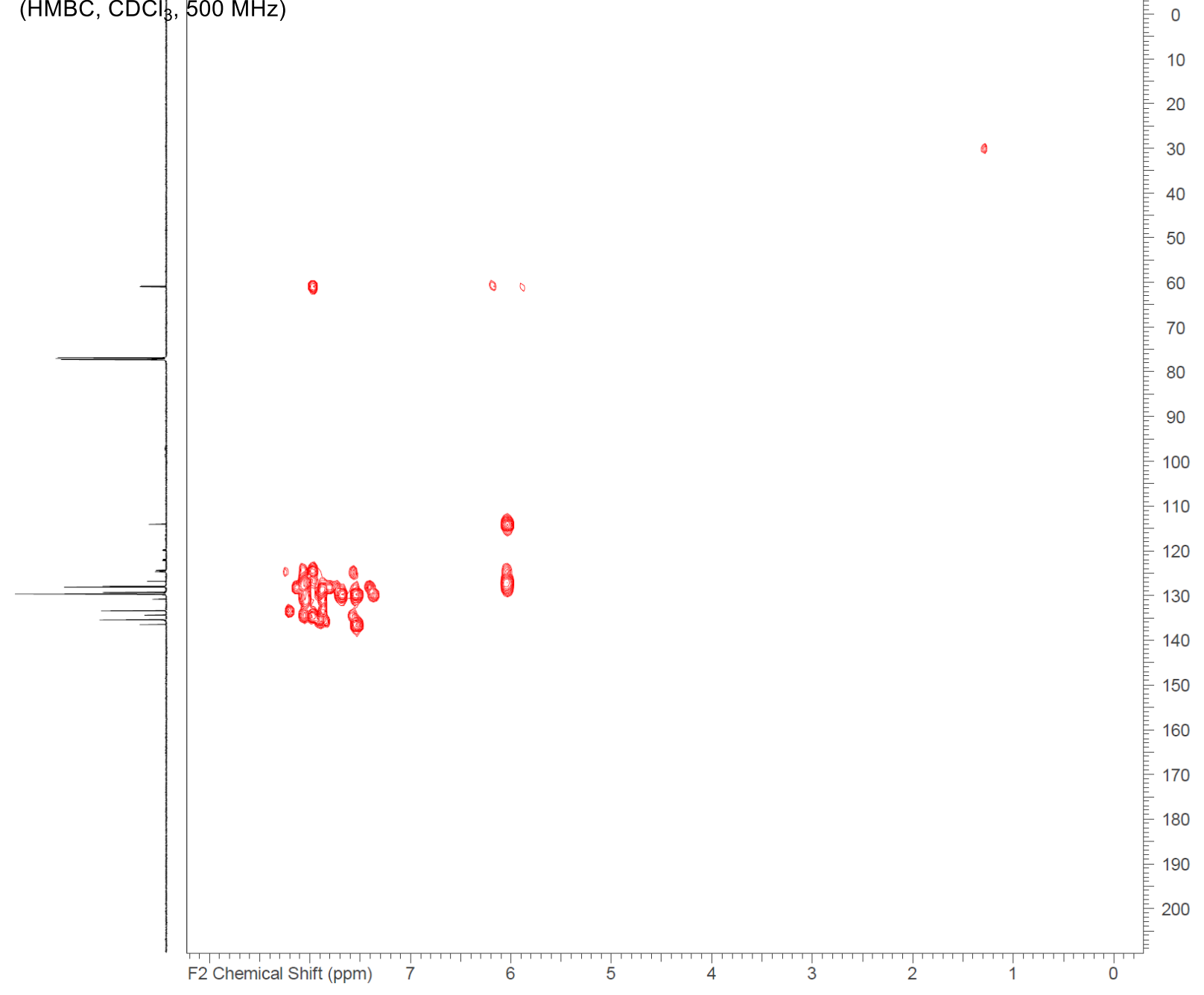



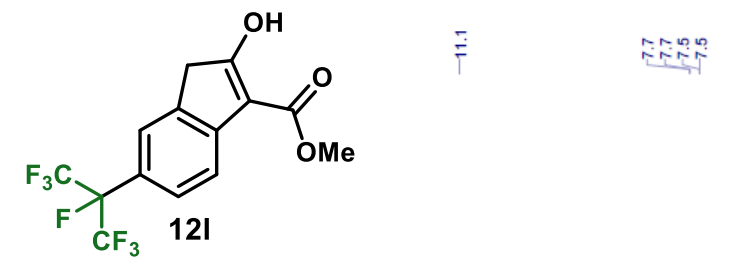

( ${ }^{1} \mathrm{H} \mathrm{NMR}, \mathrm{CDCl}_{3}, 500 \mathrm{MHz}$ )
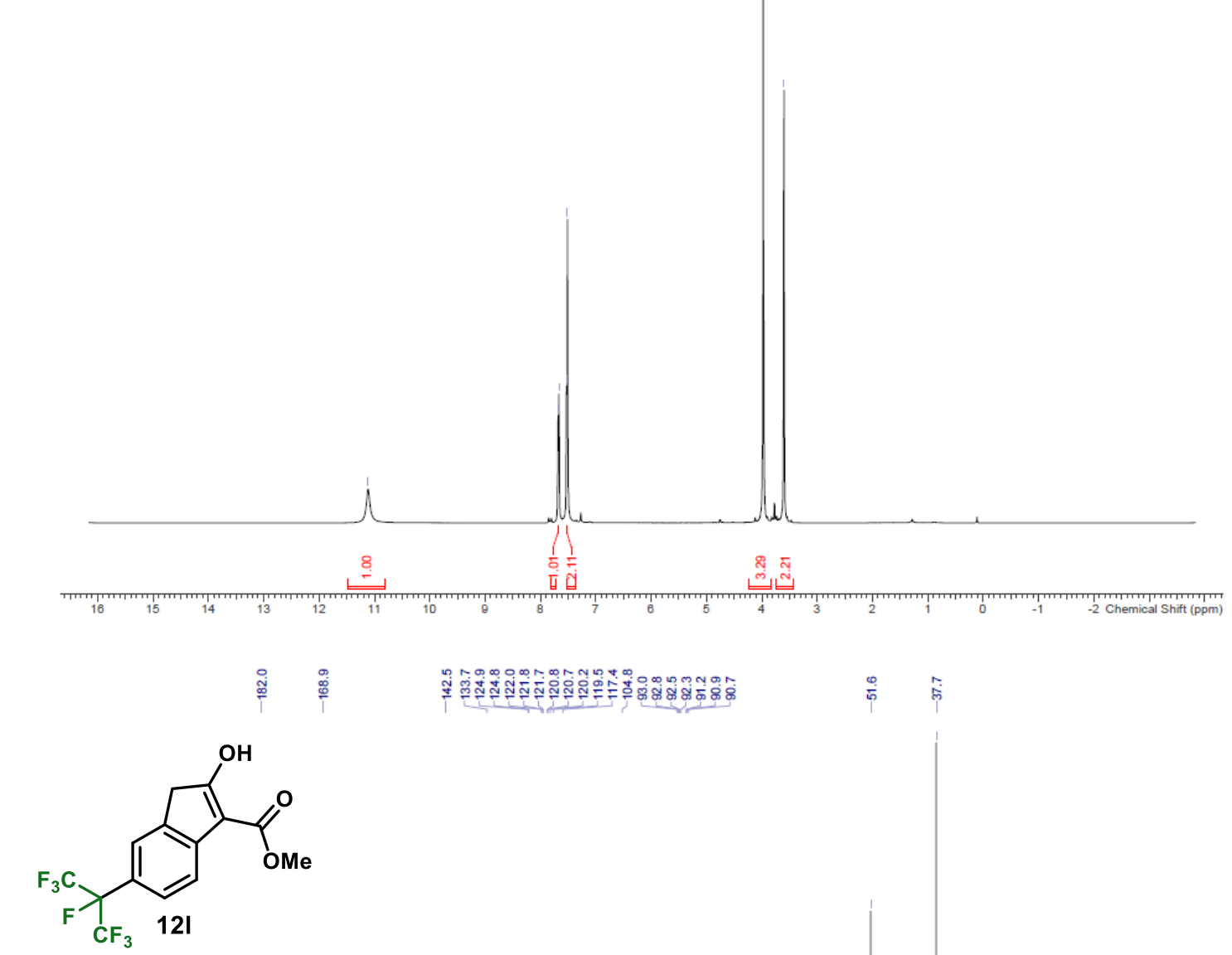

$\left({ }^{13} \mathrm{C}\left\{{ }^{1} \mathrm{H}\right\} \mathrm{NMR}, \mathrm{CDCl}_{3}, 126 \mathrm{MHz}\right)$

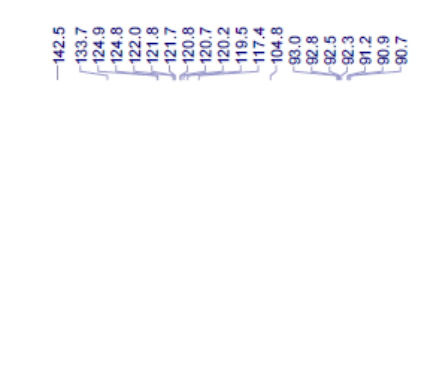




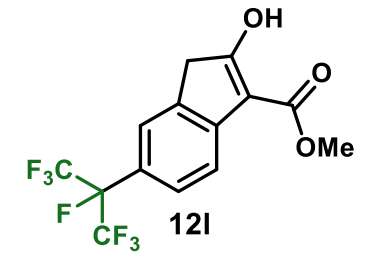

$\left({ }^{19} \mathrm{~F} \mathrm{NMR} \mathrm{CDCl}_{3}, 376 \mathrm{MHz}\right)$

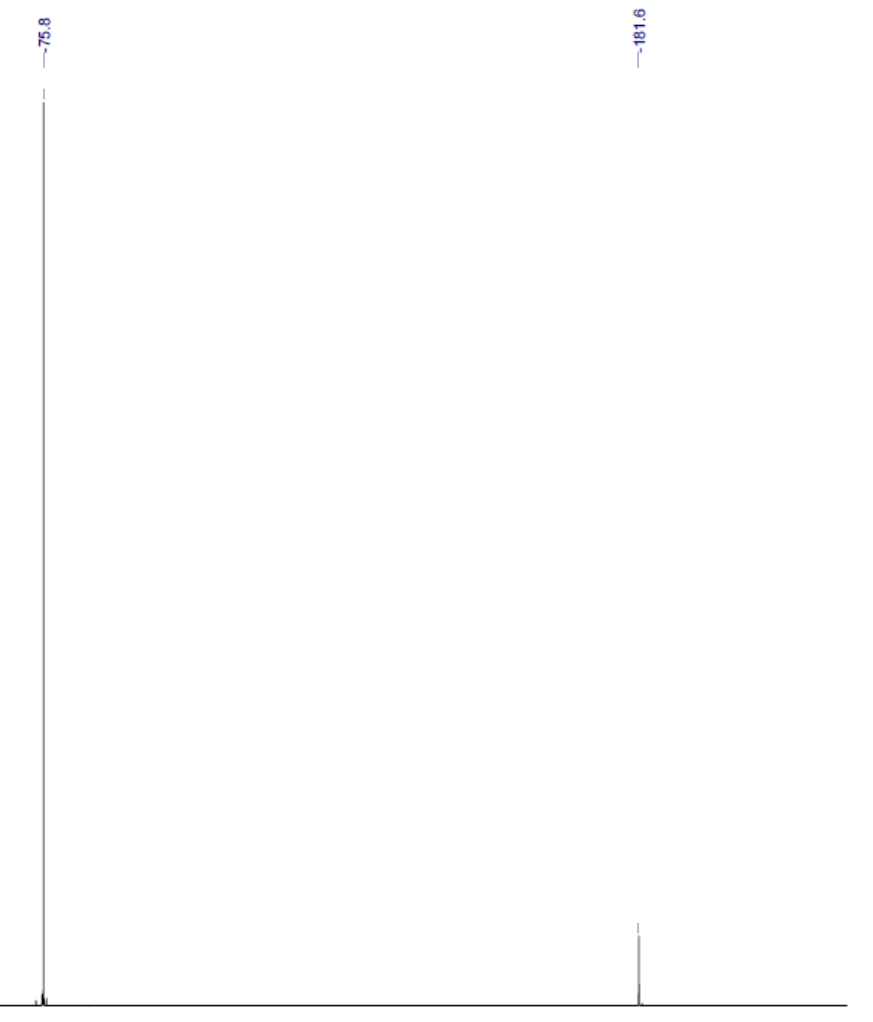

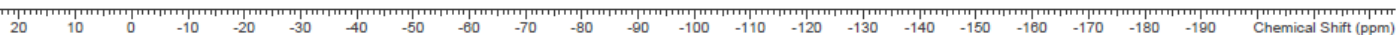









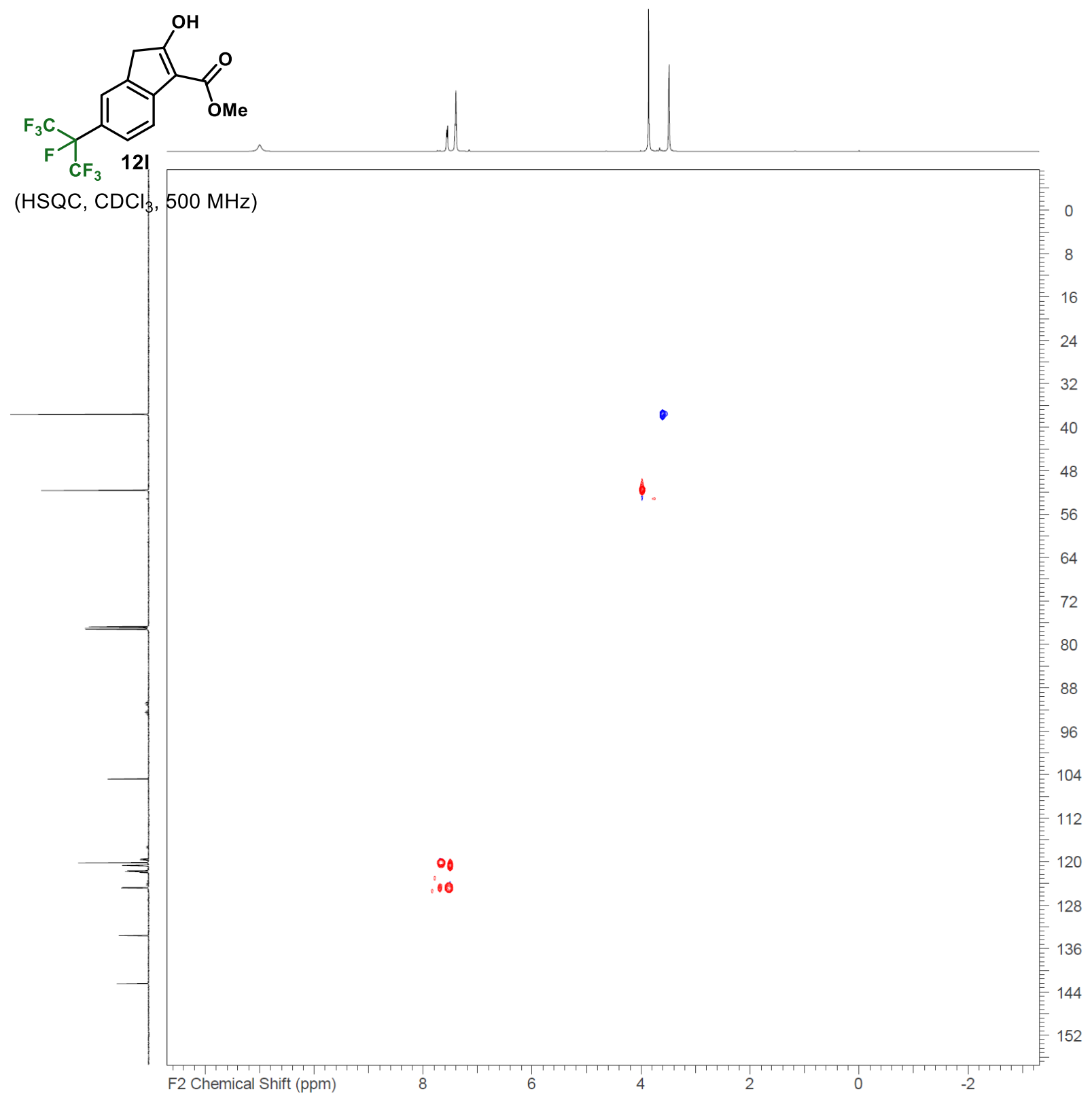




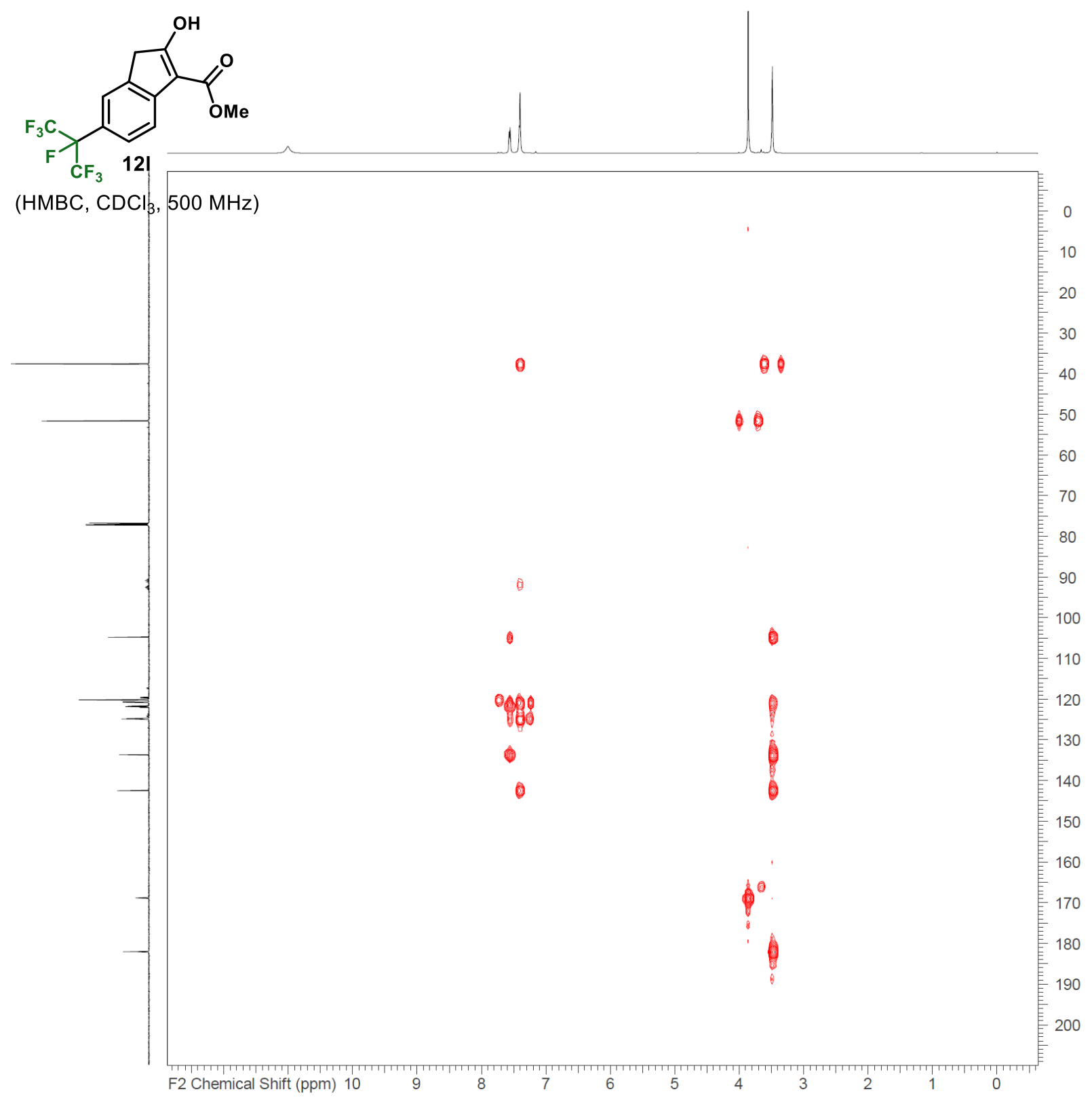






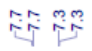

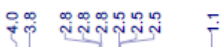

( $\left.{ }^{1} \mathrm{H} \mathrm{NMR}, \mathrm{CDCl}_{3}, 500 \mathrm{MHz}\right)$
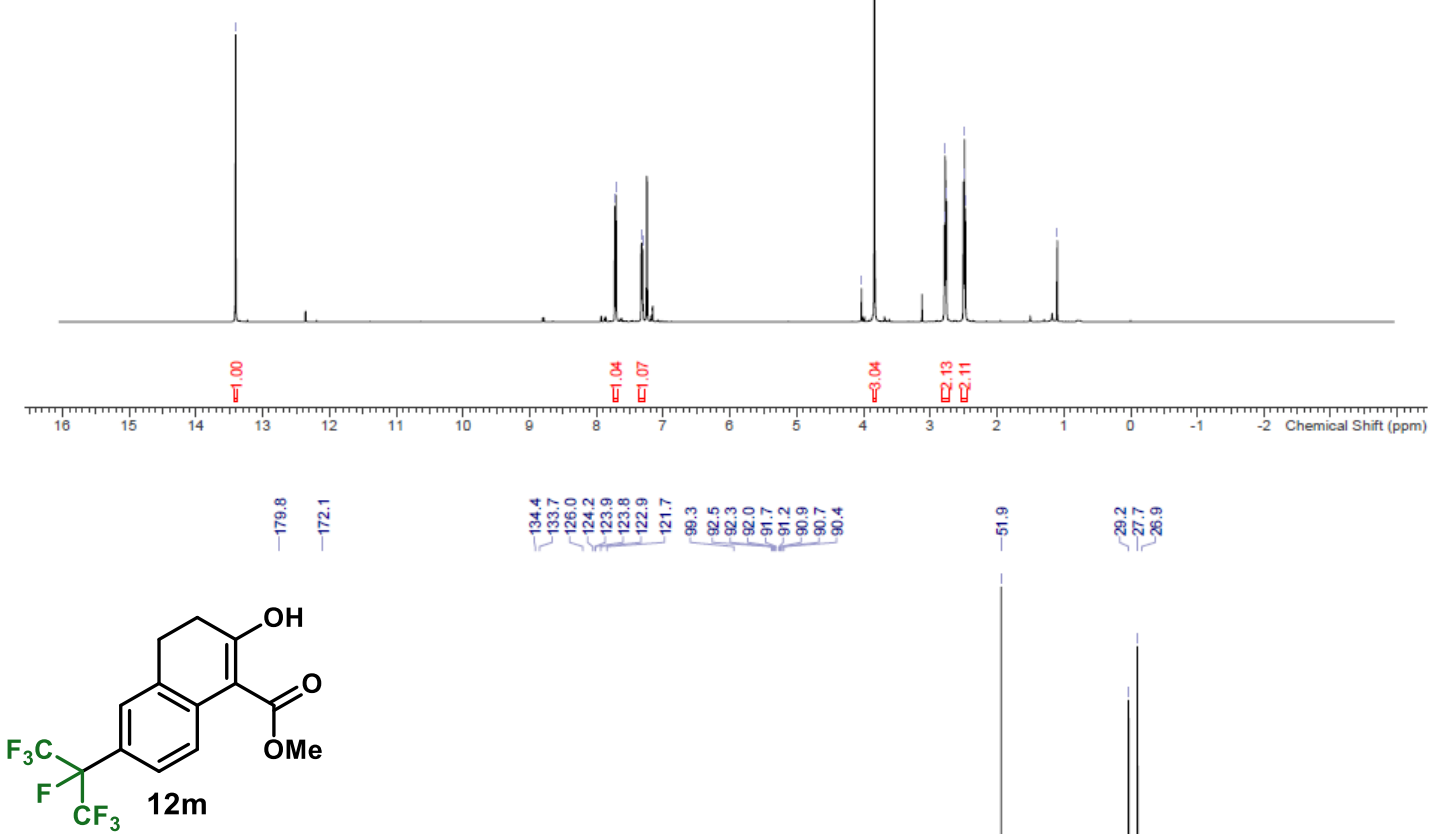

$\left({ }^{13} \mathrm{C}\left\{{ }^{1} \mathrm{H}\right\}\right.$ NMR, $\left.\mathrm{CDCl}_{3}, 126 \mathrm{MHz}\right)$

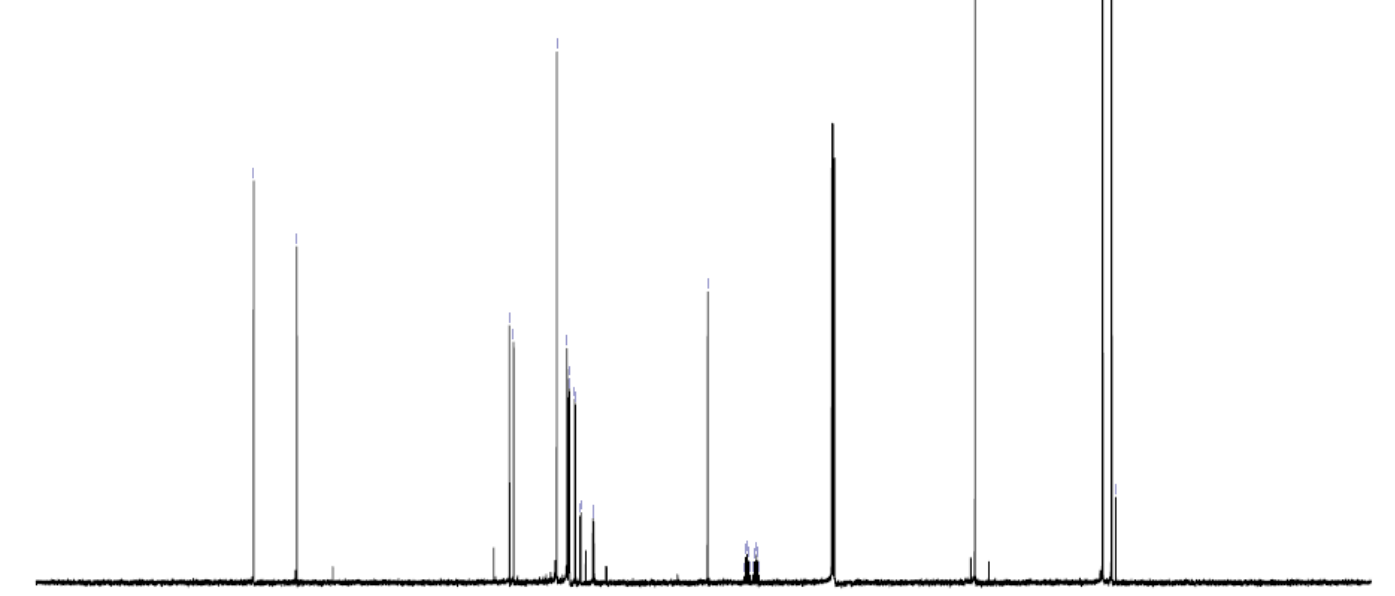

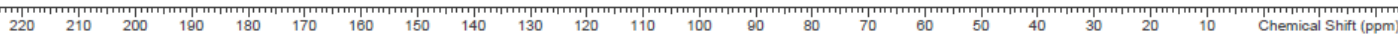




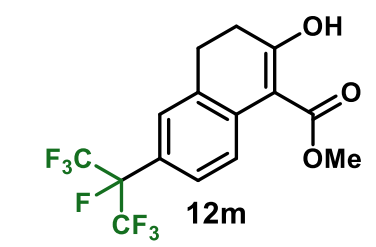

$\left({ }^{19} \mathrm{~F} \mathrm{NMR}, \mathrm{CDCl}_{3}, 376 \mathrm{MHz}\right)$
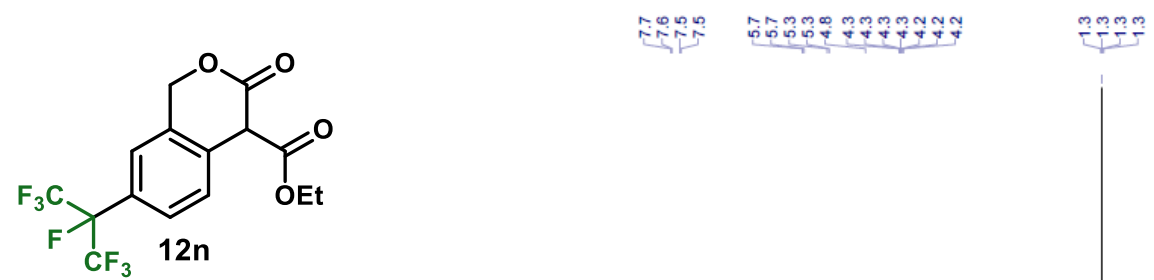

$\left({ }^{1} \mathrm{H} \mathrm{NMR}, \mathrm{CDCl}_{3}, 500 \mathrm{MHz}\right)$

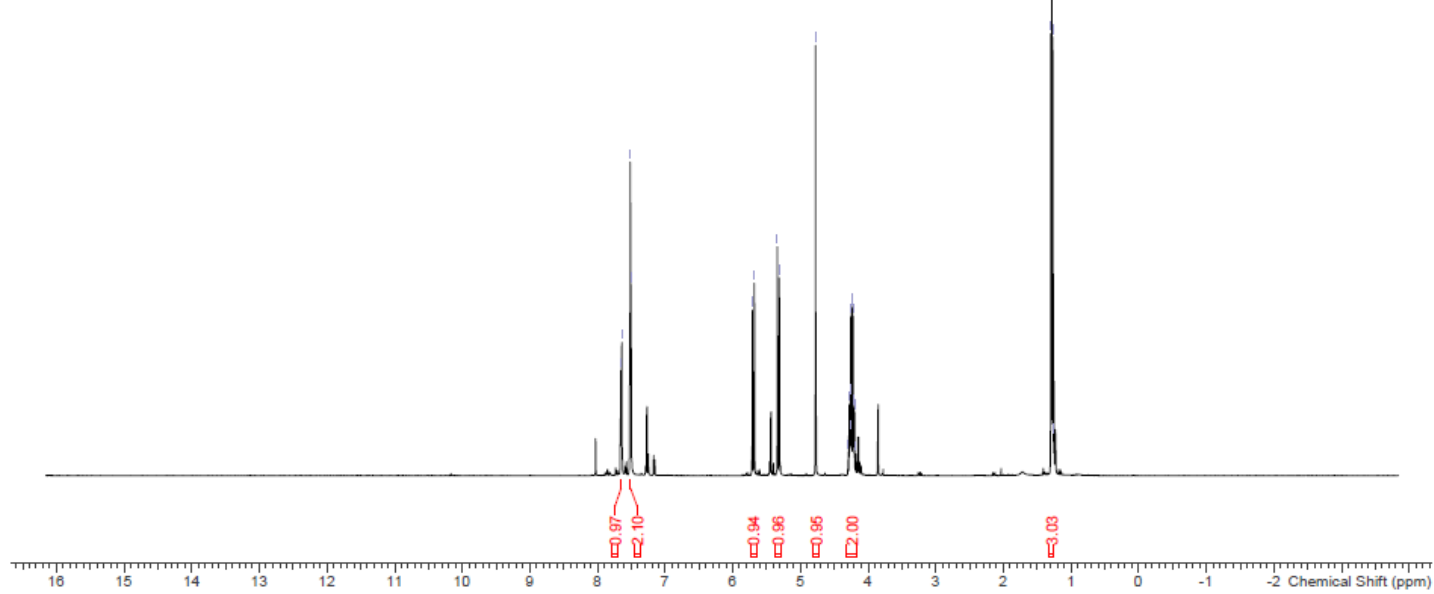



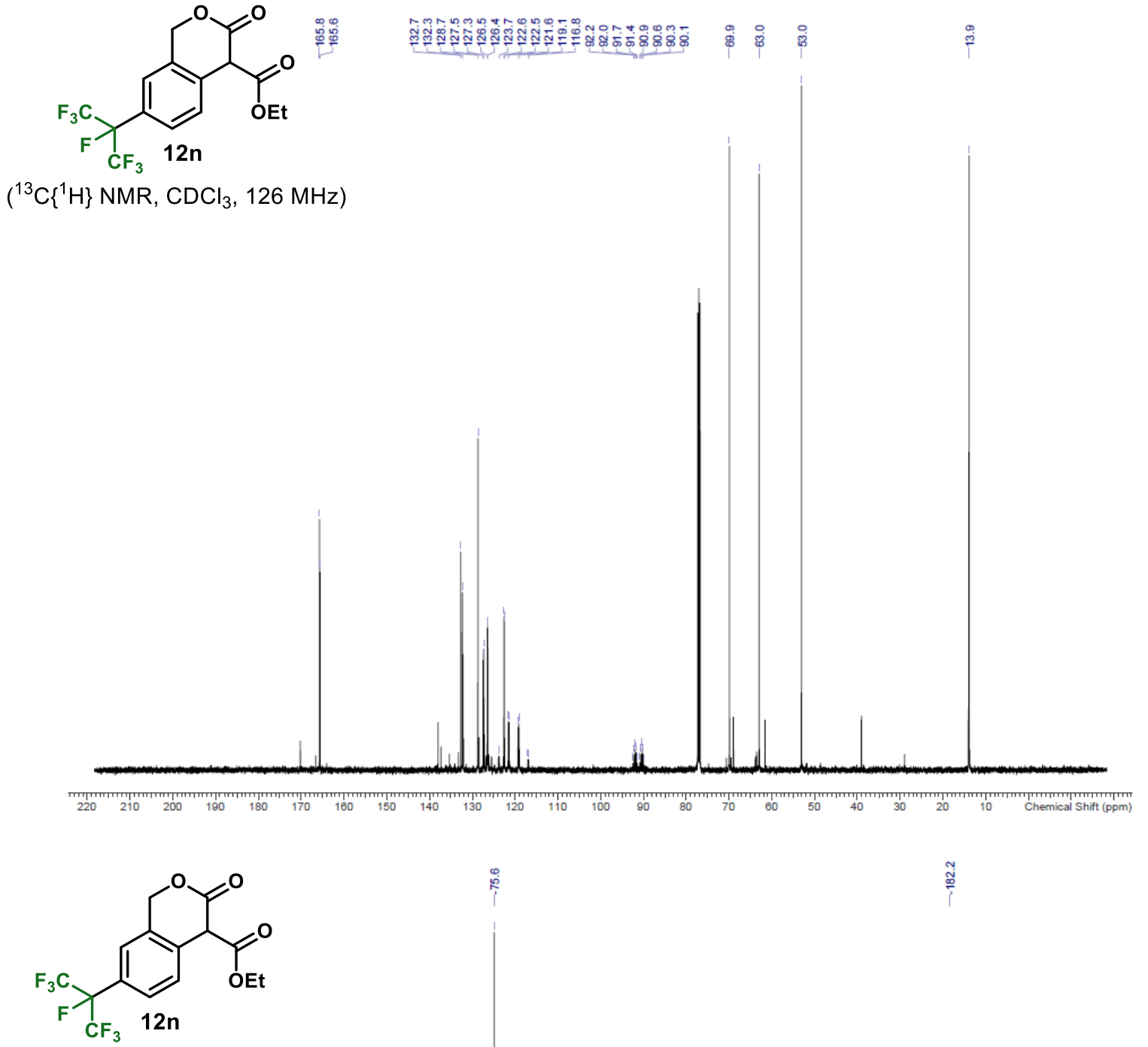

$\left({ }^{19} \mathrm{~F} \mathrm{NMR}, \mathrm{CDCl}_{3}, 376 \mathrm{MHz}\right)$

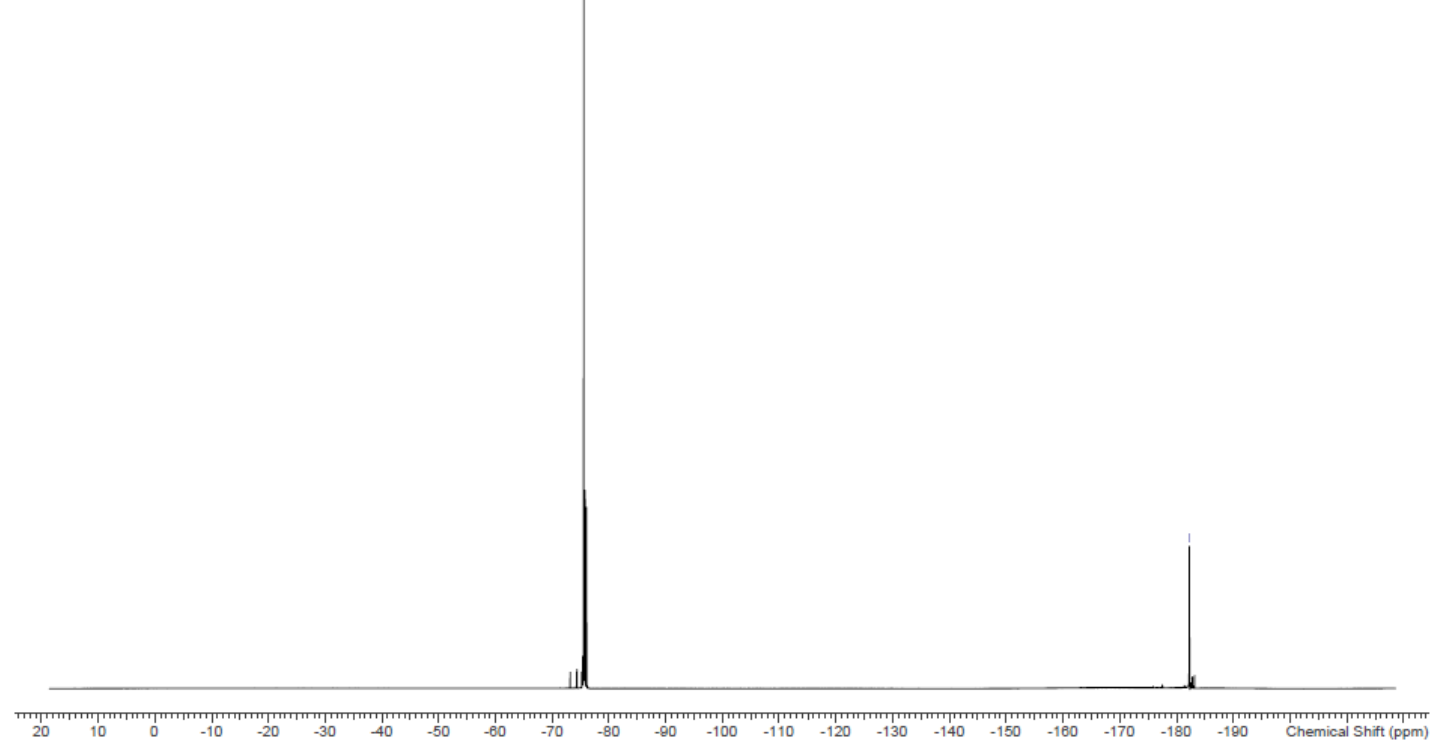




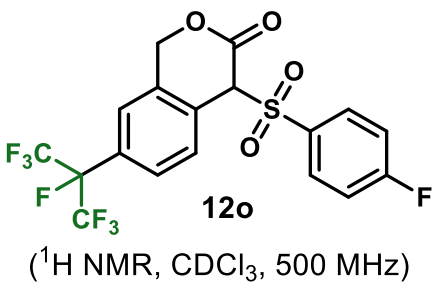

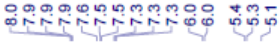

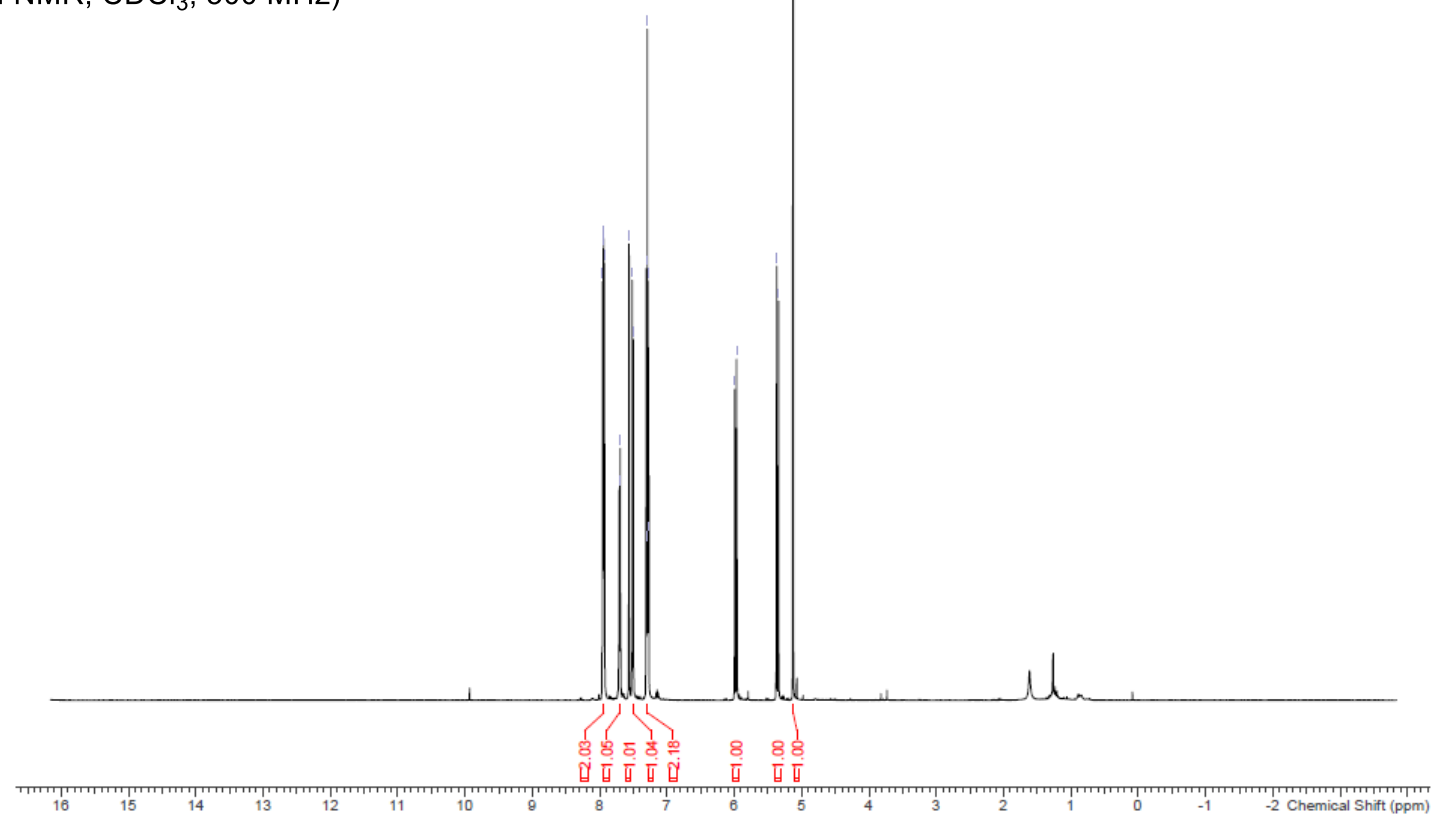

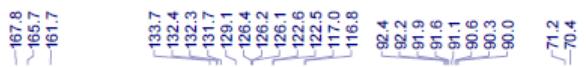

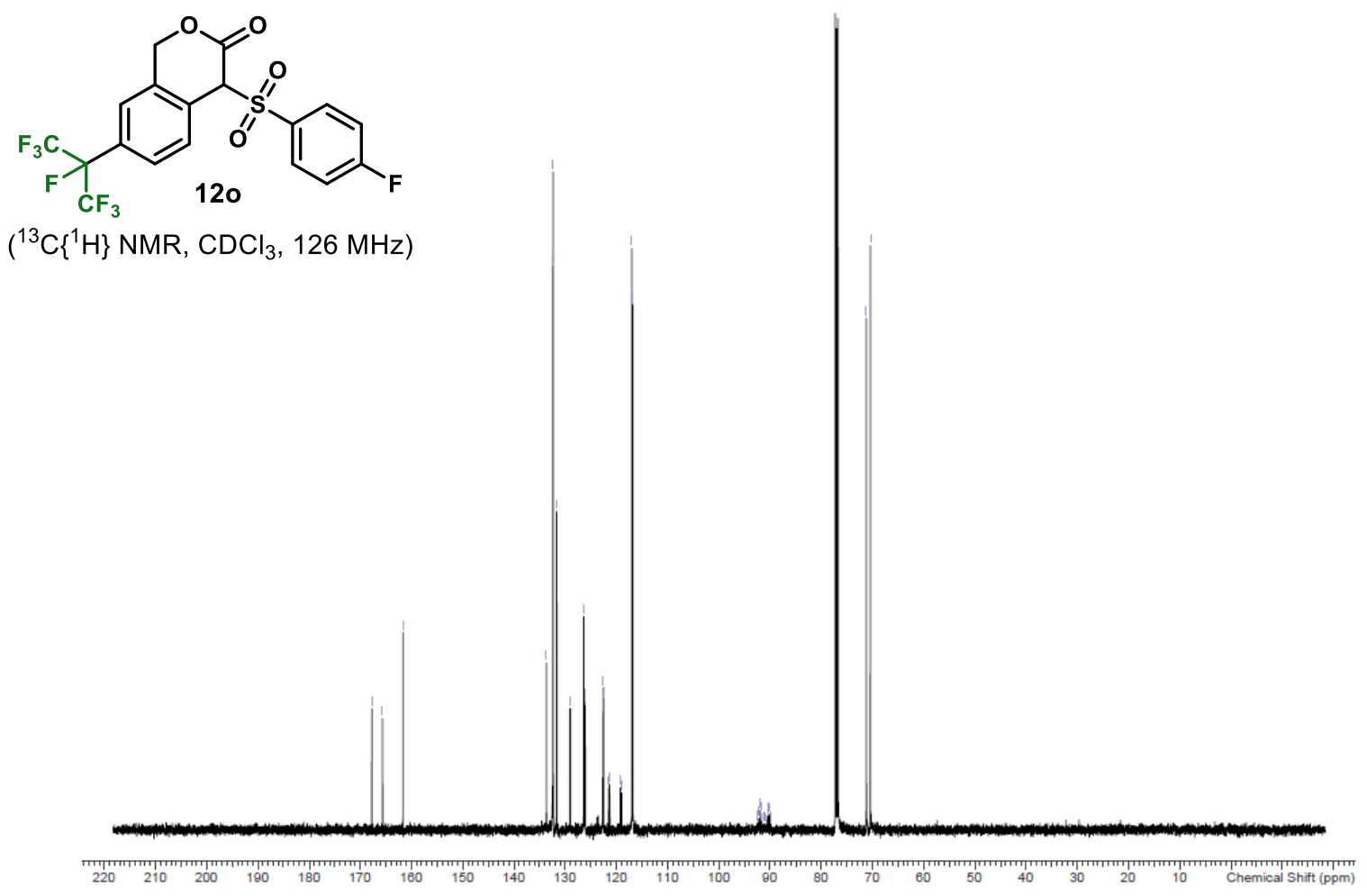

S65 


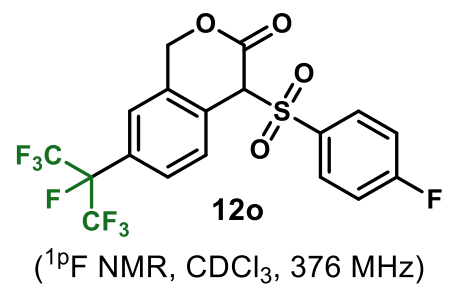

ฐี



S66 